
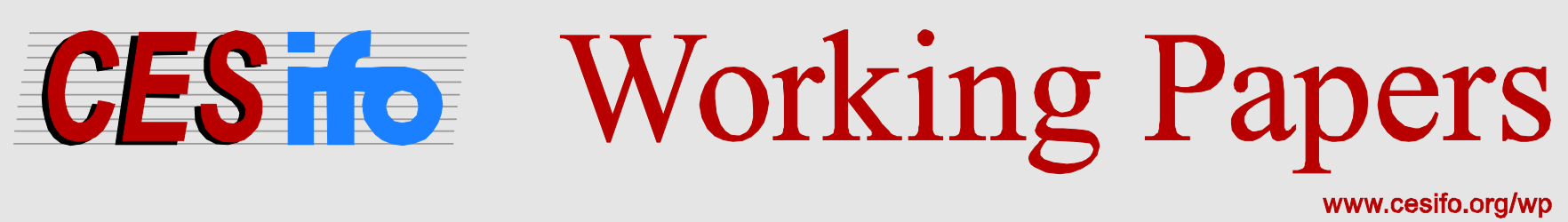

\title{
Political Advertising and Election Outcomes
}

\author{
Jörg L. Spenkuch \\ David Toniatti
}

CESIFO WORKING PAPER NO. 5780

CATEgory 2: Public CHOICE

FEBRUARY 2016

An electronic version of the paper may be downloaded

- from the SSRN website:

- from the RePEc website:

- from the CESifo website: WWW.SSRN.com

www.RePEc.org

www.CESifo-group.org/wp 


\title{
Political Advertising and Election Outcomes
}

\begin{abstract}
We implement a new approach for estimating the persuasive effects of political advertising. Our empirical strategy exploits FCC regulations that result in plausibly exogenous variation in the number of impressions across the borders of neighboring counties. Applying this approach to uniquely detailed data on television advertisement broadcasts and viewership patterns during the 2004 and 2008 presidential campaigns, our results indicate that total political advertising has virtually no impact on aggregate turnout. The point estimates are precise enough to rule out even moderately sized effects. By contrast, we find a positive and economically meaningful effect of advertising on candidates' vote shares. Evidence from a regression discontinuity design with millions of observations suggests that advertising's impact on elections is largely due to compositional changes of the electorate.
\end{abstract}

Keywords: advertising, elections, voting, turnout, persuasion.

\author{
Jörg L. Spenkuch* \\ Northwestern University \\ MEDS Department \\ Kellogg School of Management \\ 2001 Sheridan Rd. \\ USA - Evanston, IL 60208 \\ j-spenkuch@kellogg.northwestern.edu
}

\author{
David Toniatti \\ Analysis Group, Inc. \\ Boston / USA \\ David.Toniatti@analysisgroup.com
}

*corresponding author

First Draft: February 2015

This Version: December 2015

We are grateful to Georgy Egorov, Tim Feddersen, Ali Hortacsu, Ethan Kaplan, Brian Knight, Jonathan Krasno, Steven Levitt, Pablo Montagnes, Matt Notowidigdo, Maria Petrova, Philipp Tillmann, Chad Syverson, and Dan Zou for many helpful conversations. We have also benefitted from comments by audiences at the 2015 MPSA and APSA Annual Meetings, the Barcelona Summer Forum, as well as the Universities of Chicago and Maryland. Daron Shaw generously shared his data on candidate appearances with us, and Shawn Harmon was instrumental in acquiring the voter registration data. Andy Zhou provided excellent research assistance. We thank the Kilts-Nielsen Data Center at the University of Chicago Booth School of Business for access to the Nielsen data, and the University of Wisconsin Advertising Project for media tracking data from the Campaign Media Analysis Group (CMAG) and TNSMI. All views expressed in this paper as well as any remaining errors are solely our responsibility. 


\section{Introduction}

The advent of television has had a profound impact on how politicians communicate with their constituents. While Harry S. Truman traveled over thirty thousand miles and shook over half a million hands during the 1948 presidential campaign, only four years later, Dwight D. Eisenhower leveraged the power of TV advertisements to reach a far greater audience at substantially lower cost. Today, political advertising is the primary method by which candidates reach out to voters in the United States. During the most recent presidential election in 2012, both campaigns and their supporters aired more than 1.1 million TV ads (Wesleyan Media Project 2012; Washington Post 2012). Even during the preceding off-year congressional election, TV advertising accounted for between $40 \%$ and $50 \%$ of campaigns' budgets (Ridout et al. 2012).

Social scientists have long been interested in the consequences of political mass communication. Fearing that voters may be easily manipulated by self-interested agents, some equate persuasion with propaganda (e.g., Herman and Chomsky 1988; Lippmann 1922). Others, however, note that even self-serving messages may further the democratic process by providing citizens with potentially valuable information about candidates and their competitors (see Bernays 1928 and Downs 1957, among others). Despite the longstanding scholarly interest and the ubiquity of political advertising in modern democracies, our understanding of its effects remains incomplete.

Some of the best available empirical evidence suggests that political advertising is ineffective at engaging the electorate (see, e.g., Ashworth and Clinton 2007; Krasno and Green 2008) and that it has only extremely short-lived effects on individuals' opinions (Gerber et al. 2011). Taken at face value, these conclusions contradict campaigns' choices. Why allocate close to half of all available funds to a mode of campaigning that promises only minimal results?

Understanding whether political advertising affects election outcomes is also of first order importance for public policy (see, e.g., Prat 2002; Prat and Strömberg 2013). If advertisements "persuade" rather than inform constituents, then special interest groups may be able to "buy" political influence by directly targeting voters (Baron 1989, 1994; Grossman and Helpman 1996, 2001). Concerns about big outside spenders working hand in glove with candidates are especially pertinent, as the Supreme Court's recent decisions in Citizens United and SpeechNow.org v. FEC paved the way for so-called Super PACs. These political action committees may accept unlimited donations from individuals, corporations, and unions in order to overtly advocate for or against particular candidates (see, e.g., Lee et al. 2014). The vast majority of Super PACs' spending is directly related to TV advertising (ProPublica 2012). 
In this paper, we implement a new approach to estimate the impact of political advertising on election outcomes. Our empirical strategy exploits Federal Communications Commission (FCC) regulations that result in plausibly exogenous variation in the number of impressions across county borders. More precisely, the FCC grants media companies local broadcast rights for a set of counties called a demographic market area (DMA) or media market. Candidates, in turn, determine television-advertising strategies at the DMA level. By comparing neighboring counties that are in the same state but assigned to different media markets, our approach relies on thousands of regulation-induced discontinuities in the advertising exposure of constituents and thus ameliorates many of the most common endogeneity concerns. ${ }^{1}$

For instance, identification strategies that rely on cross-state variation are typically forced to assume that advertising intensity is uncorrelated with all other state-level determinants of individuals' voting decisions, such as expected winning margins or a state's effect on the Electoral College (e.g., Ashworth and Clinton 2007). ${ }^{2}$ Approaches that use only variation across media markets within the same state are implicitly assuming that campaigns do not tailor their advertising to different markets (e.g., Huber and Arceneaux 2007; Krasno and Green 2008). Such assumptions are difficult to reconcile with the observation that there is substantial variation in advertising intensity, even within nonbattleground states. ${ }^{3}$

By contrast, the identification strategy in this paper is almost ideally suited to study political advertising. In the political domain, nearly all ads are purchased at the DMA level (Goldstein and Freedman 2002), yet, on average, a set of border counties constitutes only about $5 \%$ of markets' combined population. Since ad prices as well as campaigns' strategies are likely determined by aggregate, market-level factors, one would expect that a particular border county exerts only minimal influence on the decision of how much air time to buy in a given DMA. If correct, then differences in advertising intensity across neighboring counties that are assigned to different DMAs should be practically uncorrelated with the characteristics of the respective electorates - especially when we restrict attention to counties that make up less than $2 \%$ of DMAs' populations.

\footnotetext{
${ }^{1}$ Our empirical approach builds on previous work by Ansolabehere et al. (2006) and Snyder and Strömberg (2010), who exploit media market definitions to explore the effect of news-media coverage on the incumbency advantage and on political accountability, respectively. In independent work, Shapiro (2015) uses essentially the same identification strategy to estimate a structural model of demand spillovers from TV advertising for antidepressants.

${ }^{2}$ Strömberg (2008), however, shows that campaigns' resource allocations depend greatly on states' votes in the Electoral College as well as on forecasted state-election outcomes.

${ }^{3}$ Krasno and Green (2008) and Huber and Arceneaux (2007) argue that most variation in political advertising within nonbattleground states comes from "natural experiments" in which some residents see more political ads because they live in a DMA that also encompasses counties in battleground states. Toniatti (2014), however, shows that as much as $42 \%$ of the identifying variation in Krasno and Green (2008) cannot be attributable to such natural experiments.
} 
As a partial test of our identifying assumption, we turn to observable characteristics and verify that border counties that receive more advertising are statistically indistinguishable from their neighbors that receive less. Moreover, we show that observable characteristics explain less than $1 \%$ of the variation in political advertising across neighboring border counties.

We apply our approach to uniquely detailed data for the 2004 and 2008 presidential elections. Instead of imputing viewership from self-reported media consumption or noisy cost estimates, we derive measures of how often each political ad was actually seen by using information on ad broadcasts combined with spot-level viewership data provided by The Nielsen Company.

To evaluate existing claims about political advertising's impact on voter engagement, we study aggregate turnout as well as vote shares. While the raw data suggest that advertising plays an important role in mobilizing the electorate, our within-border pair estimates imply that the positive correlation between the number of advertisements and overall turnout is spurious. Critically, the precision of the point estimates allows us to rule out even moderately large positive or negative effects.

Our results are robust with respect to an array of different specifications, including alternative measures of advertising intensity and different time windows before the election. We also find no evidence that negative and positive ads exert differential effects.

After demonstrating that our approach has the potential to detect spurious relationships in the raw data, we explore the impact of political advertising on actual votes. In stark contrast to the results with respect to aggregate turnout, we find that advertising has a nontrivial impact on candidates' vote shares. According to our estimates, a standard deviation increase in the partisan difference in advertising, i.e., the average citizen seeing about twenty-two more ads promoting one candidate rather than the other, increases the partisan difference in vote shares by about 0.7 percentage points.

In order to speak to the mechanism behind this effect, we gauge the contribution of compositional changes of the electorate (i.e., the extensive margin) relative to effects on individuals' preferences and opinions (i.e., the intensive margin). Relying on official turnout histories for more than 100 million registered U.S. voters, we implement a regression discontinuity (RD) design that compares partisans who live nearby but on opposite sides of media market borders. Our RD evidence shows that partisan differences in turnout depend on partisan differences in political advertising. Although political advertising does not appear to affect the overall size of the electorate, it alters the partisan composition of voters. The size of the RD estimates implies that compositional changes can explain most, if not all, of the effect of advertising on vote shares.

The results in this paper help to reconcile why modern campaigns advertise so much, 
despite vanishing effects on overall voter engagement and individuals' opinions about candidates (Gerber et al. 2011; Krasno and Green 2008). Our answer is that even if political advertising does not lead to lasting changes in individuals' preferences, it brings the "right" set of voters to the polls.

The finding that advertising affects election outcomes also has potentially important policy implications - especially for campaign-finance regulation. In line with existing evidence on the impact of total campaign spending (e.g., Levitt 1994), our estimates suggest that political advertising has nontrivial aggregate effects. For instance, eliminating partisan differences in advertising during the 2008 presidential campaign would have narrowed Barack Obama's lead over John McCain by roughly 600,000 votes. While a shift of 600,000 votes would not have changed the outcome of this particular race, a similar sized effect might very well decide an election that is close. In 2000, the average Florida resident saw about 161 ads supporting George W. Bush, compared with only 82 favoring Al Gore (Shaw 2007). Extrapolating from our estimates, the difference in political advertising increased Bush's vote share by about 2.4 percentage points and, thus, won him the presidency.

The remainder of the paper unfolds as follows. The next section contains a brief literature review. Section 3 provides background information on the structure of media markets and political advertising in the U.S., while Section 4 describes the data and explains our econometric approach. Section 5 presents the main empirical findings. In Section 6, we implement a regression discontinuity design in order to speak to the mechanisms by which political advertising affects vote shares. The last two sections conclude. ${ }^{4}$

\section{Related Literature}

Our paper contributes to a large body of work on the consequences of political mass communication (see, e.g., Zaller 1992). While the "minimal effects" thesis of Klapper (1960) dominated the literature until the late 1980s, more recent scholarship often reaches different, contradictory conclusions. Some, for instance, argue that political advertising enlarges the electorate by informing and engaging citizens (e.g., Freedman et al. 2004). Others, however, contend that the increasing use of negative advertisements hurts the democratic process, as it turns voters away from the polls (Ansolabehere and Iyengar 1995; Ansolabehere et al. 1999). ${ }^{5}$ Iyengar and Simon (2000) and Geys (2006) provide reviews of this literature, "which for the most part lacks compelling strategies for identifying causal effects" (DellaVigna and

\footnotetext{
${ }^{4}$ There are four appendices. Appendix A visualizes the variation in political advertising across DMAs. Appendix B provides evidence in support of the linearity assumption that underlies our workhorse empirical model. Appendix C formally derives the expression for the persuasion rate in Section 7, while Appendix D contains a detailed description of all data sources.

${ }^{5}$ In 2012, the Obama campaign allocated $82 \%$ of its advertising expenditures to negative ads. The corresponding number for the Romney campaign is 91\% (Washington Post 2012).
} 
Gentzkow 2010, p. 650).

There are a handful of exceptions. The first one is a large, randomized controlled trial by Gerber et al. (2011). Eleven months before the 2006 gubernatorial election in Texas, the authors randomly assigned the timing of an ad campaign across 18 media markets. Relying on a panel of opinion surveys, the evidence indicates a sizeable but fleeting impact on constituents' attitudes. Within one to two weeks, the campaign's effect had all but vanished. Similarly, Durante and Gutierrez (2014) exploit random variation in the timing of political advertisements in Mexico to show that ads have a positive, but short-lived impact on survey measures of voters' intentions.

Ultimately, our research design and results complement those of Gerber et al. (2011) and Durante and Gutierrez (2014). While we lack true randomization, we are able to study real-world election outcomes as opposed to self-declared attitudes and opinions. Moreover, we explore the effects of campaign advertising in a competitive environment, where average spending per media market is more than an order of magnitude higher than in the experiment of Gerber et al. (2011). Most importantly, the results in this paper show that much of advertising's impact on vote shares is due to changes in the composition of the electorate. This explains why campaigns advertise so much — often months before the election - despite small effects on individuals' opinions about candidates.

Another exception is a recent field experiment by Kendall et al. (2015), who collaborate with an Italian mayor to send voters randomized messages. Relative to the control group, voters who received campaign messages about the mayor's valence updated their beliefs and increased their support by about 4.1 percentage points. The effect was smaller when the message was delivered via mass mailings rather than by phone, or when it contained information about the mayor's ideology instead. As Kendall et al. (2015), we study actual vote shares. Motivated by the U.S. experience, however, our focus is on television ads and their quantity rather than on how voters update beliefs when presented with different information.

A third set of papers uses structural techniques to estimate the impact of political advertising. Gordon and Hartmann (2013), for instance, conclude that advertising increases aggregate turnout as well as the respective candidate's vote share. Martin (2014) argues that these effects operate primarily by "persuading" rather than "informing" constituents. Our approach differs from Gordon and Hartmann (2013) and Martin (2014) in that we rely on natural experiments to gain identification. In addition, as our data contain measures of how often each political ad was actually seen by voting-aged individuals, we do not have to impute advertising exposure.

We also contribute to rapidly growing literatures on the political economy of mass media and persuasion (see Prat and Strömberg 2013 and DellaVigna and Gentzkow 2010 for re- 
views). DellaVigna and Kaplan (2007) demonstrate that the addition of Fox News to local cable networks increased Republican presidential vote shares by about half a percentage point, implying a persuasion rate of $f=11.6 .^{6}$ In a similar vein, Enikolopov et al. (2011) estimate that Russian voters with access to an independent TV station were significantly more likely to vote for opposition parties $(f=7.7)$. In the U.S. context, Gentzkow (2006) shows that the introduction of television itself reduced voter turnout in congressional elections by about 2 percentage points per decade $(f=4.4)$, while Gentzkow et al. (2011) find that, historically, availability of at least one newspaper per county increased turnout by 1 percentage point $(f=12.8) .^{7}$

With persuasion rates between 0.01 and 1.1, our estimates of advertising's effectiveness are only a fraction of those in existing work. This is not surprising. After all, seeing a few dozen thirty-second political ads constitutes an arguably less intense treatment than having year-round access to newspapers or an additional TV station. Moreover, from a theoretical perspective the effect of partisan advertising ought to be smaller than that of slanted news, at least if one believes that journalists are more likely to truthfully reveal information than campaigns (Gentzkow and Shapiro 2006; Knight and Chiang 2011). Beyond estimating the effects of political advertising on electoral outcomes, we add to this literature by shedding light on the channels through which the persuasive effects of the media operate.

\section{Media Markets and Political Advertising in the United States}

When Dwight D. Eisenhower advertised in the 1952 Presidential election, almost all viewers received the broadcast signal through over-the-air antennae. ${ }^{8}$ Whether an advertisement reached a particular household depended on the strength of the station's signal, the local terrain, and the quality of the household's antenna. The increasing popularity of cable television over the next three decades removed these technological barriers and allowed viewers access to the content of any station offered by their cable provider. In response to cable companies' increasing market power, U.S. Congress and the Federal Communications Commission (FCC) implemented a series of policies to protect local TV stations. In particular, the 1992 Cable Act included a "must-carry" provision that required cable providers to include local broadcast stations.

In order to implement the regulation and to determine which local stations corresponded

\footnotetext{
${ }^{6}$ The persuasion rate should be interpreted as the percentage of individuals who change their behavior in response to receiving a particular message (DellaVigna and Kaplan 2007).

${ }^{7}$ Other important contributions include Groseclose and Milyo (2005) and Gentzkow and Shapiro (2010) on measuring media bias, Durante and Knight (2012) on partisan control of the media, Strömberg (2004) on radio's impact on public spending, Oberholzer-Gee and Waldfogel (2009) on media and hispanic-voter turnout, and Martin and Yurukoglu (2014) on media bias and polarization.

${ }^{8} \mathrm{~A}$ mere seventy communities had access to cable television in 1950 (FCC 2012).
} 
to a particular cable subscriber, the FCC adopted Nielsen's definition of media markets. According to Nielsen's classification system, counties in the U.S. are uniquely assigned to a demographic market area (DMA) based on historical viewing patterns. ${ }^{9}$ DMAs are usually centered around the largest metropolitan area in the region. For example, the Philadelphia DMA includes eight surrounding counties in Pennsylvania, eight counties in New Jersey, and two counties in Delaware. Any cable provider serving a customer in one of these eighteen counties is required to include local Philadelphia broadcast stations in the customer's cable package.

Similar provisions apply to satellite TV providers. If a satellite provider chooses to offer any of an area's local stations, such as an affiliate of the major TV networks, then the Satellite Home Viewer Act of 1998 requires it to carry all of them. By 2010, more than $90 \%$ of households subscribed to either cable or satellite TV (Nielsen 2011).

Importantly for our purposes, local broadcast television is the primary method that candidates use to reach voters. Out of $\$ 2.6$ billion in political advertising expenditures during the 2008 presidential campaign, approximately $\$ 2$ billion was directed at broadcast television, compared to only $\$ 200$ million for national cable networks and about $\$ 400$ million for radio (New York Times 2008). ${ }^{10}$ Advertisements placed through local broadcast networks allow candidates to reach a large number of potential voters in key geographic areas. Candidates' ability to geographically target their ads, however, is limited by the coarseness of Nielsen's DMA definitions. As a consequence, campaigns typically determine their advertising strategies at the DMA level (Goldstein and Freedman 2002; Ridout 2007).

\section{Data and Econometric Strategy}

\subsection{Econometric Approach}

We exploit this fact to propose a new approach to estimating the persuasive effects of political advertising. At its core, our empirical strategy builds on a large literature in labor economics, which uses spatial policy discontinuities to estimate the economic effects of statewide minimum wages (see Card and Krueger 1994; Dube et al. 2010), right-to-work laws (Holmes 1998), or school-zoning regulations (e.g., Black 1999; Lavy 2010). Our approach is also closely related to several papers that rely on media market definitions to explore the importance of mass media for the political economy (see Ansolabehere et al. 2006; Campbell et al. 1984; Niemi et al. 1986; Snyder and Strömberg 2010). ${ }^{11}$ In independent work, Shapiro

\footnotetext{
${ }^{9}$ Only seven counties are assigned to multiple DMAs. These counties are excluded from the analysis.

${ }^{10}$ It is important to note that, despite its recent growth, online advertising played only a minimal role in 2004 and 2008, the campaigns which we study. According to Borrell Associates (2015), a consulting firm that tracks political ad spending, digital media accounted for less than $1 \%$ of campaigns' advertising expenditures.

${ }^{11}$ Ansolabehere et al. (2006), for instance, compare incumbent vote margins in markets where content originates in the same state as voters with margins in markets where content originates out of state. Snyder
} 
(2015) uses essentially the same identification strategy to estimate a structural model of demand spillovers from pharmaceutical advertising.

For an illustration of the mechanics of our approach, consider Figure 1, which displays counties and DMAs in the state of Illinois. Illinois has 102 counties served by 10 media markets. We define a "border-county pair" as two neighboring counties that are assigned to different DMAs. In order to ensure that our results are not contaminated by comparisons across potentially very different state-level electoral environments (say, due to states' varying competitiveness), we restrict attention to border-county pairs in which both counties belong to the same state.

An example of such a pair is La Salle and Livingston Counties (highlighted in Figure 1). Both are quite rural. As of the 2000 Census, La Salle County had roughly 110,000 inhabitants and a median household income of $\$ 40,300$. Livingston County had about 40,000 residents with a median household income of $\$ 41,300$. Importantly for our purposes, they straddle a media market border. La Salle County is located at the very southwestern tip of the Chicago DMA, whereas Livingston County makes up the northeastern part of the Peoria-Bloomington market. In terms of the total population in their DMAs, La Salle and Livingston Counties comprise $1.2 \%$ and $6.1 \%$, respectively.

On average, border counties account for only about 5\% of DMAs' combined population. Since almost all political advertising is purchased at the DMA level, one would expect that prices as well as campaigns' strategies are determined by aggregate, market-level factors, on which individual border counties have only a small influence. If correct, then differences in the intensity of political advertising should be practically uncorrelated with differences in the characteristics of voters on either side of the DMA border. Loosely speaking, our estimation strategy assumes that voters in La Salle and Livingston Counties are indistinguishable, except that the former see more political ads on TV because they are assigned to the Chicago media market. Consequently, identification comes from thousands of local discontinuities created by FCC regulations. In total, our data contain 3,395 of these county-level natural experiments. ${ }^{12}$

If differences in advertising between border-pair counties are truly as good as random and if there is no heterogeneity in effect size, then inferring the causal impact of political advertising on outcome $y$ is conceptually straightforward. Consider, for instance, the econometric model

$$
\Delta_{p, t} y=\phi \Delta_{p, t} A d s+\Delta_{p, t} X^{\prime} \gamma+\Delta_{p, t} \varepsilon
$$

and Strömberg (2010) use congruency between newspaper markets and congressional districts to study the impact of press coverage on political accountability.

${ }^{12}$ There are 2,529 natural experiments in our data for 2008 and 866 in that for 2004. As explained in Section 4.2, this difference arises because the 2004 data cover only the 100 largest media markets. 
where $\Delta_{p, t}$ denotes the year $t$ difference (in the variable following it) between the counties in border pair $p, A d s$ measures the intensity of political advertising, and $X$ is a comprehensive vector of county-level controls. Estimating equation (1) on the set of border pairs that straddle media market borders within the same state produces a consistent estimate of $\phi$, the coefficient of interest. ${ }^{13}$

In the specification above, each observation corresponds to one natural experiment. Although conceptually simple, estimating $\phi$ from the differences model in equation (1) comes at the cost of hindering comparisons with other approaches. We, therefore, prefer the following fixed effects specification:

$$
y_{c, t}=\mu_{p, t}+\phi A d s_{c, t}+X_{c, t}^{\prime} \gamma+\varepsilon_{c, t}
$$

where $c$ indexes counties, and $\mu_{p, t}$ marks a year-specific fixed effect for border-county pair $p$. As long as every border county has exactly one within-state neighbor, the point estimates from specifications (1) and (2) are algebraically identical (cf. Wooldridge 2002, ch. 10), but by omitting $\mu_{p, t}$ we can assess whether more naïve strategies deliver substantively different results than our border-pair estimator.

Complications arise when border counties have multiple neighbors that are located in other DMAs. La Salle County in Figure 1, for instance, forms a within-state border-county pair not only with Livingston County, but also with (from north to south) Lee, Bureau, Putnam, Marshall, and Woodford Counties. As a consequence, the total number of border-county pairs exceeds the number of border counties, which precludes us from directly estimating the fixed effects in specification (2). We resolve this issue by stacking observations so that a particular county appears in our sample exactly as many times as it can be paired with a within-state across-DMA neighbor. Stacking observations allows us to demean all variables within each border pair-year group and to treat $\mu_{p, t}$ as a nuisance parameter (see Dube et al. 2010). Thus, by construction, the point estimates from specifications (1) and (2) are algebraically equivalent, but the fixed effects model facilitates comparisons with alternative identification strategies. ${ }^{14}$

To allow for arbitrary patterns of serial correlation and for correlation in the residuals of counties that are geographically close, we cluster standard errors at the state level. Clustering

\footnotetext{
${ }^{13}$ Our main specifications assume that the outcome is a linear function of advertising intensity. In Appendix B we use semiparametric techniques to show that linearity provides a good approximation, except in the extremes of the distribution, where there is also very little data.

${ }^{14}$ Another possibility that does not involve stacking would be to replace the border-county pair fixed effect with one for the DMA-border segment, i.e., the entire border between two media markets. This, however, comes at the cost of comparing counties that are further apart from each other and, thus, likely less similar on unobservables. Nevertheless, both approaches yield qualitatively very similar results (cf. Appendix Table A.4).
} 
by state also corrects for the correlation that is introduced by stacking.

\subsection{Data Sources}

We apply our estimation strategy to uniquely detailed data on the intensity of political advertising during the 2004 and 2008 presidential campaigns. Information on the broadcast of political advertisements is available through the Campaign Media Analysis Group (CMAG) and the Wisconsin Advertising Project (Goldstein et al. 2011; Goldstein and Rivlin 2007). According to CMAG, the data form a complete record of all political ads that aired on any of the national television or cable networks. ${ }^{15}$ In 2004, the 100 largest media markets, or about $86 \%$ of the U.S. population, are covered. For 2008, coverage was expanded to all 210 DMAs. The CMAG data include timestamps for each ad, the sponsoring group (i.e., a candidate's campaign, the national party, independent interest groups, such as PACs, etc.), the candidate it supported, as well as more detailed, human-coded information on its content. The data also contain a cost estimate for every spot.

As political advertisements air at all times of the day and during different programs, the total number of ads that are broadcast in a particular market makes for a questionable measure of advertising intensity, i.e., the number of ads that people actually saw. Most previous work uses either self-reported media consumption to measure advertising exposure, or it relies on the cost estimate in the CMAG data to impute viewership. In order to get a sense of the accuracy of the latter approach, we obtained a small number of contracts between TV stations and campaigns and spot-checked the CMAG estimate against actual cost paid. Since estimated and true costs are often very different-sometimes by nearly an order of magnitude - and since campaigns, political action committees, etc. are being charged different prices (see Moshary 2014), we eschew this method of imputing viewership.

Instead, to more directly gauge constituents' exposure to political advertising, we use detailed information on the viewership of each spot provided by The Nielsen Company. Nielsen is the market leader in television-audience measurement. At the heart of Nielsen's efforts is a proprietary metering technology that monitors the media consumption of a representative cross section of households. These data then form the basis of the so-called Nielsen ratings, which are available by gender and age group for each DMA.

Political campaigns typically pay for ads based on gross rating points (GRPs), i.e., the share of the TV audience that, according to Nielsen, viewed a particular spot. Yet, for our purposes, measuring advertising intensity in terms of GRPs has two potentially important

\footnotetext{
${ }^{15}$ Small-sample audits have found that the CMAG data are highly correlated with invoice data from television stations. For example, in an audit of Philadelphia stations, Hagen and Kolodny (2008) found that less than $2 \%$ of ads were missing from the CMAG sample.
} 
drawbacks. First, GRPs encompass all viewers, not just those of voting age. Second, almost $5 \%$ of Americans live in "zero-TV homes" (Nielsen 2013).

We, therefore, prefer to measure advertising intensity in impressions per capita among voting-aged adults. Given that CMAG and Nielsen time stamps do not perfectly match, we average the Nielsen-reported number of impressions (among all viewers age 18 and older) over thirty-minute intervals and assign the corresponding value to the particular instance in which an ad aired. To assess aggregate presidential advertising, we focus on a 60-day time window leading up the election and, for each market, sum impressions over all local broadcasts of all presidential ads, including those sponsored by the national parties and other interest groups. In symbols, aggregate presidential advertising in media market $d$ during year $t$ is defined as $A d s_{d, t} \equiv \sum_{k} \sum_{s=1}^{S_{k, d, t}} \operatorname{Imps}_{s, k}^{18+} / \operatorname{Pop}_{d, t}^{18+}$, where $k$ indexes candidates, and $S_{k, d, t}$ denotes the total number of spots in support of candidate $k$ that aired in that market within 60 days before the election. ${ }^{16}$

We measure partisan advertising in the same way, except that we sum only over ads that support a particular candidate - either through positive messaging related to the candidate or through negative messaging directed at his opponent. Since Nielsen ratings are only available at the DMA level, we assign the same advertising measures to all counties within a given market. If viewing habits in border counties differ from those in the remainder of the media market, then our advertising variable is likely to contain measurement error, which would bias our estimates towards zero. Yet, we believe that the Nielsen data constitute the best available source of information on how often a particular spot was actually seen by potential voters. $^{17}$

County-level information on the total number of voters, votes for each presidential candidate, write-ins, etc. come from the $C Q$ Voting and Elections Collection (Congressional Quarterly 2015). To calculate voter turnout, we combine these data with population estimates from the U.S. Census Bureau. All individuals age 18 and older are considered potential voters. While this broad categorization includes some individuals who are ineligible to vote (e.g., felons and non-U.S. citizens), it has the advantage of being robust to endogenous voter registration.

\footnotetext{
${ }^{16}$ According to CMAG, approximately $0.5 \%$ of spots in 2008 aired on cable channels. Since the Nielsen data do not contain information on the viewership of cable channels disaggregated by DMA, we exclude these ads from our calculations. Similarly, our baseline measure of advertising intensity does not account for spots that aired nationally on any of the major networks because the CMAG data contain no information on national ads in 2004. In 2008, less than $0.2 \%$ of ads aired nationally. Our robustness checks in Tables 4 and 6 demonstrate that including national ads has virtually no effect on the estimated coefficients with respect to the 2008 election.

${ }^{17}$ We have also experimented with other measures of advertising intensity and different time windows, obtaining quantitatively and qualitatively very similar results. Tables 4 and 6 present these robustness checks.
} 
To obtain information on the observable characteristics of counties' residents, we turn the Census Bureau and the Bureau of Labor Statistics. Lastly, Daron Shaw generously shared with us his data on candidate appearances by media market (Huang and Shaw 2009; Shaw 2007). For more detailed information on the data as well as precise definitions of all variables used throughout the analysis, see the Data Appendix.

\subsection{Descriptive Statistics 8 Tests of the Identifying Assumption}

Combining all different sources, Table 1 displays summary statistics for our county-level data set, by year and border-pair status. There is considerable variation in advertising intensity. The average county in our data records almost 75 impressions per capita. In some areas, however, voting-aged adults see as many as 339 spots, whereas other counties have virtually no presidential ads on TV (see also Appendix Figures A.1 and A.2). Variation with respect to turnout and vote shares is also quite large.

Table 1 further shows that border counties are not perfectly representative of the U.S. as a whole. Although turnout is broadly comparable across border and non-border counties, the former are less populous and have lower median incomes.

More important for our purposes is whether, conditional on constituent characteristics, advertising intensity is truly as good as random across media market borders. If so, then the estimates in this paper recover a local treatment effect. That is, we estimate the impact of political advertising on voters who viewed a given number of ads only because they lived on either side of a DMA border.

Unfortunately, the assumption that differences in advertising intensity are uncorrelated with differences in electorates' unobserved characteristics is fundamentally untestable. One may be willing to judge its plausibility, however, by asking whether differences in observables predict differences in advertising. A correlation between political advertising and border counties' observable characteristics would raise concern about a similar correlation with unobservables.

Table 2, however, provides no evidence that this concern is warranted. The results therein are based on the differences specification in equation (1), in which the outcome has been replaced with various measures of $\Delta_{p, t} A d s$. For ease of interpretation, all variables have been standardized, so that the coefficients refer to the standard deviation change in advertising resulting from a standard deviation increase in the regressor. Odd-numbered columns assess the explanatory power of demographic variables, while even-numbered ones also include proxies for economic conditions, distance to the nearest city with more than 250,000 inhabitants, as well as distance to the state capital (Campante and Do 2014).

No matter whether we consider the total number of presidential impressions per capita, 
impressions for the Democratic or Republican candidates separately, the difference between the two, or total non-presidential political advertising, few, if any, of the point estimates in Table 2 are of economically meaningful size or statistically significant. In fact, for each specification a joint $F$-test is unable to reject the null hypothesis that all coefficients are exactly equal to zero, with $p$-values ranging from 0.17 to $0.98 .{ }^{18}$ Moreover, observable county characteristics explain less than $1 \%$ of the variation in the respective dependent variable.

Our interpretation of these results is that differences in political advertising between border counties are as good as random. We hasten to add, however, that it is impossible to definitively prove the validity of our identifying assumption.

\section{Political Advertising and Election Outcomes: Empirical Evidence}

\subsection{Political Advertising and Turnout}

We now explore the effect of total political advertising on voter turnout. Pooling over the 2004 and 2008 presidential elections, Table 3 presents the results. The first three columns are based on the entire sample of U.S. counties and show naïve estimates of advertising's impact on turnout. Using all cross- and within-state variation, one would conclude that an additional ten impressions per capita raise voter turnout by almost 0.3 percentage points. Put differently, a standard deviation increase in presidential advertising increases turnout by about 2.6 percentage points. The estimate is thus not only statistically, but also economically, highly significant.

Controlling for demographics, economic conditions, lagged turnout, and all other, nonpresidential political advertising reduces the point estimate by about sixty percent. Yet, it remains statistically significant and economically sizeable. Based on these partial correlations, it would appear that political advertising leads to a nontrivial increase in voter engagement.

In order to demonstrate that the results that follow are not due to different samples, columns (4), (5), and (6) replicate the previous exercise, but restrict attention to our sample of stacked border-pair counties. ${ }^{19}$ Again, the correlation between presidential advertising and turnout is economically large. In fact, the estimates in columns (1)-(3) and (4)-(6) are not only qualitatively but also quantitatively similar.

\footnotetext{
${ }^{18}$ In univariate regressions of each outcome on each covariate, none of the resulting coefficients are statistically significant at the $5 \%$-level.

${ }^{19}$ The number of observations in the border-county sample is larger because of stacking. That is, a countyyear may appear multiple times in the data if it shares a DMA border with more than one other county (see Section 4.1). Sensitivity analyses in which individual observations are reweighted based on the number of times the county-year appears in the data demonstrate qualitatively and quantitatively similar results (cf. Table 4).
} 
Column (7) implements our cross-border pair identification strategy by adding year-specific border-pair fixed effects. This alone reduces the point estimate to near zero. Comparing neighboring counties that straddle media market borders, it appears that the correlation between turnout and political advertising is spurious. That is, campaigns advertise more in areas where citizens are more likely to vote, but TV advertising itself does not seem to affect overall voter engagement.

Controlling for lagged turnout, candidate visits as a proxy for campaign's ground operations, non-presidential advertising, as well as all covariates shown in Table 2 does little to change the coefficient. It does, however, increase precision. In our preferred specification in column (9), the $95 \%$-confidence interval ranges from -0.023 to 0.055 percentage points. Our estimation strategy thus affords us enough statistical power to rule out moderately sized positive or negative effects.

The results in the lower panel of Table 3 are based on the same specifications as those in the upper one, but allow for heterogeneity in the effect of "positive" and "negative" advertising. ${ }^{20}$ Although estimates that allow for the effect to vary by tone are less precise, they are almost equally close to zero. All in all, there is little to no evidence to conclude that political advertising has a meaningful impact on aggregate turnout.

Table 4 probes the robustness of our results with respect to the weighting scheme, different measures of advertising intensity, and various time windows before the election. It also investigates how the estimates vary by year and by the battleground status of a particular state. All point estimates are based on our border-pair strategy, using the full set of controls. The coefficients in Table 4 are generally close to zero and statistically insignificant. In particular, we obtain almost identical results when we reweight each county-year observation by the inverse number of times that it appears in our sample of stacked border-county pairs. Perhaps most importantly, our results remain qualitatively unchanged when we restrict attention to border-pair counties that contain less than $5 \%$, or even $2 \%$, of the respective DMAs' combined population. We find this reassuring, as our identifying assumption is most plausible in cases where border counties are highly unlikely to affect campaigns' strategies.

A remaining concern with our approach is measurement error in advertising intensity. Although our measure of advertising is likely more precise than those in the literature, we cannot rule out that viewing habits in border counties differ from the respective market average, or that a nontrivial number of border-county households receive their TV signal from the "wrong" DMA. In 2010, for instance, about 9.5\% of U.S. households relied on terrestrial antennae for their television programming (Nielsen 2011). If a significant number

\footnotetext{
${ }^{20}$ All evaluations of advertisements' "tone" are due to human coders of the Wisconsin Advertising Project. See Freedman and Goldstein (1999) for a detailed description of the coding process.
} 
of households watches TV stations from a neighboring DMA, then our advertising measure overstates the true difference in treatment intensity, leading to estimates that are biased toward zero. Under some assumptions, however, it is possible get a handle on the resulting bias.

Specifically, suppose that a fraction of $q$ randomly chosen households receive their TV signal from the neighboring DMA. If these households were to exclusively watch programs originating in the "wrong" market, then the actual, unattenuated effect of political advertising would equal

$$
\phi^{*}=\frac{1}{1-2 q} \widehat{\phi}
$$

where $\widehat{\phi}$ denotes the original estimate. ${ }^{21}$

To get a sense of reasonable values for $q$, consider the case in which border-county households have the same propensity to rely on antenna TV as the national average, and further assume that one in two antenna households obtain their TV signal from the "wrong" DMA. In such a case, $q \approx 0.05$ and $\phi^{*} \approx 1.1 \widehat{\phi}$. Even if households in border counties were twice as likely as the national average to watch antenna TV and if every single antenna household watched only programs that originate in the neighboring DMA, i.e., even if $q \approx 0.2$ and $\phi^{*} \approx 1.67 \hat{\phi}$, the true effect of political advertising on voter turnout would still be an order of magnitude smaller than the variables' correlation in the raw data. We, therefore, conclude that advertising has at best a small impact on aggregate turnout.

At first glance, this result confirms the findings of Ashworth and Clinton (2007) and Krasno and Green (2008), who argue that political advertising is ineffective at engaging the electorate. The main difference between our estimates and theirs is that the former are precise enough to rule out even moderately large effect sizes. Yet, as we show in the remainder of the paper, focussing on aggregate turnout as a metric for the impact of political advertising misses some of its key effects.

\subsection{Political Advertising and Vote Shares}

The evidence above suggests that our empirical approach is capable of distinguishing between true effects and relationships that are spurious. We now use it to study advertising's impact on vote shares.

\footnotetext{
${ }^{21}$ To derive (3), let turnout in border counties $A$ and $B$ be denoted by $y_{A}$ and $y_{B}$, respectively, and let measured advertising be given by $A d s_{A}$ and $A d s_{B}$. Abstracting from differences in covariates, the estimated effect of advertising equals $\widehat{\phi}=\left(y_{A}-y_{B}\right) /\left(A d s_{A}-A d s_{B}\right)$. The actual amount of advertising seen by the constituents in $A$ and $B$, however, is $A d s_{A}^{*}=(1-q) A d s_{A}+q A d s_{B}$ and $A d s_{B}^{*}=(1-q) A d s_{B}+q A d s_{A}$. It follows that $\phi^{*}=\left(y_{A}-y_{B}\right) /\left(A d s_{A}^{*}-A d s_{B}^{*}\right)=\widehat{\phi} /(1-2 q)$.
} 
Since advertising by one candidate may affect his own support and that of his competitor, Table 5 focuses on the impact of partisan differences in advertising on differences in vote shares. Both variables have been normalized such that positive values indicate an advantage of the Democratic candidate over his Republican opponent. As in the preceding analysis, columns (1) and (4) show a very strong, positive raw correlation between dependent and independent variables. If anything, this correlation is slightly weaker in our sample of stacked border counties, making it unlikely that the results that follow are due to an unrepresentative sample.

The next two sets of columns add controls for demographics and economic conditions, candidate visits, non-presidential advertising, as well as the partisan difference in vote shares during the previous election. Accounting for all covariates that appear in Table 2 decreases the estimated correlations, but does not render them economically meaningless. Based on these partial correlations, one would conclude that a standard deviation increase in the partisan difference in presidential advertising - the equivalent of potential voters seeing an additional 22.5 spots for the Democratic candidate rather than the Republican one - increases the Democratic candidate's vote share by almost 2.4 percentage points relative to that of his Republican opponent.

Columns (7)-(9) implement our border-county pair identification strategy. This leads to a further reduction in the coefficients. At the same time, the estimated impact of political advertising remains statistically significant and economically sizeable. According to our preferred specification in column (9), which includes the full set of controls and thus yields the most precise point estimate, a standard deviation increase in the partisan imbalance in advertising increases the gap in vote shares by about 0.7 percentage points. It, therefore, appears that political advertising has a nonnegligible impact on vote shares - especially if one suspects that measurement error in advertising intensity attenuates the coefficients.

Table 6 performs the same set of robustness checks that we used to check the sensitivity of our results with regard to aggregate turnout. Due to the smaller number of observations, the point estimates for the 2004 election are far less precise than those for 2008. Yet, both sets of estimates are similar to each other and to the baseline value in column (9) of the previous table. It is also reassuring that the estimated effect of political advertising on vote shares remains qualitatively the same when we restrict attention to counties whose populations comprise less than $2 \%$ of the respective media markets, i.e., counties for which we believe our identification strategy to be particularly credible. Moreover, correcting for the impact of stacking by downweighting counties that appear multiple times in our data set leaves the estimated coefficients almost unaffected. ${ }^{22}$

\footnotetext{
${ }^{22}$ Appendix Tables A.3 and A.4 demonstrate that the estimates are also robust to implementing various
} 
Next, we investigate heterogeneity in the effect of Democratic and Republican advertising. In order to do so, Table 7 presents results for vote shares that are defined relative to the entire voting-aged population. This has the benefit that we do not have to adjust for turnout when we calculate persuasion rates in Section 7. More importantly, using population-based vote shares as dependent variables allows for the possibility that one candidate's advertising has no effect on the (absolute) support for his opponent.

Empirically, however, there is some evidence to suggest that political advertising does not only affect a candidate's own vote share. In fact, the coefficients in Table 7 are in many ways surprisingly "symmetric." First, although the point estimates are imprecise, the sign pattern suggests that own advertising increases support for the respective candidate, while a rival's spots are detrimental to it. Of course, the latter finding would hold mechanically true had we used regular two-party vote shares as outcomes. With vote shares defined relative to the entire voting-eligible population, however, there is no a priori reason for the apparent symmetry in the estimates.

One plausible explanation - especially in light of our null result with respect to aggregate turnout - is that the persuasive effects of political advertising operate primarily on the intensive margin. That is, advertising might convince those who would have gone to the polls anyway to vote for one candidate rather than the other. Another possible rationalization is that political advertising works on the extensive margin by affecting who turns out to vote. For instance, advertising by the Democratic contender might mobilize core Democratic supporters all the while deterring Republican ones. In the aggregate such compositional effects might happen to offset each other, which would explain why there appears to be no significant change in overall turnout. Naturally, with aggregate data there is little hope to credibly distinguish between these competing explanations.

\section{Political Advertising and the Composition of the Electorate}

In order to be able to speak to the mechanism through which political advertising affects election outcomes, we have acquired individual-level voter-registration data for the lower forty-eight states and the District of Columbia. The Help America Vote Act of 2002 requires that all states maintain a single, computerized voter-registration list that is regularly updated by removing the deceased, voters who become ineligible, as well as duplicate entries in accordance with the National Voter Registration Act of 1993. The resulting lists include each voter's residential address, date of registration, and turnout history.

For a subset of individuals, we also have information on date of birth, gender, and party

versions of the differences estimator in equation (1), as well as to using fixed effects for entire media market borders instead of border-county pairs. 
affiliation. In particular, thirty-nine states' voter-registration files have either a dedicated "party" field, or they allow us to determine in which party's primary (if any) a given individual participated. We identify an individual as a "registered Democrat" or "registered Republican" if the state lists her as such, or if she voted in the respective party's primary. Voters who are not officially affiliated with any of the two major parties and did not participate in one of their primaries are classified as "other." ${ }^{23}$ In total, our data contain in excess of 100 million records for which we can infer party affiliation, or lack thereof.

\subsection{Econometric Approach}

To assess whether political advertising leads to changes in the partisan composition of the electorate, we geocode all addresses and leverage the information on voters' precise locations relative to DMA borders in a regression discontinuity (RD) design (Lee and Lemieux 2010; Thistlethwaite and Campbell 1960). That is, we compare turnout among registered Democrats and Republicans who live just on opposite sides of media market borders.

Specifically, we are interested in whether the partisan difference in turnout varies discontinuously at the border. In Section 6.3, we show that advertising's impact on the partisan difference in turnout is a key parameter in assessing the importance of the compositional channel.

As before, we define the partisan difference in advertising as the number of impressions per capita in support of the Democratic candidate minus that for his Republican opponent. We then say that a particular voter lives "left" ("right") of the border if partisan differences in presidential advertising are smaller (larger) in the DMA in which she resides than in the neighboring one.

Interpreting our RD setup through the standard instrumental variables framework (Hahn et al. 2001), we calculate the impact of partisan differences in political advertising on partisan differences in turnout by forming the Wald estimator:

$$
\Delta\left(t_{D}-t_{R}\right)=\frac{\lim _{m_{i} \rightarrow 0^{+}} \mathbb{E}\left[\mathbb{E}\left[t_{i} \mid i=D\right]-\mathbb{E}\left[t_{i} \mid i=R\right] \mid m_{i}\right]-\lim _{m_{i} \rightarrow 0^{-}} \mathbb{E}\left[\mathbb{E}\left[t_{i} \mid i=D\right]-\mathbb{E}\left[t_{i} \mid i=R\right] \mid m_{i}\right]}{\lim _{m_{i} \rightarrow 0^{+}} \mathbb{E}\left[A d s_{D}-A d s_{R} \mid m_{i}\right]-\lim _{m_{i} \rightarrow 0^{-}} \mathbb{E}\left[A d s_{D}-A d s_{R} \mid m_{i}\right]}
$$

Here, $t_{i}$ is an indicator for turnout of individual $i$, and $m_{i}$ denotes her distance to the nearest media market border, with negative values assigned to voters who live on the "left." $A d s_{D}$ and $A d s_{R}$ are the number Democratic and Republican impressions per capita, respectively.

\footnotetext{
${ }^{23}$ We also classify as "other" individuals whose vote history indicates that they had participated in different parties' primaries.
} 
While our voter-registration data are ideally suited to estimate the numerator of equation (4), our advertising measure varies only at the DMA level and is, therefore, likely to overstate the true difference in the advertising exposure of voters in the vicinity of media market borders. This is because individuals who reside close to the border may be more likely to use terrestrial antennae to watch TV stations from the "wrong" DMA. If true, then our Wald estimates are biased towards zero, which, in turn, makes it more difficult to pick up any potential effect.

Even in the absence of this issue, it bears emphasizing that RD methods can only identify local average treatment effects (Imbens and Angrist 1994). That is, we estimate the impact of political advertising on the set of voters who live close to media market borders. If heterogeneity in effect size is quantitatively important, then the results below may not generalize to the U.S. population as a whole.

At the same time, our RD strategy has at least two important advantages. First, constituents' exposure to radio advertising or campaigns' ground operations is unlikely to exhibit a sharp discontinuity at within-state media market borders and, therefore, should not bias our results. Second, identification in our setting actually comes from differences in discontinuities. ${ }^{24}$ Thus, unlike traditional RD designs, our estimation strategy allows for other variables to vary discontinuously across media market borders as long as these variables do not differentially affect turnout among Republicans and Democrats (see Grembi et al. 2014 for a discussion of identification in the DRD design).

\subsection{RD Estimates}

Table 8 presents basic, descriptive statistics for our voter-registration data. As all states' lists contain information on turnout in 2008, but not necessarily in 2004, we restrict attention to the 2008 general election and to individuals for whom we observe a residential address at the time of the election. That is, we exclude voters who either registered for the first time or updated their information after 2008. Given that our data are current as of the end of 2013/14 (depending on the state) and that older lists are usually unavailable, we cannot determine where these individuals lived during the 2008 campaign. ${ }^{25}$ For the average registered voter in our sample, the straight-line distance between her residence and the nearest media market

\footnotetext{
${ }^{24} \mathrm{To}$ see this, note that the numerator of equation (4) can be rearranged to $\left(\lim _{m_{i} \rightarrow 0^{+}} \mathbb{E}\left[t_{i} \mid i=D, m_{i}\right]-\lim _{m_{i} \rightarrow 0^{-}} \mathbb{E}\left[t_{i} \mid i=D, m_{i}\right]\right) \quad-\left(\lim _{m_{i} \rightarrow 0^{+}} \mathbb{E}\left[t_{i} \mid i=R, m_{i}\right]-\lim _{m_{i} \rightarrow 0^{-}} \mathbb{E}\left[t_{i} \mid i=R, m_{i}\right]\right)$. The first term denotes the discontinuity in turnout among Democrats, while the second one gives the discontinuity in turnout among Republicans.

${ }^{25}$ In our sample, voters on either side of DMA borders have, on average, been registered at their current addresses for the same number of years (cf. Appendix Table A.7), which makes it unlikely that our results are driven by selective attrition.
} 
border is about 67 kilometers. Nineteen percent, however, live within $25 \mathrm{~km}$ of a DMA border; and about two percent reside within $5 \mathrm{~km}$.

Pooling over all 13.5 million partisans living within $25 \mathrm{~km}$ of a media market border, Figures 2 and 3 depict our main RD results. Figure 2 shows raw averages for the partisan difference in advertising within 2.5 kilometer intervals on either side of the border, i.e., the denominator in equation (4). Figure 3 does so for the numerator, the partisan difference in turnout.

By construction, media market borders feature a large discontinuity in partisan advertising. On average, the size of the gap is somewhat more than 25 impressions per capita. That is, voting-aged adults to the "right" of the border see about 25 additional ads favoring the Democratic candidate rather than the Republican one. ${ }^{26}$

Interestingly, partisan differences in turnout also exhibit a discontinuity. Registered Democrats living just to the "left" of the border are approximately 3.9 percentage points less likely to go to the polls than their Republicans counterparts, but the gap narrows to about 2 percentage points among those living just on the other side. This "jump" is statistically highly significant. The evidence in Figures 2 and 3, therefore, suggests that partisan differences in political advertising induce changes in the partisan composition of the electorate.

Based on the graphical analysis, one would conclude that an increase in the partisan difference in advertising by 10 impressions per capita raises turnout of registered Democrats by almost 0.8 percentage points relative to their Republican counterparts. ${ }^{27}$ Of course, this simple analysis is not without limitations. In particular, there is no a priori reason to believe that the true functional relationship between the running variable and differences in turnout is linear. Also, Figures 2 and 3 pool over different natural experiments and may, therefore, be affected by unobserved spatial heterogeneity. In what follows, we probe the results of the graphical analysis by using nonparametric techniques (Hahn et al. 2001). More specifically, we leverage the size of our voter registration data set to estimate local polynomial fixed effects regressions within very narrow bandwidths around media market borders.

Table 9 presents the results. The estimates in the upper panel refer to the numerator of the Wald estimator and are based on the following "differences in discontinuities" specification:

$$
\begin{aligned}
y_{i, p, s} & =\alpha_{p, s}+\tau \mathbf{1}[p=D] \times \mathbf{1}\left[m_{i}>0\right]+\delta \mathbf{1}\left[m_{i}>0\right] \\
& +g_{p}^{l}\left(m_{i}\right) \times \mathbf{1}\left[m_{i}<0\right]+g_{p}^{r}\left(m_{i}\right) \times \mathbf{1}\left[m_{i}>0\right]+\varepsilon_{i, p, s},
\end{aligned}
$$

where $y_{i, p, s}$ is an indicator variable for whether voter $i$, who is a registered supporter of party $p \in\{D, R\}$ and lives close to border segment $s$, went to the polls in the 2008 general election.

\footnotetext{
${ }^{26}$ The fact that the average number of impressions varies across bins on either side of the border is due to differences in the spatial distribution of voters across DMAs.

${ }^{27}$ Formally, $\Delta\left(t_{D}-t_{R}\right) \approx(3.9-2) / 25 \approx 0.08$.
} 
$g_{p}^{l}(\cdot)$ and $g_{p}^{r}(\cdot)$ are flexibly specified, party-specific polynomials of distance, which are allowed to differ on either side of the threshold. To control for unobserved spatial heterogeneity, we divide every DMA border into segments of up to $10 \mathrm{~km}$ length and include $\alpha_{p, s}$, a partyspecific fixed effect for each of them. The parameter of interest is $\tau$. It measures by how much the partisan difference in turnout changes right at the border.

All estimates use a rectangular kernel with the respective bandwidth indicated at the top of each column. Going from left to right, the bandwidth increases from 500 meters to 5 kilometers, with the last column relying on 10-fold cross-validation for bandwidth selection (Ludwig and Miller 2005). Successive rows use higher-order polynomials to approximate $g_{p}^{l}(\cdot)$ and $g_{p}^{r}(\cdot)$.

Our nonparametric estimates of $\tau$ range from 1.5 to 3.6 percentage points. Ten out of the sixteen estimates are statistically significant at either the $5 \%$ - or $10 \%$-level. Estimates that are based on a smaller bandwidth are somewhat larger but also less precise. As we control more flexibly for distance to the border, the estimated discontinuity in the partisan difference in turnout stabilizes at or above the level suggested by the graphical analysis in Figure 3.

Appendix Table A.5 decomposes the point estimates into changes in turnout among registered Democrats and Republicans. Broadly summarizing, the sign pattern suggests that registered Democrats are more likely to vote - even in absolute terms - the more the Democratic candidate advertises relative to the Republican one. The opposite appears to be true for registered Republicans, although none of the point estimates for the latter group are statistically significant. One, admittedly speculative, explanation for why political advertising may also have demobilizing effects is that a substantial share of ads are negative. As in the laboratory experiments of Ansolabehere and Iyengar (1995), attack advertising may diminish the psychological benefits of turning out to support a particular candidate. Unfortunately, RD estimates that attempt to disentangle the effects of positive and negative advertising are too imprecise to confidently draw any conclusions. As a whole, however, the reduced form evidence implies that partisan differences in presidential advertising alter the partisan composition of the electorate.

The lower panel of Table 9 uses two-stage least squares to implement the Wald estimator. ${ }^{28}$ To facilitate comparisons with the results in Tables 3-7, we scale the coefficients so that they refer to the impact of 10 impressions per capita. The resulting Wald estimates range from 0.5 to 1.6 percentage points. The median coefficient equals 0.8 percentage points, which (after rounding) is the same number we obtained from the back-of-the envelope calculations based on our graphical analysis.

\footnotetext{
${ }^{28}$ For completeness, Appendix Table A.6 presents the "first stage" estimates, i.e., the denominator of the Wald estimator.
} 
Taking the median Wald estimate at face value, a standard deviation increase in the partisan gap in advertising raises turnout of registered Democrats by about 1.8 percentage points relative to their Republican counterparts. We, therefore, conclude that political advertising has a detectable impact on the partisan composition of the electorate.

\subsection{Assessing the Importance of Compositional Changes}

Yet, how important are these compositional shifts? Under the assumption that registered partisans are more likely to vote for their own party's candidate than for his competitor, we can gauge how much of the estimated effect of political advertising on vote shares can be explained by changes in the composition of the electorate alone.

Formally, let candidates' vote shares be given by $v_{D}$ and $v_{R}$, and assume that, conditional on going to the polls, registered partisans vote for the candidate of their own party with probability $\pi>0.5$. With $v_{D}$ and $v_{R}$ defined relative to the entire voting-eligible population, the following accounting identity must always hold:

$$
v_{D}-v_{R}=\left[\pi t_{D} s_{D}+(1-\pi) t_{R} s_{R}+\omega t_{O} s_{O}\right]-\left[(1-\pi) t_{D} s_{D}+\pi t_{R} s_{R}+(1-\omega) t_{O} s_{O}\right] .
$$

Here, $t_{p}$ denotes turnout among supporters of party $p, s_{p}$ is their population share, and $\omega$ stands for the likelihood that "others" will vote for the Democratic candidate. Noting that $s_{D} \approx s_{R}$ among voters close to media market borders, we can decompose changes in the partisan difference in vote shares into

$$
\begin{aligned}
\Delta\left(v_{D}-v_{R}\right) & \approx(2 \pi-1) s \Delta\left(t_{D}-t_{R}\right)+(2 \omega-1)(1-2 s) \Delta t_{O} \\
& +2 s\left(t_{D}-t_{R}\right) \Delta \pi+2(1-2 s) t_{O} \Delta \omega \\
& +2 s \Delta\left(t_{D}-t_{R}\right) \Delta \pi+2(1-2 s) \Delta t_{O} \Delta \omega .
\end{aligned}
$$

The first term on the right-hand side of equation (6) gives the contribution of changes in turnout among partisans, while the second one refers to turnout of unaffiliated individuals. The terms in the row beneath denote the effect of changing preferences (i.e., changes in the probability of voting for a particular party, conditional on going to the polls), while the ones in the third row refer to the interaction between shifts in both preferences and turnout.

To assess the importance of the compositional channel, suppose that political advertising has no effect on preferences and beliefs, and that it leads to no changes in turnout among unaffiliated voters. Equation (6) then simplifies to

$$
\Delta\left(v_{D}-v_{R}\right) \approx(2 \pi-1) s \Delta\left(t_{D}-t_{R}\right)
$$


Assuming that Democrats and Republicans each represent one-third of the voting population (i.e., $s=0.33$, cf. Table 8), and relying on the interquartile range of the Wald estimates for plausible values of $\Delta\left(t_{D}-t_{R}\right)$, Figure 4 plots the right-hand side of equation ( 7$)$ as a function of $\pi$.

Naturally, as the fraction of partisans who vote for the candidate of their own party increases, the partisan difference in vote shares widens. Importantly, Figure 4 shows that for values as low as $\pi=0.7$, the estimated shift in the partisan composition of the electorate increases the partisan difference in vote shares by 0.08 to 0.13 percentage points. For comparison, in Table 7 we estimated that political advertising raises the partisan difference in vote shares by 0.18 percentage points. Thus, if, conditional on going to the polls, seven out of ten partisans vote for their own party's candidate, then the compositional channel alone can explain between $44 \%$ and $73 \%$ of political advertising's impact on vote shares.

To get a sense of plausible values for $\pi$, we turn to the American National Election Survey (ANES). Among other questions, the 2008-2009 ANES Panel Study elicited respondents' vote choice in the 2008 presidential election as well as their self-declared party affiliation prior to election day. Respondents could identify as "strong Republican/Democrat," "not very strong Republican/Democrat," "independent Republican/Democrat," or as truly "independent." Almost $86 \%$ of those who self-identified as "strong" or "not very strong" Democrats later indicated that they also voted for Barack Obama. Conversely, about 92\% of self-declared Republicans supported John McCain. ${ }^{29}$ Although self-reported votes are notoriously unreliable indicators of actual choices, the available evidence suggests that $\pi$ may even exceed 0.7. If correct, then changes in turnout among partisans can explain most, if not all, of the impact of advertising on vote shares.

\subsection{Sensitivity and Robustness Checks}

We have conducted an extensive set of sensitivity and robustness checks. To conserve on space, the corresponding results are presented in Appendix Figures A.7-A.10 and in Tables A.7-A.18.

Briefly, to check for irregularities in the running variable, we look at population density in the vicinity of DMA borders. Based on the evidence in Figures A.7 and A.8, there is little reason to suspect that individuals in our sample are more likely to settle on one side of the border than on the other. Similarly, we find no evidence of economically meaningful differences in how long voters on either side of the border have been registered at their current address (cf. Table A.7), which helps to ameliorate concerns about selective attrition from our sample.

\footnotetext{
${ }^{29}$ Restricting attention to "strong" partisans results in estimates that are a few percentage points larger.
} 
Tables A.8 and A.9 test for discontinuities in voters' age and gender. The point estimates in these tables are economically small and generally statistically insignificant. In the same vein, Table A.10 shows that partisan differences in non-presidential political advertising do not systematically vary "left" and "right" of the DMA border. In particular, the sign of the estimated discontinuity does not only change from one specification to the next, but its size is an order of magnitude smaller than that in Figure 2.

The evidence in Table A.11 indicates that our RD estimates are robust to controlling for voters' observable characteristics as well as advertising related to non-presidential races. We also obtain qualitatively and quantitatively similar results when we restrict attention to the set of voters for whom our geocodes are the most precise, i.e., those for whom the geocoding procedure is able to locate the exact street address (cf. Table A.12).

In order to gauge the impact of measurement error in advertising intensity, we turn to the FCC's Significantly Viewed List (FCC 2005). In 2005, the FCC issued an updated, comprehensive assessment of all media markets in the U.S. In particular, it released a list of counties where out-of-market broadcast stations have a nontrivial viewership. In Table A.13, we restrict our sample to voters who live in counties where no out-of-market station appears on the FCC's list. Consistent with the idea that measurement error introduces attenuation bias, the resulting Wald estimates range from 0.007 to 0.077 . While these estimates are generally larger than their counterparts in Table 9, we note that the smaller sample size leads to standard errors that make any quantitative comparisons highly speculative.

Since media market borders coincide with those of counties, there exists the possibility that other variables change discontinuously at the DMA border. If these variables exert a differential effect on turnout among registered Democrats and Republicans, then the estimates from our "differences in discontinuities" design might be biased. To ameliorate this concern, in Appendix Tables A.14 and A.15 we test for discontinuities in newspaper circulation and local-school expenditures. ${ }^{30}$ Broadly summarizing, the estimated coefficients are neither consistently positive nor negative and, with one exception, are statistically indistinguishable from zero.

We have also explored potential heterogeneity in the effect of advertising on partisans' turnout decisions. Since Nielsen reports the number of impressions disaggregated by viewers' gender and age, it is possible to relate discontinuities in turnout among different groups of partisans to group specific changes in advertising intensity. Tables A.16 and A.17 contain the results. Although the Wald estimates for males are perhaps somewhat larger than those for females, relative to the standard errors the implied differences in effect size are too small to

\footnotetext{
${ }^{30}$ Data on these outcomes come from the Alliance for Audited Media and the National Center for Education Statistics, respectively. See the Data Appendix for details.
} 
draw sharp conclusions. The same applies to the Wald estimates with regard to different age groups (cf. Table A.17). We are, therefore, unable to answer the question whether political advertising is more effective at changing the behavior of some voters than others.

\subsection{Total Presidential Advertising and Turnout}

So far we have restricted attention to registered partisans, as this has allowed us to assess the importance of the compositional channel. We now provide a partial test of the idea that political advertising also transmits useful information.

In doing so we focus on "independent" voters, i.e., individuals who are not affiliated with one of the two major parties. Theoretical work that relates the quality of voters' information to turnout typically concludes that, in a given election, informed individuals are more likely to vote than uninformed ones (see Feddersen and Pesendorfer 1996, 1999). The intuition behind this result is that informed voters are less likely to make a mistake by choosing the ex post worse candidate. If correct, and if political advertising does contain new information, then we would expect that independent voters who see more political ads on TV are more likely to turn out than those who see fewer spots.

Using a slight modification of our RD design, we test this hypothesis in the upper panel of Table 10. Instead of assigning a particular voter to either side of the DMA border according to the partisan difference in presidential advertising, we now do so based on whether total presidential advertising in her DMA exceeds that in the neighboring one. Hence, the Wald estimates in Table 10 refer to the effect of total presidential advertising on turnout among independents.

All of the sixteen coefficients in the upper panel are economically small. Ten are even negative. Importantly, the estimates are precise enough to rule out meaningfully large positive effects. All in all, we find no evidence in favor of the idea that political advertising endows independent voters with useful information. At the same time, we note that a better test would also consider actual votes, which we no not observe.

Lastly, in the lower panel of Table 10 we demonstrate that our previous result of a minimal effect of presidential advertising on overall turnout is not an artifact of using aggregate data (see also Appendix Figures A.9 and A.10). This finding is qualitatively robust to focusing on voters in communities that do not appear on the FCC's Significantly Viewed List - though the resulting estimates are much less precise (cf. Appendix Table A.18). In sum, we conclude that political advertising induces changes in the partisan composition of the electorate, which appear to offset in the aggregate.

To be clear, we do not claim that changes in the partisan composition of the electorate will always exactly cancel out. However, in an environment with two candidates who have roughly 
the same number of supporters and if ads have both mobilizing and demobilizing effects, one would expect a considerably smaller net impact - especially when both campaigns advertise in similar proportions.

\section{Discussion}

To put the estimated effect of political advertising on vote shares into perspective, we follow DellaVigna and Kaplan (2007) and calculate persuasion rates, i.e., the percentage of individuals who changed their behavior in response to seeing political ads. Formally, the persuasion rate is defined as

$$
f_{p}=\frac{1}{1-\widetilde{y}_{p}} \frac{\Delta y_{p}}{\Delta A d s_{p}},
$$

where $\Delta y_{p} / \Delta A d s_{p}$ approximates the change in the outcome of interest induced by seeing additional advertisements in support of candidate $p$, and $1-\widetilde{y}_{p}$ is the fraction of individuals who may be swayed by the respective candidate's message. ${ }^{31}$

We take the outcome of interest to be the partisan difference in vote shares defined as a percentage of the entire voting-aged population. Defining $y$ in this way has two advantages. First, it is not necessary to adjust for turnout. Second, we capture advertising's positive effect on own vote shares as well as any negative impact on the support for political rivals (cf. Table 7). The latter point is important. If the Democratic candidate, for instance, is purely office motivated, then he should be indifferent between one more vote for himself or one less for his Republican competitor. As a consequence, $1-\widetilde{y}_{D}$, the target audience for his ads, includes everybody who does not already vote for him, i.e., everybody who would either abstain or vote for his opponent.

First, we calculate the persuasion rate of one additional spot, given the observed overall level of advertising and candidates' equilibrium vote shares. To proxy for $\Delta y_{p} / \Delta A d s_{p}$, we rely on the point estimates in column (8) of Table 7 , divided by ten to account for the fact that the coefficients refer to the impact of ten impressions per capita. With the respective numbers in hand, the persuasion rate of Democratic spots is given by $f_{D} \approx 0.02 \%$, while that for Republican advertising equals $f_{R} \approx 0.01 \% .^{32}$

Next, we consider the share of potential voters who changed their behavior in response to a candidates' total advertising. To proxy for $\widetilde{y}_{p}$ in the absence of advertising by the respective candidate, we use the results in columns (2) and (5) of Table 7 and predict counterfactual vote shares. $\Delta y_{p} / \Delta A d s_{p}$ is, again, given by the appropriately scaled coefficients in column

\footnotetext{
${ }^{31}$ Appendix C derives equation (8) formally.

${ }^{32}$ More explicitly, $f_{D} \approx(1 / 0.6996)(0.0017) / 10 \approx 0.0002$ as well as $f_{R} \approx(1 / 0.7400)(0.0008) / 10 \approx 0.0001$.
} 
(8) of the same table. The resulting persuasion rates are $f_{D} \approx 1.1 \%$ and $f_{R} \approx 0.3 \% .33$

Regardless of whether we calculate the persuasion rate for a single spot or with respect to all of a candidates' combined advertising, the respective numbers are only a fraction of the persuasion rates reported in the literature (cf. DellaVigna and Gentzkow 2010). This may not come as a surprise. Arguably, watching a thirty-second political ad constitutes a far less intense treatment than having year-round access to additional TV stations or newspapers. Even adjusted for time, from a theoretical perspective the effect of partisan advertising ought to be smaller than that of slanted news, at least as long as journalists are more likely to be trusted than campaigns (Knight and Chiang 2011). However, given the ongoing debate about campaign finance regulation, the perhaps more important question is: Does advertising have economically meaningful aggregate effects?

Within 60 days leading up to the 2008 presidential election, the average voting-aged citizen saw about 45 spots in support of Barack Obama and almost 30 ads favoring John McCain. According the U.S. Census Bureau about 206 million Americans were eligible to vote that year (File and Crissey 2012). Given the persuasion rates above, political advertising impacted almost 2.9 million voting decisions. Naturally, the effects of Democratic and Republican ads will partially offset each other, resulting in a smaller net impact. Still, simply eliminating the partisan difference in advertising by reducing the number of impressions in favor of Barack Obama to the same level as those for John McCain would have narrowed the difference in votes by roughly 600,000 . While this would not have made much of a difference in 2008, in years in which the election is close a similar sized shift might well decide the overall outcome of the race.

As a further way of putting the impact of political advertising into perspective, we note that a shift of 600,000 votes is about three times as large as the nationwide "FOX News effect" (DellaVigna and Kaplan 2007). While DellaVigna and Kaplan (2007) report much higher persuasion rates than we do, the scale and reach of political advertising results in a nonnegligible aggregate impact.

\section{Concluding Remarks}

In this paper we study the persuasive effects of political advertising. To this end, we implement a new approach to estimating the impact of advertising on electoral outcomes. Our empirical strategy exploits FCC regulations that result in plausibly exogenous variation in the number of impressions across media market borders. Using aggregate county-level data as well as individual turnout histories for millions of U.S. voters, we show that advertising affects election outcomes by altering the partisan composition of the electorate. Since regis-

\footnotetext{
${ }^{33}$ Again, $f_{D} \approx(1 / 0.7028)(0.0017)(44.8 / 10) \approx .0108$ and $f_{R} \approx(1 / 0.7422)(0.0008)(29.6 / 10) \approx 0.0033$
} 
tered partisans are considerably more likely to vote for their own party's candidate than his competitor, these compositional changes give rise to nontrivial effects on actual vote shares.

We find no evidence, however, that advertising has a meaningful impact on overal turnout. In the aggregate, the mobilizing and demobilizing effects of political ads tend to cancel out. This explains why a large number of previous studies have detected only minimal or even no effects. More generally, our findings help to reconcile an important puzzle. Why do modern campaigns advertise so much, despite negligible changes in overall voter engagement and individuals' opinions about candidates? Even if political advertising does not have a lasting impact on preferences or beliefs, the evidence in this paper shows that it brings the "right" set of voters to the polls.

The results above have potentially important implications for public policy, especially for campaign finance regulation. Given the size of the estimates above, partisan imbalances in political advertising have the potential to decide close elections.

While advertising may be welfare-improving if it provides voters with new information about candidates and their competitors, our finding that most of its impact comes from a partisan reshuffling of the electorate is difficult to reconcile with an information-based explanation. Any model in which political advertising supplies citizens with valuable information would have to rationalize why there is no measurable effect on independent voters, all the while partisans, whose beliefs about the relative quality of candidates are presumably more settled, react to it - and do so in opposite ways. By contrast, models in which advertising mobilizes core supporters by affecting the perceived benefit of voting are consistent with the most salient patterns in the data (see, e.g., Shachar and Nalebuff 1999). ${ }^{34}$ Since candidates' advertising efforts appear to partially offset each other, and absent large informational benefits, a benevolent social planner would curb at least some of the associated spending.

\section{References}

Ansolabehere, S., and S. Iyengar (1995). Going Negative: How Political Advertising Shrinks and Polarizes the Electorate. New York: Free Press.

, - a a A A Simon (1999). "Replicating Experiments Using Aggregate and Survey Data: The Case of Negative Advertising and Turnout." American Political Science Review, 93(4): 901-909.

— E. Snowberg, and J. Snyder (2006). "Television and Incumbency Advantage in U.S. Elections." Legislative Studies Quarterly, 31(4): 4669-490.

\footnotetext{
${ }^{34}$ Consistent with this argument, Durante and Gutierrez (2014) find that political advertising in Mexico is more effective at convincing individuals who voted for the respective party in the past, while Hopkins and Ladd (2014) argue that the "Fox News effect" is due to reinforcing the loyalties of Republican supporters.
} 
Ashworth, S., and J. Clinton (2007). "Does Advertising Affect Turnout?" Quarterly Journal of Political Science, 2(1): 27-41.

BAron, D. (1989). "Service-induced Campaign Contributions and the Electoral Equilibrium." Quarterly Journal of Economics, 104(1):45-72.

(1994). "Electoral Competition with Informed and Uninformed Voters." American Political Science Review, 88(1): 33-47.

Bernays, E. (1928). Propaganda. New York: Horace Liveright.

Black, S. (1999). "Do Better Schools Matter? Parental Valuation of Elementary Education." Quarterly Journal of Economics, 114(2): 577-599.

Borrell Associates (2015). "2015-2016 Political Advertising Outlook." retrieved from http://www.borrellassociates.com/industry-papers/archives (November 1, 2015)

Campante, F., and Q.-A. Do (2014). "Isolated Capital Cities, Accountability and Corruption: Evidence from US States." American Economic Review, 108(8): 2456-2481.

Campbell, J., J. Alford, and K. Henry (1984). "Television Markets and Congressional Elections." Legislative Studies Quarterly, 9(4): 665-678.

Card, D., and A. Krueger (1994). "Minimum Wages and Employment: A Case Study of the New Jersey and Pennsylvania Fast Food Industries." American Economic Review, 84(4): 772-793.

Congressional Quarterly. (2015). CQ Voting and Elections Collection. Washington, D.C.: CQ Press.

DellaVigna, S., and M. Gentzkow (2010). "Persuasion: Empirical Evidence." Annual Review of Economics, 2: 643-669.

— , and E. Kaplan (2007). "The Fox News Effect: Media Bias and Voting." Quarterly Journal of Economics, 122(3): 1187-1234.

Downs, A. (1957). An Economic Theory of Democracy. New York: Harper.

Dube, A., T. Lester, and M. Reich (2010). "Minimum Wage Effects Across State Borders: Estimates using Contiguous Counties." Review of Economics and Statistics, 92(4): 945-964.

Durante, R., and B. Knight (2012). "Partisan Control, Media Bias, And Viewer Responses: Evidence From Berlusconi's Italy." Journal of the European Economic Association, 10(3): 451481.

Exogenous Variation in Ads Viewership." mimeographed, Sciences Po.

Enikolopov, R., M. Petrova, and E. Zhuravskaya (2011). "Media and Political Persuasion: Evidence from Russia." American Economic Review, 111(7): 3253-3285.

Federal Communications Commission (2005). "Implementation of the Satellite Home Viewer Extension and Reauthorization Act of 2004." Report and Order FCC 05-187.

(2012). "Evolution of Cable Television." retrieved from http://www.fcc.gov/encyclopedia/evolution-cable-television (April 12, 2015).

Feddersen, T., and W. Pesendorfer (1996). "The Swing Voter's Curse." American Economic 
Review, 86(3): 408-424.

, and _ (1999). "Abstention in Elections with Asymmetric Information and Diverse

Preferences." American Political Science Review, 93(2): 381-398.

File, T., and S. Crissey (2012). "Voting and Registration in the Election of November 2008."

U.S. Census Bureau Report No. P20-562RV.

Freedman, P., and K. Goldstein (1999). "Measuring Media Exposure and the Effects of Negative Campaign Ads." American Journal of Political Science, 43(4): 1189-1208.

, M. Franz, and K. Goldstein (2004). "Campaign Advertising and Democratic Citizenship." American Journal of Political Science, 48(4): 723-741.

Gerber, A., J. Gimpel, D. Green, and D. Shaw (2011). "How Large and Long-lasting Are the

Persuasive Effects of Televised Campaign Ads? Results from a Randomized Field Experiment." American Political Science Review, 105(1): 135-150.

Gentzkow, M. (2006). "Television and Voter Turnout." Quarterly Journal of Economics, 121(3): 931-972.

— and J. Shapiro (2006). "Media Bias and Reputation." Journal of Political Economy, 114(2): 280-316.

— , and _ (2010). "What Drives Media Slant? Evidence form U.S. Daily Newspapers." Econometrica, 78(1): 37-71.

— _ , and M. Sinkinson (2011). "The Effect of Newspaper Entry and Exit on Electoral Politics." American Economic Review, 101(7): 2980-3018.

Geys, B. (2006). "Explaining Voter Turnout: A Review of Aggregate-Level Research." Electoral Studies, 25: 637-663.

Goldstein, K., and P. Freedman (2002). "Campaign Advertising and Voter Turnout: New Evidence for a Stimulation Effect." Journal of Politics, 64(3): 721-740. , S. Niebler, J. Neiheisel, and M. Holleque (2011). "Presidential, Congressional, and

Gubernatorial Advertising, 2008." Combined File [dataset]. Initial release. Madison,WI: The University ofWisconsin Advertising Project.

, and J. Rivlin (2007). "Presidential advertising, 2003-2004." Combined File [dataset].

Final release. Madison, WI: The University of Wisconsin Advertising Project.

Gordon, B., and W. Hartmann (2013). "Advertising Effects in Presidential Elections." Marketing Science, 32(1): 19-35.

Grembi, V., T. Nannicini, and U. Troiano (2014). "Policy Responses to Fiscal Restraints: A Difference-in-Discontinuities Design," mimeographed, University of Michigan.

Groseclose, T., and J. Milyo (2005). "A Measure of Media Bias." Quarterly Journal of Economics, 120(4): 1191-1237.

Grossman, G., and E. Helpman (1996). "Electoral Competition and Special Interest Policies." Review of Economic Studies, 63(2): 265-286. , and E. Helpman (2001). Special Interest Politics. Cambridge, MA: MIT Press. 
Hagen, M., and R. Kolodny (2008). "Finding the Cost of Campaign Advertising." The Forum, 6(1): $1-14$.

Hahn, J., P. Todd, and W. van Der KlaAuw (2001). "Identification and Estimation of Treatment Effects with a Regression-Discontinuity Design." Econometrica, 69(1): 201-209.

Herman, E., and N. Chomsky (1988). Manufacturing Consent. New York: Pantheon.

Holmes, T. (1998). "The Effects of State Policies on the Location of Manufacturing: Evidence from State Borders." Journal of Political Economy, 106(4): 667-705.

Hopkins, D., and J. LADD (2014). "The Consequences of Broader Media Choice: Evidence from the Expansion of Fox News," Quarterly Journal of Political Science, 9(1): 115-135.

Huang, T., and D. Shaw (2009). "Beyond the Battlegrounds? Electoral College Strategies in the 2008 Presidential Election." Journal of Political Marketing, 8(4): 272-291.

Huber, G., and K. Arceneaux (2007). "Identifying the Persuasive Effect of Presidential Advertising." American Journal of Political Science, 51(4): 957-977.

Imbens, G., and J. Angrist (1994). "Identification and Estimation of Local Average Treatment Effects." Econometrica, 62(2): 467-475.

, and T. Lemieux (2008). "Regression Discontinuity Designs: A Guide to Practice." Journal of Econometrics, 142(2): 615-635.

Iyengar, S., and A. Simon (2000). "New Perspectives and Evidence on Political Communication and Campaign Effects." Annual Review of Psychology, 51: 149-169.

Kendall, C., T. Nannicini, and F. Trebbi (2015). "How Do Voters Respond to Information? Evidence from a Randomized Campaign." American Economic Review, 105(1): 322-353.

Klapper, J. (1960). The Effects of Mass Communication. New York: Free Press.

Knight, B., and C.-F. Chinng (2011). "Media Bias and Influence: Evidence from Newspaper Endorsements." Review of Economic Studies, 78(3): 795-820.

Krasno, J., and D. Green (2008). "Do Televised Presidential Ads Increase Voter Turnout? Evidence from a Natural Experiment." Journal of Politics, 70(1): 245-261.

LAVy, V. (2010). "Effects of Free Choice Among Public Schools." Review of Economic Studies, $77(3): 1164-1191$.

Lee, C., B. Ferguson, and D. Early (2014). "After Citizens United: The Story in the States." Report of the Brennan Center for Justice at New York University School of Law.

Lee, D., and T. Lemieux (2010). "Regression Discontinuity Designs in Economics." Journal of Economic Literature, 48(2): 281-355.

Levitt, S. (1994). "Using Repeat Challengers to Estimate the Effect of Campaign Spending on Election Outcomes in the U.S. House." Journal of Political Economy, 104(4): 777-798.

Lippmann, W. (1922). Public Opinion. New York: Harcourt, Brace.

Ludwig, J., and D. Miller (2005). "Does Head Start Improve Children's Life Chances? Evidence from a Regression Discontinuity Design.” NBER Working Paper No. 11702.

Martin, D. (2014). "The Informational Content of Campaign Advertising," mimeographed, Emory 
University.

, and A. Yurukoglu (2014). "Bias in Cable News: Real Effects and Polarization," mimeographed, Stanford GSB.

MCCrary, J. (2008). "Manipulation of the Running Variable in the Regression Discontinuity Design: A Density Test." Journal of Econometrics, 142(2): 698-714.

Moshary, S. (2014). "Price Discrimination across PACs and the Consequences of Political Advertising Regulation," mimeographed, MIT.

New York Times (2008). "About \$2.6 Billion Spent on Political Ads in 2008." retrieved from http://nyti.ms/1yYC1kb (April 12, 2015)

Nielsen (2011). "State of the Media: The Cross-Platform Report, Q3 2011." retrieved from http://www.nielsen.com/us/en/insights/reports/2012/cross-platform-report-q3-2011.html (April 12, 2015)

(2013). "Free to Move Between Screens: The Cross-Platform Report, Q4 2012." retrieved from http://www.nielsen.com/us/en/insights/reports/2013/the-nielsen-march-2013cross-platform-report-free-to-move-betwe.html (April 12, 2015).

Niemi, R., L. Powell, and P. Bicknell (1986). "The Effects of Congruity between Community and District on Salience of U.S. House Candidates." Legislative Studies Quarterly, 11(2): 187-201.

Oberholzer-Gee, F., and J. Waldfogel (2009). "Media Markets and Localism: Does Local News en Español Boost Hispanic Voter Turnout?" American Economic Review, 99(5): 21202128.

Prat, A. (2002). "Campaign Advertising and Voter Welfare." Review of Economic Studies, 69(4): 999-1017.

— a and D. Strömberg (2013). "The Political Economy of Mass Media" (pp. 135-187) in D. Acemoglu, M. Arellano, and E. Dekel (eds.), Advances in Economics and Econometrics, Vol. 2. Cambridge, UK: Cambridge University Press.

ProPublica (2012). “A Tangled Web: Who's Making Money From All This Campaign Spending?" retrieved from http://www.propublica.org/special/a-tangled-web (April 12, 2015)

Ridout, T. (2007). "Television Advertising during the Presidential Nomination Season," (pp. 99116) in W. MAYER (ed.), The Making of the Presidential Candidates 2008. New York: Rowman \& Littlefield.

Ridout, T., M. Franz, K. Goldstein, and W. Feltus (2012). "Separation by Television Program: Understanding the Targeting of Political Advertising in Presidential Elections." Political Communication, 29(1): 1-23.

Shachar, R., and B. Nalebuff (1999). "Follow the Leader: Theory and Evidence on Political Participation." American Economic Review, 89(3): 525-547.

Shapiro, B. (2015). "Positive Spillovers and Free Riding in Advertising of Prescription Pharmaceuticals: The Case of Antidepressants." mimeographed, University of Chicago.

Shaw, D. (2007). The Race to 270: The Electoral College and the Campaign Strategies of 2000 and 
2004. Chicago: University of Chicago Press.

Snyder, J., and D. Strömberg (2010). "Press Coverage and Political Accountability." Journal of Political Economy, 118(2): 355-408.

StrömberG, D. (2004). "Radio's Impact on Public Spending." Quarterly Journal of Economics, 119(1): 189-221.

(2008). "How the Electoral College Influences Campaigns and Policy: The Probability of Being Florida." American Economic Review, 98(3): 769-807.

Thistlethwaite, D., and D. Campbell (1960). "Regression-Discontinuity Analysis: An Alternative to the Ex Post Facto Experiment." Journal of Educational Psychology, 51(6): 309-317.

Toniatti, D. (2014). "Political Advertising and Voter Turnout." Dissertation, University of Chicago.

Wesleyan Media Project (2012) "Presidential Ad War Tops 1M Airings." retrieved from http://mediaproject.wesleyan.edu/releases/presidential-ad-war-tops-1m-airings/ (April 12, 2015)

Washington Post (2012). "Mad Money: TV Ads in the 2012 Presidential Campaign." retrieved from http://www.washingtonpost.com/wp-srv/special/politics/track-presidential-campaignads-2012 (April 12, 2015)

Wooldridge, J. (2002). Econometric Analysis of Cross Section and Panel Data. Cambridge, MA: MIT Press.

Zaller, J. (1992). The Nature and Origins of Mass Opinion. Cambridge, UK: Cambridge University Press. 


\section{APPENDIX MATERIALS}

\section{A. Visualizing Variation in Presidential Advertising}

\section{A.1. Total Presidential Advertising}

Appendix Figure A.1 depicts the total number of presidential impressions per capita (among votingaged adults) within sixty days leading up to the 2008 general election for all media markets in the lower forty-eight states. Evidently, there is much variation in advertising exposure both within and across states.

As one would expect given the structure of the Electoral College, media markets that are either fully contained or overlap with "swing states" receive the bulk of presidential advertising. In June of 2008, the Washington Post identified the following sixteen states as those on which campaigns would focus their efforts: Colorado, Florida, Iowa, Michigan, Minnesota, Missouri, Nevada, New Hampshire, New Jersey, New Mexico, North Carolina, Ohio, Oregon, Pennsylvania, Virginia, and Wisconsin (Washington Post 2008). In retrospect, Oregon turned out to be safely in the hands of Barack Obama and, thus, received little presidential advertising from either party. Indiana and Montana, however, emerged as additional battleground states later in the campaign. Although other states, such as California or Texas, saw substantially fewer presidential ads, only 22 out of 210 media markets registered zero advertisements in the CMAG data.

\section{A.2. Partisan Differences in Presidential Advertising}

Appendix Figure A.2 shows the partisan difference in presidential impressions per capita, defined as $\widetilde{A d s}=A d s_{D}-A d s_{R}$. There is, again, a great deal of across- as well as within-state variation.

While overall advertising in non-battleground states is rather low, it is not necessarily uniformly distributed across media markets. In the state of Texas, for instance, there are 17 markets that registered at least as many ads in favor of McCain as Obama. In 3 markets, however, Obama advertised more than his competitor. In general, the partisan difference in advertising is smaller in media markets that are entirely contained within non-battleground states than in those that fall within or overlap with swing states. The Amarillo DMA in Texas, for instance, overlaps with the state of New Mexico, which is presumably why the McCain campaign and its supporters advertised so heavily there - much more so than in the remainder of Texas and considerably more than the Obama campaign. Importantly, DMAs that are partly contained within battleground states contribute most of the variation in partisan differences in political advertising within non-battleground states.

The partisan difference in presidential advertising also varies considerably within swing states. In Ohio, for instance, the Democratic candidate and his supporters advertised more than their Republican counterparts in seven out of twelve media markets. The Obama campaign advertised relatively more in the north and south of the state, i.e., in the Toledo and Cleveland DMAs as well 
as in the Dayton and Cincinnati markets, whereas McCain won the advertising battle in the Lima, Columbus, Zanesville, Parkersburg, and Steubenville DMAs. Interestingly, there is some evidence that the campaigns did not just target their core supporters. In 2000 and 2004, for instance, the majority of counties in the Steubenville DMA had been won by the respective Democratic rather than the Republican candidate. Similarly, outside the vicinity of Cleveland, Dayton, Toledo, and Cincinnati, the majority of voters are Republican leaning, and, therefore, quite comparable to those outside of Columbus (who saw relatively more ads favoring John McCain).

Even battleground states in which Obama advertised far more than McCain exhibit a fair amount of cross-DMA and, thus, across border-pair county variation. For instance, relative to McCain, Obama actually advertised less in the Charlottesville DMA, but more in all other Virginia markets. Overall, there is a surprising amount of variation both within battleground and non-battleground states.

\section{B. Assessing the Linearity Assumption}

In this section we assess to which extent the linearity assumption in our work horse empirical model provides an adequate approximation of the functional relationship between advertising intensity and different outcomes. To this end, we rely on partial residual plots (Ezekiel 1924; Larsen and McCleary 1972).

Specifically, to reduce the dimensionality of the data, i.e., to partial out the effect of all covariates but advertising, we first estimate the model in equation (2) on our sample of stacked border-pair counties, using the full set of controls. We then rely on the estimates of the other model parameters to residualize the outcome variable. ${ }^{35}$ In Figures A.3-A.6, we plot the resulting residuals against the respective measure of advertising. For comparison, we also graph the regression line implied by our linear model (dashed line) versus a nonparametric, i.e., locally smoothed, estimate of the same relationship (solid line).

By construction, the slope of the regression line in these plots equals the coefficient on advertising in our multivariate regressions in the main text. If a linear model approximates the data well, then one would expect the solid line to be close to the dashed one. Put differently, if the linear baseline model provides a good approximation, then a semi-parametric estimate of the relationship of interest should be approximately linear.

In Figure A.3, we focus on the relationship between total presidential advertising and turnout. Reassuringly, the two lines are virtually indistinguishable. We take this as evidence that a linear model is, in fact, adequate.

The evidence in Figure A.4 suggests a similar conclusion. Except in the very extremes, partisan differences in vote shares appear to be approximately linear in partisan differences in presidential advertising.

\footnotetext{
${ }^{35}$ In symbols, the partial residual of outcome $y_{c, t}$ is given by $\widetilde{\varepsilon}_{c, t} \equiv y_{c, t}-\widehat{\mu}_{p, t}-X_{c, t}^{\prime} \widehat{\gamma}$, where we follow the convention to denote estimated parameter values with a circumflex. Note that $\widetilde{\varepsilon}_{c, t}$ "includes" the component $\widehat{\phi} A d s_{c, t}$. That is, by contruction, $\widetilde{\varepsilon}_{c, t}=\widehat{\phi} A d s_{c, t}+\widehat{\varepsilon}_{c, t}$.
} 
In Figures A.5 and A.6, we examine the relationship between candidates' vote shares and their own advertising efforts as well as that of their competitors. Again, except for advertising levels in excess of 150 impressions per capita, a linear functional form appears to fit the data quite well. Since 150 impressions per capita corresponds to the 97th percentile in our data, we conclude that the error from assuming linearity is likely very small. In sum, we find little evidence to suggest that the functional form assumptions in our baseline model are a cause for concern.

\section{Derivation of Equation (8)}

Here, we formally derive the expression for the persuasion rate in Section 7. The main difference between our setup and existing derivations, i.e., DellaVigna and Kaplan (2007) and Enikolopov et al. (2011), is that we consider the outcome of interest to be the difference in candidates' vote shares, which are defined with respect to the entire voting-eligible population. The expressions below show that this leaves the basic structure of the formula unchanged.

Formally, let $y_{D}$ and $y_{R}$ denote the observed vote shares of the Democratic and Republican candidates, respectively. Further, let $f_{p}$ denote the persuasion rate of the spots sent by candidate $p \in$ $\{R, D\}$ with $A d s_{p}$ indicating their quantity. Hypothetical vote shares in the absence of advertising by candidate $p$ are given by $\widetilde{y}_{D}^{p}$ and $\widetilde{y}_{R}^{p}$. Assuming that $f_{p}$ is constant and does not vary by audience, the partisan difference in vote shares equals

$$
y_{p}-y_{\neg p}=\left(\widetilde{y}_{p}^{p}-\widetilde{y}_{\neg p}^{p}\right)+\underbrace{f_{p}\left(1-\widetilde{y}_{p}^{p}-\widetilde{y}_{\neg p}^{p}\right) A d s_{p}}_{\text {effect on "abstainers" }}+\underbrace{f_{p}\left(\widetilde{y}_{\neg p}^{p}\right) A d s_{p}}_{\text {effect on supporters of rival }} .
$$

Collecting terms and rearranging gives

$$
f_{p}=\frac{1}{1-\widetilde{y}_{p}^{p}} \frac{\left(y_{p}-y_{\neg p}\right)-\left(\widetilde{y}_{p}^{p}-\widetilde{y}_{\neg p}^{p}\right)}{A d s_{p}} .
$$

Setting $\Delta y=\left(y_{p}-y_{\neg p}\right)-\left(\widetilde{y}_{p}^{p}-\widetilde{y}_{\neg p}^{p}\right)$ and $\Delta A d s_{p}=A d s_{p}$ produces equation (8), as desired.

\section{Data Appendix}

This appendix provides a description of all data used in the paper, as well as precise definitions together with the sources of all variables. We first describe each source of data. We then explain the construction of our samples, and how we calculate every variable.

\section{D.1. Data Sources}

\section{D.1.1. Campaign Media Analysis Group}

Data on political advertising during the 2004 and 2008 general elections come from Kantar Media and the Campaign Media Analysis Group (CMAG). We obtained these data through the Wisconsin Advertising Project (http://wiscadproject.wisc.edu/). The 2004 sample includes political 
advertising spots aired in the 100 largest DMAs. In 2008, CMAG expanded coverage to all 210 DMAs.

\section{D.1.2. Nielsen Media Data}

Data on advertisement ratings come from the Nielsen Media Data file. The data include the estimated number of viewers of each recorded advertisement in any of the 210 DMAs, by gender and age group. ${ }^{36}$ Because Nielsen does not include estimates for every single political advertisement in the CMAG sample, we assign a viewership estimate to each political advertisement based on the average viewership of all advertisements recorded in the Nielsen data that air within the same 30 minute window (i.e., 0-29 minutes and 30-59 minutes) as the political advertisement. About 95.3\% of political advertisements are successfully matched through this process. ${ }^{37}$ When no viewership data are available within the same 30-minute window as the political advertisement, the number of viewers is imputed based CMAG's estimated cost for the spot. The imputed value is calculated from a linear regression of the estimated number of viewers on a quadratic function of CMAG's estimated cost for other spots in the same market and year that were successfully matched to Nielsen data.

Nielsen data also include a crosswalk that maps each county to demographic market areas. All but seven counties are uniquely assigned to a DMA. Apache County (AZ), El Dorado County (CA), Kern County (CA), Riverside County (CA), Blue Earth County (MN), Lea County (NM), and Oneida County (NY) are assigned to more than one DMA. These seven counties are excluded from the analysis.

\section{D.1.3. Election Results}

County-level information on the total number of voters, votes for each presidential candidate, writeins, etc. come from the $C Q$ Voting and Elections Collection (Congressional Quarterly 2015). These data include results from the 2000, 2004, 2008 elections. Counties in Alaska are excluded from the analysis because the election results are not available at the county-level. The 2008 election results from Adair County (MO) and Abbeville County (SC) are missing from the raw data. We add the respective results, as reported on the respective states' websites.

\section{D.1.4. U.S. Census Data}

Information on the racial composition of each county come from the U.S. Census Intercensal Estimates of the Resident Population by Sex, Race, and Hispanic Origin for Counties, and are based on an official estimate as of July 1 for each year. ${ }^{38}$

\footnotetext{
${ }^{36}$ Nielsen includes data on three types of advertisement spots: Spot TV, Network Clearance Spot TV, and Syndicated Clearance Spot TV.

${ }^{37}$ This statistic is based all political advertisements within 60 days of the U.S. Presidential election, the main specification in the paper.

${ }^{38}$ The U.S. Census aggregates information from Clifton Forge (VA) and Alleghany County (VA). As a result, we exclude these two counties from the analysis. Broomfield County (CO) separated from Boulder
} 
Information on the number of individuals that are at least 18 years old come from two sources. First, the number of adults 20 years or older come from the U.S. Census Intercensal Estimates of the Resident Population by Five-Year Age Groups, Sex, Race, and Hispanic Origin for Counties. These data are based on an official estimate as of July 1 for each year. The number of 18 and 19 year olds in each year are imputed based on a linear interpolation of the number of 18 and 19 year olds using the 2000 and 2010 Decennial Censuses of Population and Housing.

Data on poverty and income come from the U.S. Census Small Area Income 8 Poverty Estimates (SAIPE).

Information on counties' spatial position come from 2010 U.S. Census TIGER/Line shapefiles. The distance between two counties is the minimum distance between the county borders, measured as an equirectangular projection of the longitude and latitude using every tenth geocoded point. Any counties less than 10 kilometers apart by this measure are characterized as neighboring counties.

\section{D.1.5. Candidate Visits}

Information on the number of candidate visits to each media market was generously provided to us by Daron Shaw (Huang and Shaw 2009; Shaw 2007). The data for the 2004 election cover the period from September 3 to November 1, and that for the 2008 election encompass visits between June 11 and November 4. Only public appearances by candidates are counted. Private fund-raising events, vacation days, and working days in Washington, D.C. are excluded.

\section{D.1.6. Voter Registration Data}

Information on turnout of individual voters comes from official voter registration lists that are maintained by the states. Instead of approaching each state's board of elections individually, we purchased these data in bulk from emerges.com, a non-partisan data vendor that specializes in compiling and standardizing public records, including registered voter lists. The data we obtained are current as of 2013/14 (depending on the state) and contain voters' residential addresses and turnout histories. For most states, the data also include information on individuals' date of birth and gender. Thirty-nine states have either a dedicated party affiliation field, or they contain sufficient information for us to infer in which party's primary (if any) a given voter participated. ${ }^{39}$ We confine our analysis to voters for whom we can infer party affiliation, or lack thereof. In total the data from these states contain more than 155 million records. To make use of the spatial information in the data we rely on the Census Bureau's TIGER/Line shapefiles in geocoding voters' residential addresses.

County (CO) in 2001. Because the 2000 U.S. Census and 2000 election results are not available for these counties individually, we also exclude them from the analysis.

${ }^{39}$ The following states' list do not contain enough information to let us infer in which party's primary (if any) a voter participated: AL, MI, MO, MN, MT, ND, VT, WA, WI. 


\section{D.1.7. Newspaper Circulation Data}

Information on newspaper circulation by ZIP code come from the Alliance for Audited Media's "Spring 2015 Newspaper Geo/Circ Report." These data include ZIP code-level numbers for home delivery, single-copy sales, individually paid, total paid, gross total, and total average projected circulation for every edition of approximately 1,100 newspapers across North America. To spatially

locate ZIP code centroids, we rely on the USA ZIP Code Boundaries map maintained by the Environmental Systems Research Institute (ESRI). The ZIP code boundaries in our file are based on the situation in December 2014.

\section{D.1.8. School District Expenditure Data}

Information on school districts' expenditures and enrollment numbers come from the National Center of Education Statistics (NCES) Common Core of Data School Finance Survey for the 2009-10 school year. To spatially locate school district centroids, we rely on the Census Bureau's TIGER/Line shapefiles for school district boundaries as of 2009/10.

\section{D.2. Samples}

Our county-level data include all counties with information on how many political advertising spots aired during the 2004 and 2008 U.S. Presidential campaigns, Nielsen ratings for the respective DMAs, and county-level votes for the 2000, 2004, and 2008 U.S. Presidential elections. Our analysis of the sample of "border-pair counties" is further restricted to all counties that share a border with at least one other county that is assigned to a different demographic market area within the same state. In what follows, we give precise definitions for each sample.

All Counties is a data set that includes all counties with information on political advertising spots aired during the 2004 and 2008 U.S. Presidential campaigns, Nielsen ratings for the advertising spots aired in demographic market area of the county, and county-level votes for the 2000, 2004, and 2008 U.S. Presidential elections. The unit of observation in this data set is a county-year. The data encompass a total of 5,139 observations and 3,110 unique counties.

Border-Pair Counties is a data set that includes all county-year observations in the All Counties data set that share a border with another county that is assigned to a different demographic market area within the same state. The unit of observation is a county-year-pair. As explained in the main text, a county-year may appear in the data set more than once if it shares a border with more than one county in the same state but in a different DMA. There are a total of 6,790 observations in this data set, 3,240 unique year-counties, and 2,012 unique counties.

Border-Pair Differences is a data set of the differences between paired counties in the BorderPair Counties data set. The order of differencing is normalized such that the difference in total presidential impressions per capita is weakly positive. Paired counties with the same value of total 
presidential impressions per capita are differenced randomly. There are a total of 3,395 observations in this data set.

Our RD sample is based on the voter registration files of the lower forty-eight states and the District of Columbia. We restrict attention to voters who live in one of the 39 states for which we have sufficient information to infer party affiliation (or lack thereof), and for whom we can derive geocodes either based on their exact street address, zip code, or city (more than $98 \%$ of all records; see Table 8 for numbers split by the quality of "match"), and who live in a state with at least one within-state DMA border segment (c. $90 \%$ of records). The remaining observations - about $28 \%$ of the geocoded sample - are excluded because a voter either registered for the first time or updated her registration after the 2008 election. Given that our data are current as of the end of 2013/14 and that older lists are generally unavailable, we have no way of determining where these individuals lived in November of 2008. In total, our RD sample includes 106,463,198 observations.

Our analysis of newspaper circulation includes all newspaper-zip code observations for which the centroid of a particular ZIP code falls within $35 \mathrm{~km}$ of the nearest within-state DMA border and for which the respective newspaper has positive circulation in at least one zip code within $35 \mathrm{~km}$ of that DMA border.

Our analysis of school districts' expenditures includes all "elementary," "secondary," and "combined" schools districts whose centroids fall within $35 \mathrm{~km}$ of the nearest within-state DMA border and who report positive current expenditures on the NCES Common Core of Data School Finance Survey for the 2009-10 school year.

\section{D.3. Variable Definitions}

\section{D.3.1. Advertising Measures}

Presidential Impressions per Capita is the total amount of local broadcast advertisingmeasured as the total Nielsen-reported number of impressions among viewers above the age of 18 divided by the U.S. Census estimate of the market population age 18 and older-by candidates, parties, and interest groups related to the U.S. Presidential Democratic and Republican candidates within 60 days of the election.

Positive Presidential Imps. per Cap. is the amount of local broadcast advertising - measured in impressions per capita for the market population age 18 and older - by candidates, parties, and interest groups related to the U.S. Presidential Democratic and Republican candidates within 60 days of the election that promotes any candidate. The tone of the advertisement is determined by human coders of the University of Wisconsin Advertising Project.

Negative Presidential Imps. per Cap. is the amount of local broadcast advertising - measured in impressions per capita for the market population age 18 and older-by candidates, parties, 
and interest groups related to the U.S. Presidential Democratic and Republican candidates within 60 days of the election that attacks or contrasts candidates. The tone of the advertisement is determined by human coders of the University of Wisconsin Advertising Project.

Imps. per Cap. within 180 Days Before Election is the total amount of local broadcast advertising - measured in impressions per capita for the market population age 18 and older-by candidates, parties, and interest groups related to the U.S. Presidential Democratic and Republican candidates within 180 days of the election.

Imps. per Cap. within 120 Days Before Election is the total amount of local broadcast advertising - measured in impressions per capita for the market population age 18 and older - by candidates, parties, and interest groups related to the U.S. Presidential Democratic and Republican candidates within 120 days of the election.

Imps. per Cap. within 30 Days Before Election is the total amount of local broadcast advertising - measured in impressions per capita for the market population age 18 and older - by candidates, parties, and interest groups related to the U.S. Presidential Democratic and Republican candidates within 30 days of the election.

Partisan Difference in Imps. per Cap. is the difference in the total amount of local broadcast advertising - measured in impressions per capita for the market population age 18 and olderbetween Democratic and Republican candidates, parties, and interest groups related to the U.S. Presidential Democratic and Republican candidates within 60 days of the election. A positive number indicates relatively more Democratic advertising.

Presidential GRPs is the total amount of advertising - measured by the total impressions to viewers 18 years old and older multiplied by 100 and divided by the Market Size Universe Estimates provided by Nielsen for viewers 18 years old and older - by candidates, parties, and interest groups within 60 days of the election.

Number of Political Ads is the total amount of local broadcast advertising - measured as the total number of seconds of advertising divided by 30-by candidates, parties, and interest groups related to the U.S. Presidential Democratic and Republican candidates within 60 days of the election.

Number of Unique Ads is the total number of different / unique spots - as identified by the "creative" name according to CMAG - by candidates, parties, and interest groups related to the U.S. Presidential Democratic and Republican candidates that aired on the local broadcast stations in a particular market within 60 days of the election.

Impressions per Capita for Viewers Age 2 and Older is the total amount of advertisingmeasured in impressions per capita for the market population age 2 and older - by candidates, parties, and interest groups within 60 days of the election. 
Impressions per Capita using 15 Minute Window Rating is the total amount of advertisingmeasured in impressions per capita for the market population age 18 and older where impressions are based on average number of impressions for a spot in the advertisement's 15 minute window-by candidates, parties, and interest groups within 60 days of the election.

Impressions per Capita including National Broadcasts (2008 only) is the total amount of advertising - measured in impressions per capita for the market population age 18 and older including any national advertisements on one of the four major broadcast networks as listed in CMAG - by candidates, parties, and interest groups within 60 days of the election. When no viewership data are available within the same 30 minute window for a particular market, the number of viewers is imputed based on the viewership in other markets and the particular market's Universe Estimates.

Non-Presidential Political Advertising is the total amount of political advertising - measured in impressions per capita for the market population age 18 and older - by candidates, parties, and interest groups related to Congressional, Gubernatorial, and other non-U.S. Presidential elections within 60 days of the election.

Republican Non-Presidential Political Advertising is the total amount of political advertisingmeasured in impressions per capita for the market population age 18 and older - by candidates, parties, and interest groups related to Congressional, Gubernatorial, and Republican other non-U.S. Presidential elections within 60 days of the election.

Democratic Non-Presidential Political Advertising is the total amount of political advertisingmeasured in impressions per capita for the market population age 18 and older - by candidates, parties, and interest groups related to Congressional, Gubernatorial, and Democratic other non-U.S. Presidential elections within 60 days of the election.

Partisan Difference in Non-Presidential Political Advertising is defined as Democratic Non-Presidential Political Advertising minus Republican Non-Presidential Political Advertising (both measured in impressions per capita among voting-aged adults).

Candidate Visits are the total number of visits by Presidential and Vice-Presidential candidates of the two major parties aggregated to the DMA level.

Republican Candidate Visits are the total number of visits by Republican Presidential and Vice-Presidential candidates aggregated to the DMA level.

Democratic Candidate Visits are the total number of visits by Democratic Presidential and Vice-Presidential candidates aggregated to the DMA level.

Partisan Difference in Candidate Visits is defined as Democratic Candidate Visits minus Republican Candidate Visits. 


\section{D.3.2. Election Results}

Turnout (\%) is the total number of votes for all U.S. Presidential candidates divided by the population age 18 and older.

Lagged Turnout (\%) is the total number of votes for all U.S. Presidential candidates in the previous U.S. Presidential election divided by the population age 18 and older.

Democratic Two-Party Vote Share (\%) is the number of votes for the Democratic U.S. Presidential candidate divided by the total number of votes for the U.S. Presidential Democratic and Republican candidates.

Republican Two-Party Vote Share (\%) is the number of votes for the Republican U.S. Presidential candidate divided by the total number of votes for the U.S. Presidential Democratic and Republican candidates.

Partisan Difference in Two-Party Vote Share (\%) is the number of votes for the Democratic U.S. Presidential candidate minus the number of votes for the Republican U.S. Presidential candidate divided by the total number of votes for the U.S. Presidential Democratic and Republican candidates.

Democratic Vote Share (as Percentage of the Voting-Aged Population) is the number of votes for the Democratic U.S. Presidential candidate divided by the number of adults in the county 18 years old and older.

Republican Vote Share (as Percentage of the Voting-Aged Population) is the number of votes for the Republican U.S. Presidential candidate divided by the number of adults in the county 18 years old and older.

Partisan Difference in Vote Shares (as Percentage of the Voting-Aged Population) is the number of votes for the Democratic U.S. Presidential candidate minus the number of votes for the Republican U.S. Presidential candidate divided by the number of adults in the county 18 years old and older.

Battleground State is the list of states characterized as a "toss up" by RealClearPolitics.com approximately six to eight weeks prior to the election. The 2004 definition is based on the earliest polling data posted on the site on September 21, 2004. The 2008 definition is based on polling data from August 24, 2008.

Nonbattleground State is the list of states not characterized as a "toss up" by RealClearPolitics.com approximately six to eight weeks prior to the election. The 2004 definition is based on the earliest polling data posted on the site on September 21, 2004. The 2008 definition is based on polling data from August 24, 2008. 


\section{D.3.3. Demographic \& Economic Measures}

Percent White (\%) is the percentage of population that is characterized as White alone as measured by the U.S. Census Intercensal Estimates of the Resident Population by Sex, Race, and Hispanic Origin for Counties.

Percent Black (\%) is the percentage of population that is characterized as Black or African American alone as measured by the U.S. Census Intercensal Estimates of the Resident Population by Sex, Race, and Hispanic Origin for Counties.

Percent Hispanic (\%) is the percentage of population that is characterized as Hispanic alone as measured by the U.S. Census Intercensal Estimates of the Resident Population by Sex, Race, and Hispanic Origin for Counties.

Percent Asian (\%) is the percentage of population that is characterized as Asian alone as measured by the U.S. Census Intercensal Estimates of the Resident Population by Sex, Race, and Hispanic Origin for Counties.

Percent Other Race (\%) is the percentage of population that is characterized as American Indian, Native Hawaii, Other Pacific Islander, or two more races as measured by the U.S. Census Intercensal Estimates of the Resident Population by Sex, Race, and Hispanic Origin for Counties.

Percent Minority (\%) is the percentage of population that is not characterized as White alone as measured by the U.S. Census Intercensal Estimates of the Resident Population by Sex, Race, and Hispanic Origin for Counties.

Percent High School Dropouts (\%) is based on a linear interpolation of the percentage of the population with less than a high school education, as identified in the GeoLytics Estimates Premium data for 2000 and 2010. GeoLytics takes these numbers from the Decennial Censuses of Population and Housing.

Percent High School Educated (\%) is based on a linear interpolation of the percentage of the population with a high school education only, as identified in the GeoLytics Estimates Premium data for 2000 and 2010. GeoLytics takes these numbers from the Decennial Censuses of Population and Housing.

Percent College Educated (\%) is based on a linear interpolation of the percentage of the population with at least an associate's degree, as identified in the GeoLytics Estimates Premium data for 2000 and 2010. GeoLytics takes these numbers from the Decennial Censuses of Population and Housing.

Median Household Income (in $\$ \mathbf{1 , 0 0 0}$ ) is a measure of median household income in the county from the Small Area Income 8 Poverty Estimates (SAIPE) provided by the U.S. Census.

Percent in Poverty (\%) is measure of percentage of residents in poverty in the county based on the U.S. Census Small Area Income 83 Poverty Estimates (SAIPE). 
Employment to Population Ratio (\%) is the total number of employed individuals divided by the total population age 16 and older. Employment data are based on the average number of employed individuals during the election year based on the Bureau of Labor Statistic's Quarterly Census of Employment and Wages. The number of adults age 16 and older are constructed using two sources. The number of adults 20 years or older come from the U.S. Census Intercensal Estimates of the Resident Population by Five-Year Age Groups, Sex, Race, and Hispanic Origin for Counties, and based on an estimate of July 1 for each year. The number of 16-19 year olds in each year are based on a linear interpolation of the number of 16-19 year olds using the 2000 and 2010 Decennial Census of Population and Housing.

Distance to State Capital is defined as the straight-line distance from the respective county's centroid to the capital of the same state.To spatially locate ZIP code centroids, we rely on the Census Bureau's TIGER/Line shapefiles.

Distance to Nearest City $>$ 250,000 Population is defined as the straight-line distance from the respective county's centroid to the nearest city with more than 250,000 inhabitants. To spatially locate ZIP code centroids, we rely on the Census Bureau's TIGER/Line shapefiles. Population figures for cities come from the 2010 Decennial Census of Population and Housing.

Total Voting-Aged Population (in 1,000s) is a county-level measure of all adults age 18 and older. The number of adults 20 years or older come from the U.S. Census Intercensal Estimates of the Resident Population by Five-Year Age Groups, Sex, Race, and Hispanic Origin for Counties, and based on an estimate of July 1 for each year. The number of 18 and 19 year olds in each year are based on a linear interpolation of the number of 18 and 19 year olds using the 2000 and 2010 Decennial Census of Population and Housing.

Population Share of Media Market is defined as the population of a particular county divided by the population of all counties assigned to the same DMA as the county.

\section{D.3.4. Voter Registration Variables}

Turnout in 2008 is an indicator variable equal to one if an individual's turnout history indicates that she voted in the 2008 general election, and zero otherwise.

Distance to Nearest Media Market Border (in meters) is defined as the straight-line distance from an individual's official residence to the nearest point on any DMA border within the state of registration. As explained in the main text, we multiply this number by negative one for all voters who live in a media market where the partisan difference in presidential impressions per capita (as defined above) is smaller than in the neighboring one.

Party Affiliation is a set of indicator variables derived from the party field in states' voter registration lists in conjunction with individuals' turnout histories. We classify an individual voter as "registered Republican" or "registered Democrat" if the state lists her as such. We amend this classification by taking into account in which party's primaries, if any, a voter participated. Individuals 
who are not registered as partisans with the respective states and whose turnout history indicates that they have not participated in any of the major two parties' primaries are grouped in the residual category: "unaffiliated / independent." The same is true for individuals who participated in different parties' primaries.

Years Registered at Current Address is defined as the number of years, as of 2008, since a voter registered at the address in our data, based on the date of registration in states' files.

Age is defined as an individuals' age, as of 2008. This variable is missing for voters in states that do not supply information on date of birth in their voter registration files.

Female is an indicator variable equal to one if the individual is listed as female on the state's list, and zero if the record indicates a male. This variable is missing for voters in states that do not supply information on gender in their voter registration files.

\section{D.3.5. Newspaper and School District Variables}

Distance to Nearest Media Market Border (in meters) is defined as the straight-line distance from a ZIP code or school district's centroid to the nearest point on any DMA border within the same state. We multiply this number by negative one for all centroids who fall within in a media market where the partisan difference in presidential advertising (as defined above) is smaller than in the neighboring DMA.

Newspaper Circulation is defined as a newspapers' maximal average circulation (over all of its editions) in a particular ZIP code divided by the respective number of households, both as reported by the Alliance for Audited Media.

Log Expenditures per Student is defined as the natural logarithm of the ratio between a school district's current expenditures and its number of students. 
Figure 1: Counties and Media Markets in the State of Illinois

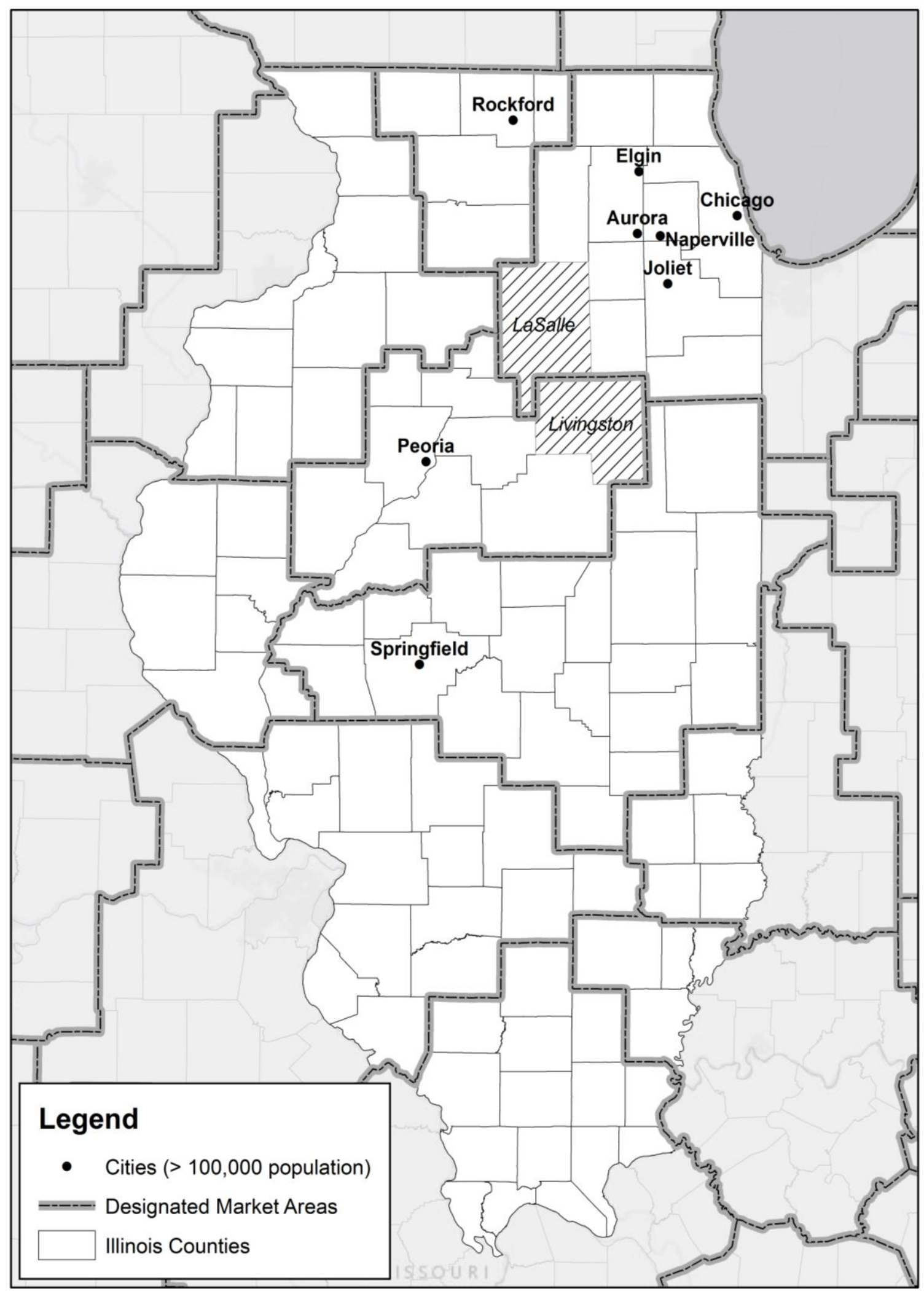

Notes: Figure displays counties, media markets, and cities with a population of more than 100,000 in the state of Illinois. 
Figure 2: Average Partisan Difference in Political Advertising in the RD Setup, 2008 Presidential Election

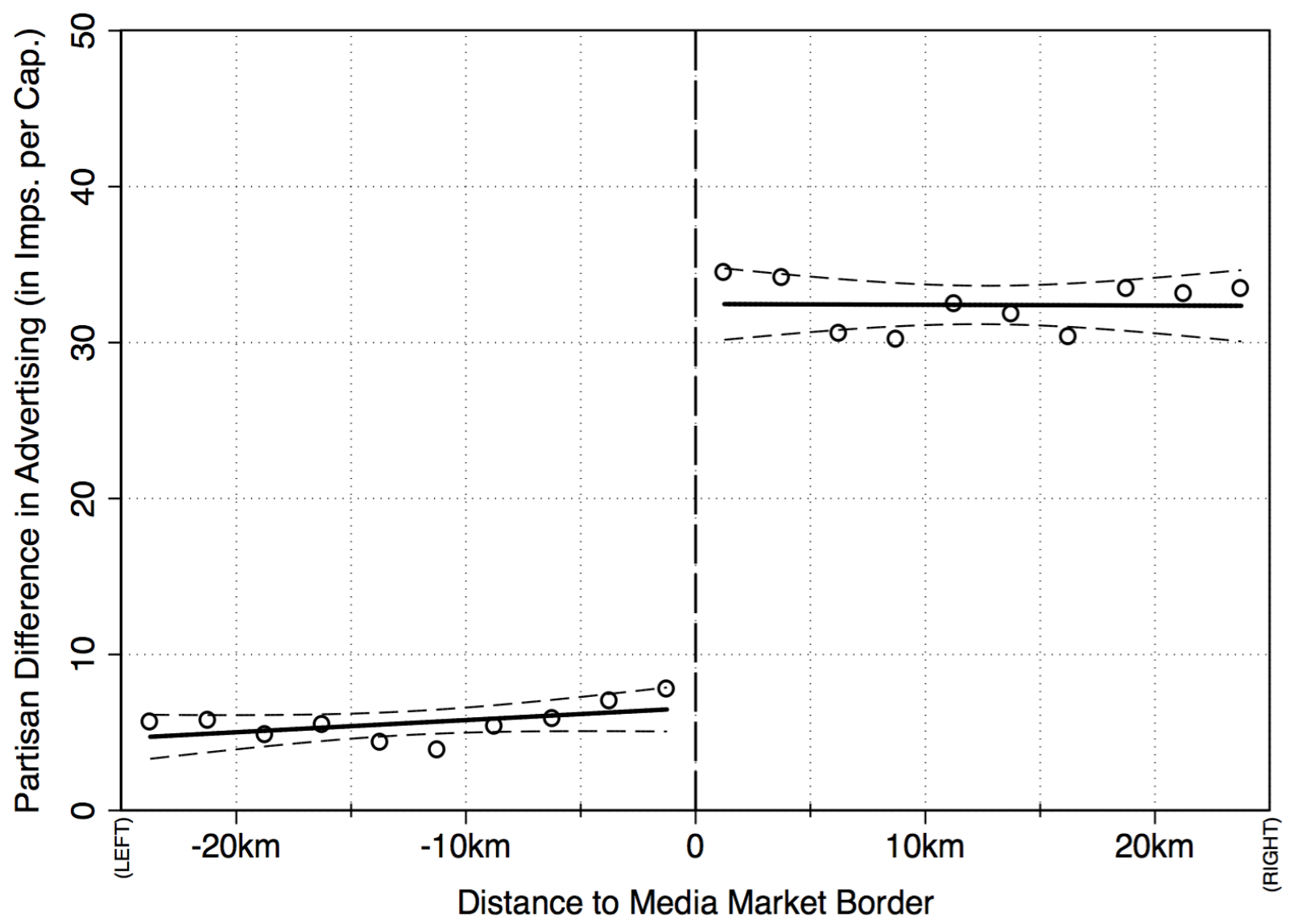

Notes: Figure plots the mean partisan difference in advertising during the 2008 presidential election within $2.5 \mathrm{~km}$ wide bins around media market borders. Larger values indicate more advertising in support of the Democratic candidate than for his Republican competitor. The sample consists of all registered Democrats and Republicans for whom our voter-registration data contain a valid address as of the 2008 election. As explained in the main text, we use voters' residential addresses to calculate distance to the nearest within-state media market border, with negative values assigned to individuals who live in a media market in which the partisan differential in presidential advertising is lower than in the neighboring one. For precise definitions and the sources of all variables, see the Data Appendix.

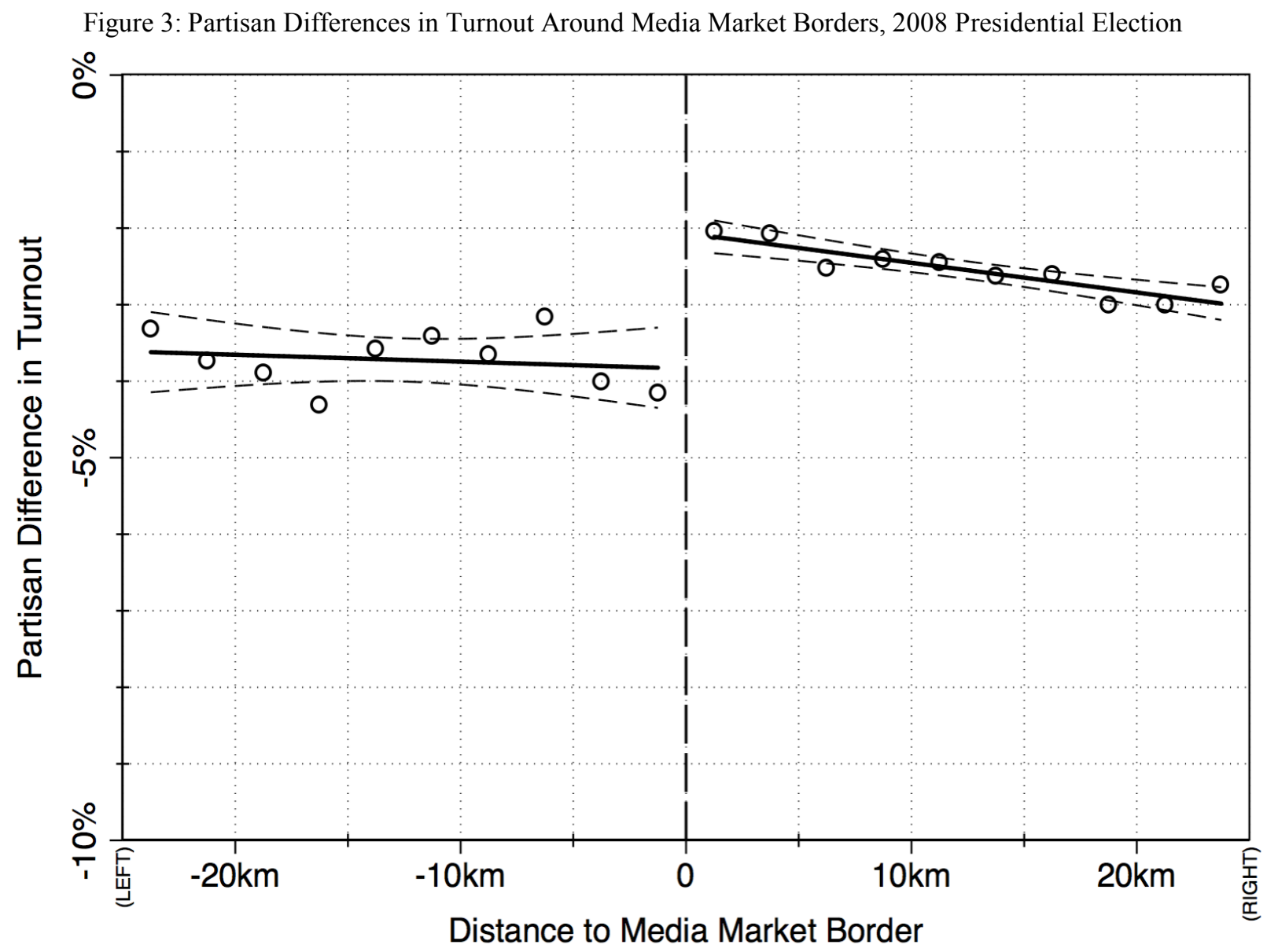

Notes: Figure plots the mean partisan difference in turnout during the 2008 presidential election within $2.5 \mathrm{~km}$-wide bins around media market borders. Larger values indicate higher turnout among registered Democrats relative to their Republican counterparts. The sample consists of registered Democrats and Republicans for whom our voterregistration data contain a valid address as of the 2008 election. As explained in the main text, we use voters' residential addresses to calculate distance to the nearest within-state media market border, with negative values assigned to individuals who live in a media market in which the partisan differential in presidential advertising is lower than in the neighboring one. For precise definitions and the sources of all variables, see the Data Appendix. 
Figure 4: Assessing the Importance of Compositional Changes of the Electorate

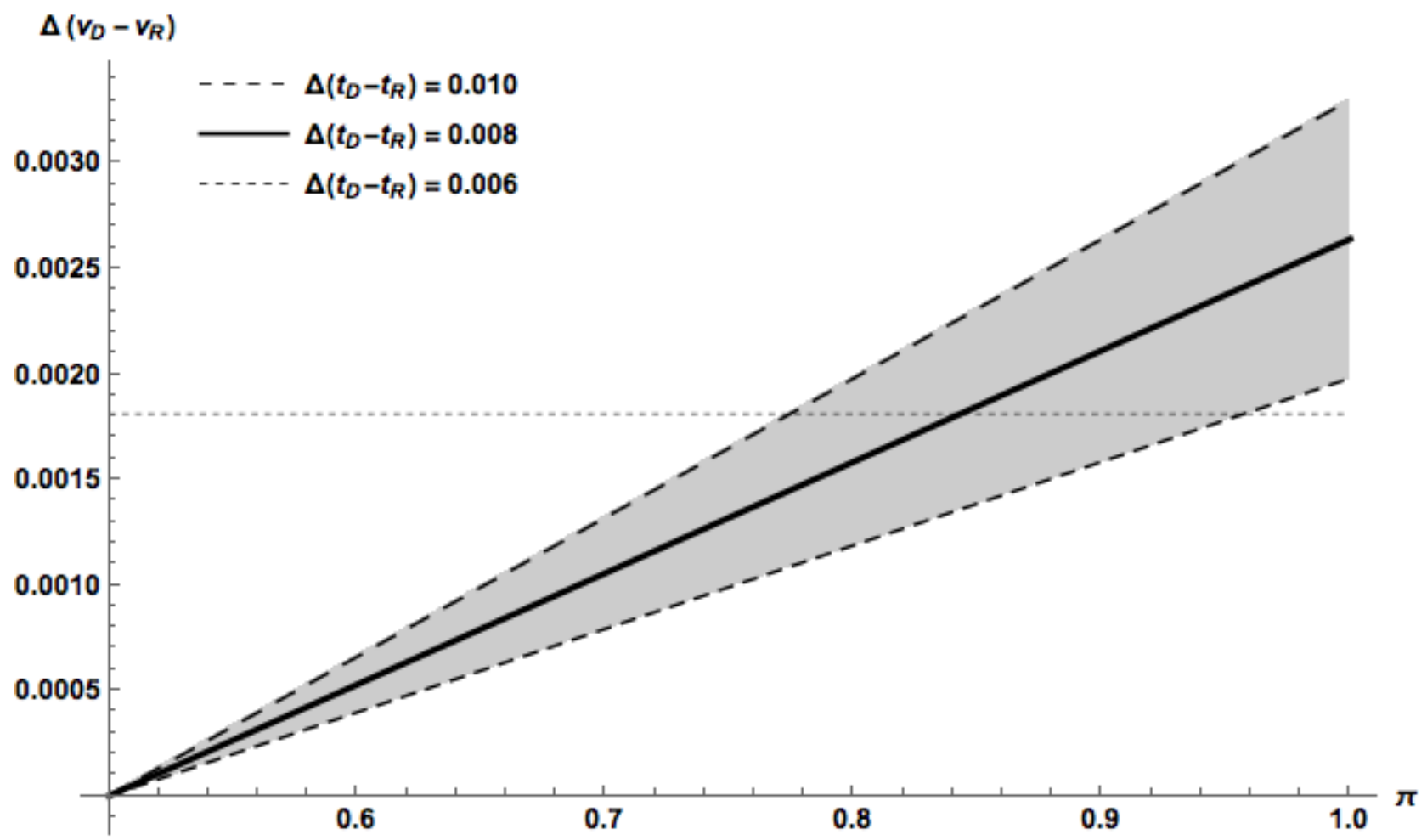

Notes: Figure plots $\Delta\left(\mathrm{v}_{\mathrm{D}}-\mathrm{v}_{\mathrm{R}}\right)$, as defined in equation (7), as a function of $\pi$ and for a range of plausible values of $\Delta\left(\mathrm{t}_{\mathrm{D}}\right.$ $\left.t_{R}\right)$. Substantively, $\Delta\left(v_{D}-v_{R}\right)$ measures the change in the partisan difference in vote shares due to changes in the partisan composition of the electorate alone. The horizontal line indicates the effect size implied by the coefficient in column (9) of Table 7. See the main text for details. 
Table 1: Descriptive Statistics, Pooling across $2004 \& 2008$

\begin{tabular}{|c|c|c|c|c|c|c|c|c|}
\hline & \multicolumn{4}{|c|}{ All Counties } & \multicolumn{4}{|c|}{ Border-Pair Counties } \\
\hline & Mean & SD & Min & Max & Mean & SD & Min & Max \\
\hline \multicolumn{9}{|l|}{ Media Market Measures: } \\
\hline Presidential Impressions per Capita (in 10s) & 7.46 & 9.87 & 0.00 & 33.85 & 7.78 & 10.01 & 0.00 & 33.85 \\
\hline Partisan Difference in Imps. per Cap. (in 10s) & 1.16 & 2.24 & -5.55 & 9.35 & 1.21 & 2.27 & -5.55 & 9.35 \\
\hline Number of Political Ads (in 1,000s) & 6.15 & 8.39 & 0.00 & 34.67 & 6.32 & 8.36 & 0.00 & 34.67 \\
\hline Non-Presidential Political Imps. per Cap. (in 10s) & 15.28 & 13.83 & 0.00 & 60.26 & 15.15 & 13.81 & 0.00 & 60.26 \\
\hline Candidate Visits & 2.21 & 3.40 & 0.00 & 18.00 & 2.21 & 3.37 & 0.00 & 18.00 \\
\hline \multicolumn{9}{|l|}{ County-Level Variables: } \\
\hline Turnout $(\%)$ & 58.47 & 9.27 & 19.20 & 100.00 & 57.86 & 9.25 & 24.93 & 100.00 \\
\hline Lagged Turnout (\%) & 56.32 & 9.71 & 15.16 & 100.00 & 55.82 & 9.54 & 26.29 & 100.00 \\
\hline Democratic Two-Party Vote Share (\%) & 41.49 & 13.45 & 5.03 & 93.40 & 41.05 & 12.45 & 5.03 & 89.54 \\
\hline Republican Two-Party Vote Share (\%) & 58.51 & 13.45 & 6.60 & 94.97 & 58.95 & 12.45 & 10.46 & 94.97 \\
\hline Percent White (\%) & 79.86 & 19.03 & 2.78 & 99.12 & 80.37 & 18.73 & 2.92 & 99.12 \\
\hline Percent Minority (\%) & 20.14 & 19.03 & 0.88 & 97.22 & 19.63 & 18.73 & 0.88 & 97.08 \\
\hline Percent High School Dropouts (\%) & 22.76 & 8.73 & 3.24 & 65.46 & 23.94 & 8.86 & 3.24 & 65.46 \\
\hline Percent High School Educated (\%) & 54.75 & 6.65 & 23.55 & 74.30 & 55.17 & 6.46 & 25.82 & 74.30 \\
\hline Percent College Educated (\%) & 22.48 & 8.99 & 6.45 & 67.63 & 20.89 & 8.20 & 6.45 & 62.24 \\
\hline Median Household Income (in $\$ 1,000$ ) & 42.36 & 11.22 & 18.38 & 111.58 & 40.71 & 10.23 & 18.38 & 102.25 \\
\hline Percent in Poverty $(\%)$ & 13.72 & 5.51 & 2.25 & 49.38 & 14.35 & 5.55 & 3.05 & 49.38 \\
\hline Employment to Population Ratio (\%) & 44.65 & 18.21 & 9.06 & 383.44 & 42.38 & 16.58 & 12.55 & 383.44 \\
\hline Distance to State Capital (in 100km) & 1.90 & 1.27 & 0.00 & 8.27 & 1.87 & 1.18 & 0.02 & 8.27 \\
\hline Distance to Nearest City $>250,000$ Population (in $100 \mathrm{~km}$ ) & 5.68 & 3.44 & 0.00 & 43.30 & 5.49 & 3.20 & 0.09 & 16.60 \\
\hline Total Voting-Aged Population (in 1,000s) & 82 & 251 & 0 & 7,285 & 57 & 169 & 0 & 2,828 \\
\hline Number of Unique Counties & \multicolumn{4}{|c|}{3,110} & \multicolumn{4}{|c|}{2,012} \\
\hline Number of County-Year Observations & \multicolumn{4}{|c|}{5,139} & \multicolumn{4}{|c|}{3,240} \\
\hline
\end{tabular}

Notes: Entries are descriptive statistics for the most important variables in our county-level data set. For precise definitions and the sources of all variables, see the Data Appendix. 
Table 2: Political Advertising and Border-County Characteristics

\begin{tabular}{|c|c|c|c|c|c|c|c|c|c|c|}
\hline \multirow{3}{*}{$\begin{array}{l}\text { Independent Variables } \\
\text { (in Standard Deviation Units) } \\
\Delta \text { Total Voting-Aged Population }\end{array}$} & \multicolumn{8}{|c|}{$\Delta$ Presidential Advertising (in Standard Deviation Units) } & \multirow{2}{*}{\multicolumn{2}{|c|}{$\begin{array}{c}\Delta \text { Total Non-Presidential } \\
\text { Political Advertising }\end{array}$}} \\
\hline & \multicolumn{2}{|c|}{$\begin{array}{c}\text { Both } \\
\text { Candidates }\end{array}$} & \multicolumn{2}{|c|}{$\begin{array}{c}\text { Democratic } \\
\text { Candidate }\end{array}$} & \multicolumn{2}{|c|}{$\begin{array}{c}\text { Republican } \\
\text { Candidate }\end{array}$} & \multicolumn{2}{|c|}{$\begin{array}{c}\text { Partisan } \\
\text { Difference } \\
\end{array}$} & & \\
\hline & $\begin{array}{l}-0.014 \\
(0.026)\end{array}$ & $\begin{array}{l}-0.014 \\
(0.027)\end{array}$ & $\begin{array}{c}0.000 \\
(0.031)\end{array}$ & $\begin{array}{l}-0.001 \\
(0.032)\end{array}$ & $\begin{array}{l}-0.030 \\
(0.022)\end{array}$ & $\begin{array}{l}-0.029 \\
(0.022)\end{array}$ & $\begin{array}{c}0.037 \\
(0.037)\end{array}$ & $\begin{array}{c}0.035 \\
(0.040)\end{array}$ & $\begin{array}{c}0.018 \\
(0.022)\end{array}$ & $\begin{array}{c}0.019 \\
(0.019)\end{array}$ \\
\hline$\Delta$ Percent Black & $\begin{array}{c}0.011 \\
(0.032)\end{array}$ & $\begin{array}{c}0.024 \\
(0.035)\end{array}$ & $\begin{array}{c}0.017 \\
(0.030)\end{array}$ & $\begin{array}{c}0.027 \\
(0.034)\end{array}$ & $\begin{array}{c}0.002 \\
(0.031)\end{array}$ & $\begin{array}{c}0.017 \\
(0.034)\end{array}$ & $\begin{array}{c}0.024 \\
(0.022)\end{array}$ & $\begin{array}{c}0.022 \\
(0.025)\end{array}$ & $\begin{array}{l}-0.022 \\
(0.029)\end{array}$ & $\begin{array}{l}-0.001 \\
(0.034)\end{array}$ \\
\hline$\Delta$ Percent Hispanic & $\begin{array}{c}0.037 \\
(0.028)\end{array}$ & $\begin{array}{c}0.037 \\
(0.027)\end{array}$ & $\begin{array}{c}0.042 \\
(0.027)\end{array}$ & $\begin{array}{c}0.042 \\
(0.027)\end{array}$ & $\begin{array}{c}0.027 \\
(0.029)\end{array}$ & $\begin{array}{c}0.027 \\
(0.028)\end{array}$ & $\begin{array}{c}0.033 \\
(0.024)\end{array}$ & $\begin{array}{c}0.033 \\
(0.025)\end{array}$ & $\begin{array}{l}-0.002 \\
(0.030)\end{array}$ & $\begin{array}{l}-0.002 \\
(0.031)\end{array}$ \\
\hline$\Delta$ Percent Asian & $\begin{array}{c}0.013 \\
(0.020)\end{array}$ & $\begin{array}{c}0.011 \\
(0.021)\end{array}$ & $\begin{array}{c}0.000 \\
(0.022)\end{array}$ & $\begin{array}{l}-0.004 \\
(0.024)\end{array}$ & $\begin{array}{c}0.029 \\
(0.019)\end{array}$ & $\begin{array}{c}0.029 \\
(0.020)\end{array}$ & $\begin{array}{l}-0.037 \\
(0.028)\end{array}$ & $\begin{array}{l}-0.042 \\
(0.029)\end{array}$ & $\begin{array}{l}-0.023 \\
(0.019)\end{array}$ & $\begin{array}{c}-0.026 \\
(0.021)\end{array}$ \\
\hline$\Delta$ Percent Other Race & $\begin{array}{c}-0.044 \\
(0.037)\end{array}$ & $\begin{array}{l}-0.034 \\
(0.037)\end{array}$ & $\begin{array}{c}-0.052 \\
(0.037)\end{array}$ & $\begin{array}{c}-0.044 \\
(0.036)\end{array}$ & $\begin{array}{l}-0.029 \\
(0.035)\end{array}$ & $\begin{array}{c}-0.017 \\
(0.037)\end{array}$ & $\begin{array}{l}-0.047 \\
(0.032)\end{array}$ & $\begin{array}{l}-0.049 * \\
(0.027)\end{array}$ & $\begin{array}{l}-0.019 \\
(0.032)\end{array}$ & $\begin{array}{l}-0.005 \\
(0.033)\end{array}$ \\
\hline$\Delta$ Percent High School Dropouts & $\begin{array}{c}-0.001 \\
(0.049)\end{array}$ & $\begin{array}{c}0.014 \\
(0.052)\end{array}$ & $\begin{array}{c}0.009 \\
(0.047)\end{array}$ & $\begin{array}{c}0.020 \\
(0.050)\end{array}$ & $\begin{array}{l}-0.015 \\
(0.051)\end{array}$ & $\begin{array}{c}0.005 \\
(0.053)\end{array}$ & $\begin{array}{c}0.033 \\
(0.041)\end{array}$ & $\begin{array}{c}0.026 \\
(0.044)\end{array}$ & $\begin{array}{c}0.034 \\
(0.040)\end{array}$ & $\begin{array}{c}0.069 * * \\
(0.033)\end{array}$ \\
\hline$\Delta$ Median Household Income & & $\begin{array}{l}-0.008 \\
(0.045)\end{array}$ & & $\begin{array}{c}-0.002 \\
(0.045)\end{array}$ & & $\begin{array}{c}-0.014 \\
(0.048)\end{array}$ & & $\begin{array}{c}0.015 \\
(0.049)\end{array}$ & & $\begin{array}{c}0.013 \\
(0.028)\end{array}$ \\
\hline$\Delta$ Percent in Poverty & & $\begin{array}{l}-0.037 \\
(0.057)\end{array}$ & & $\begin{array}{c}-0.024 \\
(0.055)\end{array}$ & & $\begin{array}{l}-0.050 \\
(0.058)\end{array}$ & & $\begin{array}{c}0.025 \\
(0.046)\end{array}$ & & $\begin{array}{l}-0.061 \\
(0.038)\end{array}$ \\
\hline$\Delta$ Employment to Population Ratio & & $\begin{array}{l}-0.033 \\
(0.041)\end{array}$ & & $\begin{array}{l}-0.033 \\
(0.043)\end{array}$ & & $\begin{array}{l}-0.029 \\
(0.037)\end{array}$ & & $\begin{array}{l}-0.017 \\
(0.040)\end{array}$ & & $\begin{array}{l}-0.020 \\
(0.022)\end{array}$ \\
\hline$\Delta$ Distance to State Capital & & $\begin{array}{l}-0.005 \\
(0.033)\end{array}$ & & $\begin{array}{c}-0.012 \\
(0.033)\end{array}$ & & $\begin{array}{c}0.005 \\
(0.037)\end{array}$ & & $\begin{array}{l}-0.025 \\
(0.044)\end{array}$ & & $\begin{array}{c}-0.034 \\
(0.040)\end{array}$ \\
\hline$\Delta$ Distance to Nearest Major City & & $\begin{array}{l}-0.025 \\
(0.035)\end{array}$ & & $\begin{array}{l}-0.031 \\
(0.035)\end{array}$ & & $\begin{array}{l}-0.015 \\
(0.035)\end{array}$ & & $\begin{array}{c}-0.031 \\
(0.036)\end{array}$ & & $\begin{array}{c}0.016 \\
(0.041)\end{array}$ \\
\hline $\mathrm{H}_{0}$ : All Coefficients $=0$ & & & & & & & & & & \\
\hline F-Statistic & 0.378 & 0.380 & 0.477 & 0.321 & 0.527 & 0.861 & 1.078 & 1.318 & 0.359 & 1.484 \\
\hline$p$-value & 0.910 & 0.964 & 0.846 & 0.982 & 0.809 & 0.590 & 0.393 & 0.242 & 0.921 & 0.166 \\
\hline R-Squared & 0.002 & 0.004 & 0.002 & 0.004 & 0.002 & 0.004 & 0.004 & 0.007 & 0.001 & 0.006 \\
\hline
\end{tabular}

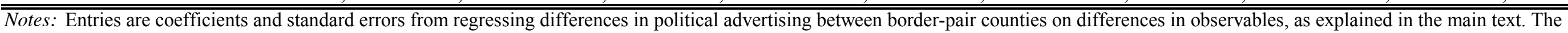

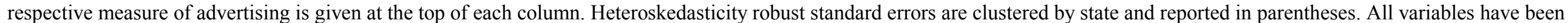

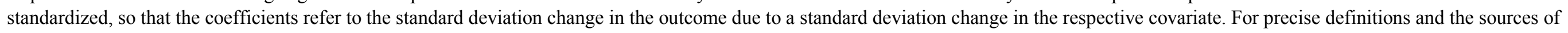
all variables, see the Data Appendix. ***, **, and * denote statistical significance at the $1 \%-, 5 \%$-, and 10\%-levels, respectively. 
Table 3: Estimating the Impact of Political Advertising on Voter Turnout, 2004 \& 2008 Presidential Elections

A. All Presidential Advertising

Percent Voter Turnout

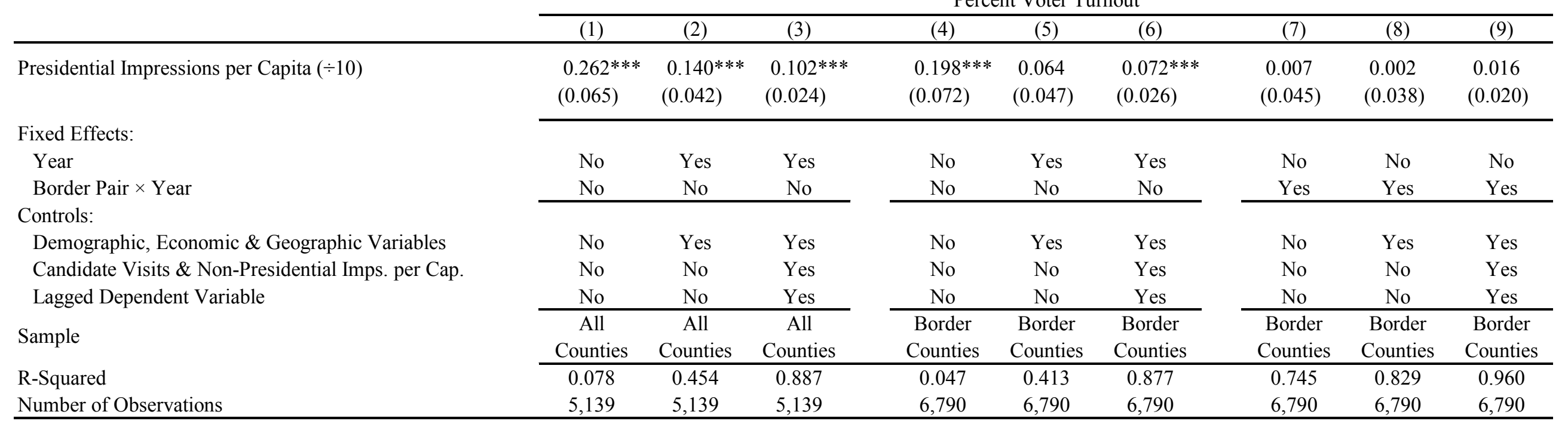

B. Positive vs. Negative Presidential Advertising

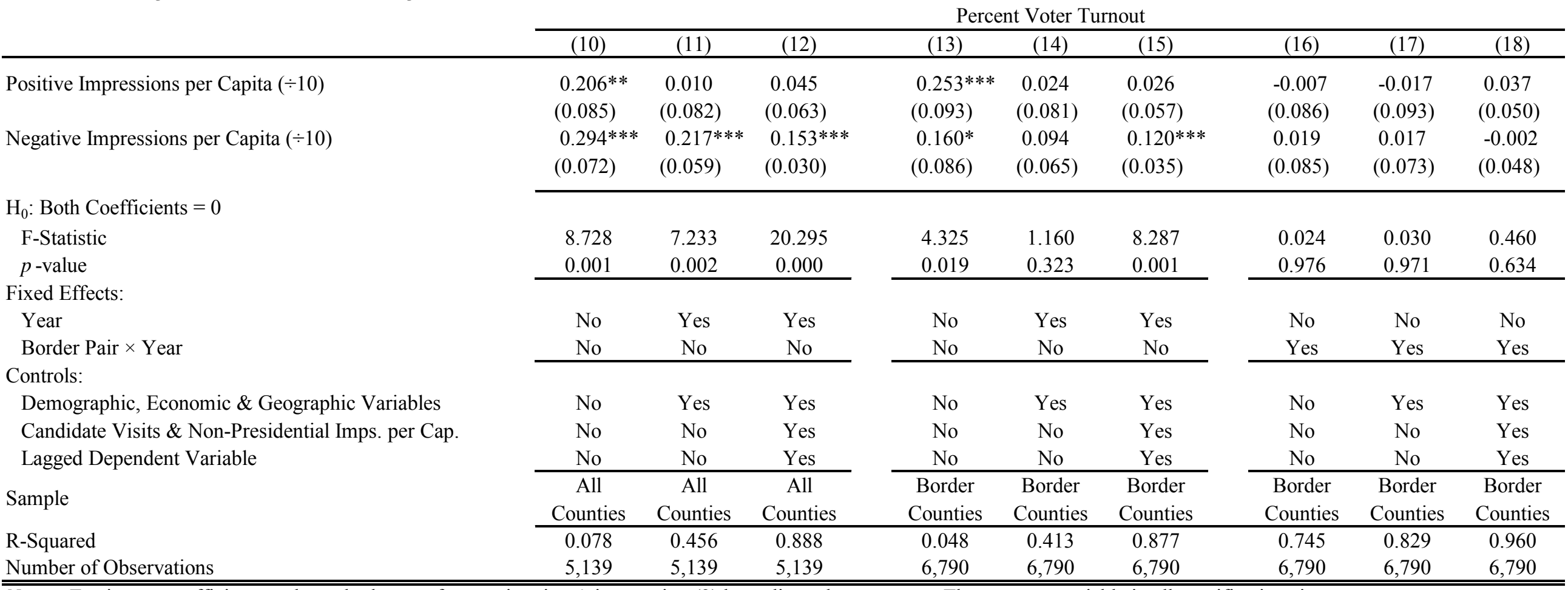

Notes: Entries are coefficients and standard errors from estimating $\phi$ in equation (2) by ordinary least squares. The outcome variable in all specifications is voter turnout as percentage of counties' voting-aged population. The upper panel estimates the impact of all presidential advertising, while the lower panel distinguishes between positive and negative ads.

Estimates in the first three columns within each panel are based on the sample of all U.S. counties with available advertising measures for the 2004 and 2008 presidential elections.

Estimates in the remaining six columns rely on our sample of stacked border-pair counties instead, as explained in the main text. The set of included controls and fixed effects varies across columns. Heteroskedasticity robust standard errors are clustered by state and reported in parentheses. ***, **, and * denote statistical significance at the $1 \%$-, $5 \%$-, and $10 \%$ levels, respectively. 
Table 4: Sensitivity Analysis for the Impact of Political Advertising on Aggregate Turnout

\begin{tabular}{|c|c|c|c|c|c|c|}
\hline & \multicolumn{2}{|c|}{ Pooled } & \multicolumn{2}{|c|}{2004 Election } & \multicolumn{2}{|c|}{2008 Election } \\
\hline & Coefficient & $p$-value & Coefficient & $p$-value & Coefficient & $p$-value \\
\hline Baseline & $\begin{array}{c}0.016 \\
(0.020)\end{array}$ & 0.434 & $\begin{array}{c}0.002 \\
(0.034)\end{array}$ & 0.949 & $\begin{array}{c}0.022 \\
(0.021)\end{array}$ & 0.300 \\
\hline Downweighting Stacked Observations & $\begin{array}{c}0.018 \\
(0.013)\end{array}$ & 0.177 & $\begin{array}{c}0.007 \\
(0.023)\end{array}$ & 0.764 & $\begin{array}{c}0.021 \\
(0.015)\end{array}$ & 0.163 \\
\hline \multicolumn{7}{|l|}{ By Population Share of Media Market: } \\
\hline$<15 \%$ & $\begin{array}{c}0.015 \\
(0.020)\end{array}$ & 0.459 & $\begin{array}{c}0.000 \\
(0.034)\end{array}$ & 0.999 & $\begin{array}{c}0.022 \\
(0.020)\end{array}$ & 0.294 \\
\hline$<10 \%$ & $\begin{array}{c}0.015 \\
(0.020)\end{array}$ & 0.466 & $\begin{array}{c}0.001 \\
(0.035)\end{array}$ & 0.975 & $\begin{array}{c}0.021 \\
(0.021)\end{array}$ & 0.317 \\
\hline$<5 \%$ & $\begin{array}{c}0.019 \\
(0.021)\end{array}$ & 0.376 & $\begin{array}{c}0.005 \\
(0.037)\end{array}$ & 0.898 & $\begin{array}{c}0.026 \\
(0.020)\end{array}$ & 0.205 \\
\hline$<2 \%$ & $\begin{array}{c}0.021 \\
(0.027)\end{array}$ & 0.449 & $\begin{array}{c}0.008 \\
(0.039)\end{array}$ & 0.849 & $\begin{array}{c}0.028 \\
(0.027)\end{array}$ & 0.310 \\
\hline \multicolumn{7}{|l|}{ Alternative Advertising Measures: } \\
\hline Total Number of Ads (in 1,000s) & $\begin{array}{c}0.008 \\
(0.021)\end{array}$ & 0.700 & $\begin{array}{c}0.013 \\
(0.053)\end{array}$ & 0.810 & $\begin{array}{c}0.008 \\
(0.023)\end{array}$ & 0.735 \\
\hline Number of Unique Ads & $\begin{array}{c}0.002 \\
(0.004)\end{array}$ & 0.533 & $\begin{array}{c}0.000 \\
(0.008)\end{array}$ & 0.995 & $\begin{array}{c}0.003 \\
(0.004)\end{array}$ & 0.498 \\
\hline Gross Rating Points $(\div 1,000)$ & $\begin{array}{c}0.015 \\
(0.019)\end{array}$ & 0.414 & $\begin{array}{c}0.002 \\
(0.033)\end{array}$ & 0.942 & $\begin{array}{c}0.021 \\
(0.019)\end{array}$ & 0.267 \\
\hline Imps. per Cap. within 180 Days Before Election $(\div 10)$ & $\begin{array}{c}0.008 \\
(0.013)\end{array}$ & 0.525 & $\begin{array}{c}0.002 \\
(0.027)\end{array}$ & 0.929 & $\begin{array}{c}0.010 \\
(0.014)\end{array}$ & 0.477 \\
\hline Imps. per Cap. within 120 Days Before Election $(\div 10)$ & $\begin{array}{c}0.009 \\
(0.013)\end{array}$ & 0.521 & $\begin{array}{c}0.002 \\
(0.027)\end{array}$ & 0.943 & $\begin{array}{c}0.010 \\
(0.014)\end{array}$ & 0.465 \\
\hline Imps. per Cap. within 30 Days Before Election $(\div 10)$ & $\begin{array}{c}0.018 \\
(0.029)\end{array}$ & 0.546 & $\begin{array}{c}0.005 \\
(0.050)\end{array}$ & 0.922 & $\begin{array}{c}0.024 \\
(0.031)\end{array}$ & 0.448 \\
\hline Imps. per Cap. for Viewers Age 2 and Older $(\div 10)$ & $\begin{array}{c}0.020 \\
(0.025)\end{array}$ & 0.429 & $\begin{array}{c}0.003 \\
(0.042)\end{array}$ & 0.944 & $\begin{array}{c}0.028 \\
(0.026)\end{array}$ & 0.297 \\
\hline Imps. per Cap. using 15 min Window Ratings $(\div 10)$ & $\begin{array}{c}0.016 \\
(0.020)\end{array}$ & 0.439 & $\begin{array}{c}0.002 \\
(0.034)\end{array}$ & 0.958 & $\begin{array}{c}0.022 \\
(0.021)\end{array}$ & 0.301 \\
\hline Imps. per Cap. incl. Nat'l Broadcasts $(\div 10,2008$ only) & -- & -- & $\begin{array}{l}-- \\
--\end{array}$ & -- & $\begin{array}{c}0.024 \\
(0.021)\end{array}$ & 0.249 \\
\hline \multicolumn{7}{|l|}{ By Battleground Status: } \\
\hline Battleground State & $\begin{array}{c}0.018 \\
(0.034)\end{array}$ & 0.604 & $\begin{array}{c}-0.004 \\
(0.019)\end{array}$ & 0.854 & $\begin{array}{c}0.060 \\
(0.032)\end{array}$ & 0.099 \\
\hline Nonbattleground State & $\begin{array}{c}0.015 \\
(0.024)\end{array}$ & 0.519 & $\begin{array}{c}0.032 \\
(0.037)\end{array}$ & 0.393 & $\begin{array}{c}0.014 \\
(0.026)\end{array}$ & 0.587 \\
\hline
\end{tabular}

Notes: Entries are coefficients and standard errors on $\phi$ in equation (2), estimated on various subsamples of the data. The outcome variable in each specification is voter turnout as percentage of counties' voting-aged population, while total presidential advertising is the independent variable of interest. All estimates are based on our sample of stacked border-pair counties, controlling for year-specific border-pair fixed effects and the full set of controls, as in column (9) of Table 3. Heteroskedasticity robust standard errors are clustered by state and reported in parentheses. $p$-values for the null hypothesis of no effect of presidential advertising on turnout are reported next to each coefficient. As noted in the main text, when we downweigh stacked observations, we weigh each county-year observation by the inverse of the number of times that it appears in our sample of stacked border-county pairs. For precise definitions and the sources of all variables, see the Data Appendix. 
Table 5: Estimating the Impact of Political Advertising on Two-Party Vote Shares, 2004 \& 2008 Presidential Elections

\begin{tabular}{|c|c|c|c|c|c|c|c|c|c|}
\hline & \multicolumn{9}{|c|}{ Partisan Difference in Presidential Two-Party Vote Shares } \\
\hline & $(1)$ & $(2)$ & $(3)$ & $(4)$ & $(5)$ & $(6)$ & $(7)$ & $(8)$ & $(9)$ \\
\hline Difference Between Democratic and & $2.424 * * *$ & $2.443 * * *$ & $1.039 * * *$ & $1.673 * *$ & $1.900 * * *$ & $1.076 * * *$ & $0.744^{*}$ & $0.597 * *$ & $0.309 * * *$ \\
\hline Republican Imps. per Cap. $(\div 10)$ & $(0.642)$ & $(0.578)$ & $(0.272)$ & $(0.651)$ & $(0.639)$ & $(0.296)$ & $(0.405)$ & $(0.259)$ & $(0.089)$ \\
\hline \multicolumn{10}{|l|}{ Fixed Effects: } \\
\hline Year & No & Yes & Yes & No & Yes & Yes & No & No & No \\
\hline Border Pair $\times$ Year & No & No & No & No & No & No & Yes & Yes & Yes \\
\hline \multicolumn{10}{|l|}{ Controls: } \\
\hline Demographic, Economic \& Geographic Variables & No & Yes & Yes & No & Yes & Yes & No & Yes & Yes \\
\hline Candidate Visits \& Non-Presidential Imps. per Cap. & No & No & Yes & No & No & Yes & No & No & Yes \\
\hline Lagged Dependent Variable & No & No & Yes & No & No & Yes & No & No & Yes \\
\hline \multirow{2}{*}{ Sample } & All & All & All & Border & Border & Border & Border & Border & Border \\
\hline & Counties & Counties & Counties & Counties & Counties & Counties & Counties & Counties & Counties \\
\hline R-Squared & 0.041 & 0.401 & 0.919 & 0.024 & 0.344 & 0.900 & 0.793 & 0.897 & 0.986 \\
\hline Number of Observations & 5,139 & 5,139 & 5,139 & 6,790 & 6,790 & 6,790 & 6,790 & 6,790 & 6,790 \\
\hline
\end{tabular}

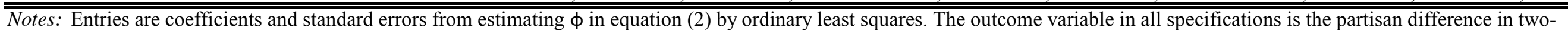

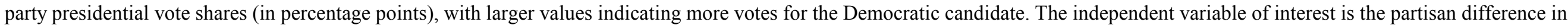

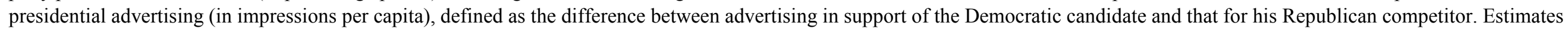

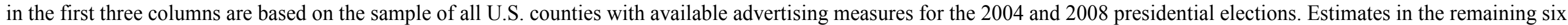

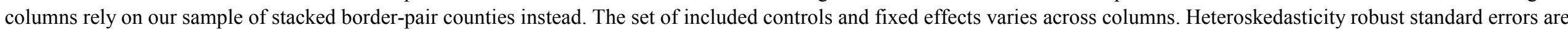
clustered by state and reported in parentheses. ***, **, and * denote statistical significance at the 1\%-, 5\%-, and 10\%-levels, respectively. 
Table 6: Sensitivity Analysis for the Effect of Partisan Differences in Political Advertising on Partisan Differences in Two-Party Vote Shares

\begin{tabular}{|c|c|c|c|c|c|c|}
\hline & \multicolumn{2}{|c|}{ Pooled } & \multicolumn{2}{|c|}{2004 Election } & \multicolumn{2}{|c|}{2008 Election } \\
\hline & Coefficient & $p$-value & Coefficient & $p$-value & Coefficient & $p$-value \\
\hline Baseline & $\begin{array}{c}0.309 \\
(0.089)\end{array}$ & 0.001 & $\begin{array}{c}0.096 \\
(0.148)\end{array}$ & 0.518 & $\begin{array}{c}0.333 \\
(0.106)\end{array}$ & 0.003 \\
\hline Downweighting Stacked Observations & $\begin{array}{c}0.294 \\
(0.065)\end{array}$ & 0.000 & $\begin{array}{c}0.157 \\
(0.117)\end{array}$ & 0.188 & $\begin{array}{c}0.301 \\
(0.080)\end{array}$ & 0.000 \\
\hline \multicolumn{7}{|l|}{ By Population Share of Media Market: } \\
\hline$<15 \%$ & $\begin{array}{c}0.314 \\
(0.089)\end{array}$ & 0.001 & $\begin{array}{c}0.098 \\
(0.144)\end{array}$ & 0.500 & $\begin{array}{c}0.335 \\
(0.108)\end{array}$ & 0.003 \\
\hline$<10 \%$ & $\begin{array}{c}0.327 \\
(0.090)\end{array}$ & 0.001 & $\begin{array}{c}0.134 \\
(0.139)\end{array}$ & 0.340 & $\begin{array}{c}0.340 \\
(0.109)\end{array}$ & 0.003 \\
\hline$<5 \%$ & $\begin{array}{c}0.350 \\
(0.102)\end{array}$ & 0.001 & $\begin{array}{c}0.138 \\
(0.143)\end{array}$ & 0.340 & $\begin{array}{c}0.378 \\
(0.124)\end{array}$ & 0.004 \\
\hline$<2 \%$ & $\begin{array}{c}0.385 \\
(0.151)\end{array}$ & 0.014 & $\begin{array}{c}0.342 \\
(0.280)\end{array}$ & 0.229 & $\begin{array}{c}0.414 \\
(0.181)\end{array}$ & 0.027 \\
\hline \multicolumn{7}{|l|}{ Alternative Advertising Measures: } \\
\hline Total Number of Ads (in 1,000s) & $\begin{array}{c}0.290 \\
(0.095)\end{array}$ & 0.004 & $\begin{array}{c}0.057 \\
(0.254)\end{array}$ & 0.823 & $\begin{array}{c}0.296 \\
(0.106)\end{array}$ & 0.008 \\
\hline Number of Unique Ads & $\begin{array}{c}0.058 \\
(0.023)\end{array}$ & 0.018 & $\begin{array}{c}0.062 \\
(0.031)\end{array}$ & 0.055 & $\begin{array}{c}0.059 \\
(0.024)\end{array}$ & 0.019 \\
\hline Gross Rating Points $(\div 1,000)$ & $\begin{array}{c}0.295 \\
(0.085)\end{array}$ & 0.001 & $\begin{array}{c}0.094 \\
(0.140)\end{array}$ & 0.504 & $\begin{array}{c}0.315 \\
(0.103)\end{array}$ & 0.004 \\
\hline Imps. per Cap. within 180 Days Before Election $(\div 10)$ & $\begin{array}{c}0.265 \\
(0.086)\end{array}$ & 0.004 & $\begin{array}{c}0.093 \\
(0.158)\end{array}$ & 0.560 & $\begin{array}{c}0.281 \\
(0.096)\end{array}$ & 0.005 \\
\hline Imps. per Cap. within 120 Days Before Election $(\div 10)$ & $\begin{array}{c}0.266 \\
(0.090)\end{array}$ & 0.005 & $\begin{array}{c}0.092 \\
(0.157)\end{array}$ & 0.564 & $\begin{array}{c}0.283 \\
(0.102)\end{array}$ & 0.008 \\
\hline Imps. per Cap. within 30 Days Before Election $(\div 10)$ & $\begin{array}{c}0.257 \\
(0.147)\end{array}$ & 0.088 & $\begin{array}{c}0.077 \\
(0.218)\end{array}$ & 0.724 & $\begin{array}{c}0.297 \\
(0.196)\end{array}$ & 0.137 \\
\hline Imps. per Cap. for Viewers Age 2 and Older $(\div 10)$ & $\begin{array}{c}0.388 \\
(0.110)\end{array}$ & 0.001 & $\begin{array}{c}0.117 \\
(0.184)\end{array}$ & 0.528 & $\begin{array}{c}0.419 \\
(0.132)\end{array}$ & 0.003 \\
\hline Imps. per Cap. using 15 min Window Ratings $(\div 10)$ & $\begin{array}{c}0.311 \\
(0.089)\end{array}$ & 0.001 & $\begin{array}{c}0.098 \\
(0.149)\end{array}$ & 0.513 & $\begin{array}{c}0.335 \\
(0.107)\end{array}$ & 0.003 \\
\hline Imps. per Cap. incl. Nat'l Broadcasts $(\div 10,2008$ only) & $\begin{array}{l}-- \\
--\end{array}$ & -- & $\begin{array}{l}-- \\
--\end{array}$ & -- & $\begin{array}{c}0.322 \\
(0.108)\end{array}$ & 0.005 \\
\hline \multicolumn{7}{|l|}{ By Battleground Status: } \\
\hline Battleground State & $\begin{array}{c}0.450 \\
(0.162)\end{array}$ & 0.017 & $\begin{array}{c}0.642 \\
(0.625)\end{array}$ & 0.380 & $\begin{array}{c}0.432 \\
(0.168)\end{array}$ & 0.030 \\
\hline Nonbattleground State & $\begin{array}{c}0.184 \\
(0.101)\end{array}$ & 0.075 & $\begin{array}{c}0.063 \\
(0.175)\end{array}$ & 0.719 & $\begin{array}{c}0.223 \\
(0.128)\end{array}$ & 0.089 \\
\hline
\end{tabular}

Notes: Entries are coefficients and standard errors on $\phi$ in equation (2), estimated on various subsamples of the data. The outcome variable in each specification is the partisan difference in two-party vote shares (in percentage points), while the partisan difference in presidential advertising is the independent variable of interest. All estimates are based on our sample of stacked border-pair counties, controlling for year-specific border-pair fixed effects and the full set of controls, as in column (9) of Table 5. Heteroskedasticity robust standard errors are clustered by state and reported in parentheses. $p$-values for the null hypothesis of no effect of partisan differences in advertising are reported next to each coefficient. As noted in the main text, when we downweigh stacked observations, we weigh each county-year observation by the inverse of the number of times that it appears in our sample of stacked border-county pairs. For precise definitions and the sources of all variables, see the Data Appendix. 
Table 7: Estimating the Impact of Partisan Advertising on the Behavior of All Eligible Voters, 2004 \& 2008 Presidential Elections

\begin{tabular}{|c|c|c|c|c|c|c|c|c|c|}
\hline & \multicolumn{3}{|c|}{$\begin{array}{c}\text { Democratic Vote Share } \\
\text { (as Percentage of the Voting-Aged Population) }\end{array}$} & \multicolumn{3}{|c|}{$\begin{array}{c}\text { Republican Vote Share } \\
\text { (as Percentage of the Voting-Aged Population) }\end{array}$} & \multicolumn{3}{|c|}{$\begin{array}{c}\text { Partisan Difference in Vote Shares } \\
\text { (as Percentage of the Voting-Aged Population) }\end{array}$} \\
\hline & $(1)$ & $(2)$ & (3) & (4) & $(5)$ & $(6)$ & $(7)$ & $(8)$ & $(9)$ \\
\hline Democratic Imps. per Cap. $(\div 10)$ & $\begin{array}{l}0.214 \\
(0.151)\end{array}$ & $\begin{array}{r}0.072 * \\
(0.037)\end{array}$ & & $\begin{array}{l}-0.187 \\
(0.133)\end{array}$ & $\begin{array}{l}-0.099 * \\
(0.054)\end{array}$ & & $\begin{array}{l}0.401 \\
(0.243)\end{array}$ & $\begin{array}{l}0.170^{* *} \\
(0.064)\end{array}$ & \\
\hline Republican Imps. per Cap. $(\div 10)$ & $\begin{array}{l}-0.141 \\
(0.177)\end{array}$ & $\begin{array}{l}-0.005 \\
(0.057)\end{array}$ & & $\begin{array}{l}0.125 \\
(0.154)\end{array}$ & $\begin{array}{l}0.076 \\
(0.068)\end{array}$ & & $\begin{array}{l}-0.266 \\
(0.289)\end{array}$ & $\begin{array}{l}-0.082 \\
(0.094)\end{array}$ & \\
\hline $\begin{array}{l}\text { Difference Between Democratic and } \\
\text { Republican Imps. per Cap. }(\div 10)\end{array}$ & & & $\begin{array}{l}0.077^{* *} \\
(0.037)\end{array}$ & & & $\begin{array}{l}-0.101^{*} \\
(0.053)\end{array}$ & & & $\begin{array}{l}0.176^{* * *} \\
(0.063)\end{array}$ \\
\hline \multicolumn{10}{|l|}{$\mathrm{H}_{0}$ : Both Coefficients $=0$} \\
\hline $\begin{array}{l}\text { F-Statistic } \\
p \text {-value }\end{array}$ & $\begin{array}{l}1.259 \\
0.216 \\
\end{array}$ & $\begin{array}{l}2.569 \\
0.003 \\
\end{array}$ & - & $\begin{array}{l}1.018 \\
0.363 \\
\end{array}$ & $\begin{array}{l}1.594 \\
0.090\end{array}$ & -- & $\begin{array}{l}1.283 \\
0.204\end{array}$ & $\begin{array}{l}3.155 \\
0.000\end{array}$ & -- \\
\hline \multicolumn{10}{|l|}{ Fixed Effects: } \\
\hline $\begin{array}{l}\text { Year } \\
\text { Border Pair } \times \text { Year }\end{array}$ & $\begin{array}{l}\text { No } \\
\text { Yes }\end{array}$ & $\begin{array}{l}\text { No } \\
\text { Yes }\end{array}$ & $\begin{array}{l}\text { No } \\
\text { Yes }\end{array}$ & $\begin{array}{l}\text { No } \\
\text { Yes }\end{array}$ & $\begin{array}{l}\text { No } \\
\text { Yes }\end{array}$ & $\begin{array}{l}\text { No } \\
\text { Yes }\end{array}$ & $\begin{array}{l}\text { No } \\
\text { Yes }\end{array}$ & $\begin{array}{l}\text { No } \\
\text { Yes }\end{array}$ & $\begin{array}{l}\text { No } \\
\text { Yes }\end{array}$ \\
\hline \multicolumn{10}{|l|}{ Controls: } \\
\hline Demographic, Economic \& Geographic Variables & No & Yes & Yes & No & Yes & Yes & No & Yes & Yes \\
\hline Candidate Visits \& Non-Presidential Imps. per Cap. & No & Yes & Yes & No & Yes & Yes & No & Yes & Yes \\
\hline Lagged Dependent Variable & No & Yes & Yes & No & Yes & Yes & No & Yes & Yes \\
\hline Sample & $\begin{array}{c}\text { Border } \\
\text { Counties }\end{array}$ & $\begin{array}{c}\text { Border } \\
\text { Counties } \\
\end{array}$ & $\begin{array}{c}\text { Border } \\
\text { Counties }\end{array}$ & $\begin{array}{c}\text { Border } \\
\text { Counties }\end{array}$ & $\begin{array}{c}\text { Border } \\
\text { Counties } \\
\end{array}$ & $\begin{array}{c}\text { Border } \\
\text { Counties }\end{array}$ & $\begin{array}{c}\text { Border } \\
\text { Counties }\end{array}$ & $\begin{array}{c}\text { Border } \\
\text { Counties }\end{array}$ & $\begin{array}{c}\text { Border } \\
\text { Counties }\end{array}$ \\
\hline R-Squared & 0.802 & 0.980 & 0.980 & 0.721 & 0.975 & 0.975 & 0.770 & 0.985 & 0.984 \\
\hline Number of Observations & 6,790 & 6,790 & 6,790 & 6,790 & 6,790 & 6,790 & 6,790 & 6,790 & 6,790 \\
\hline
\end{tabular}

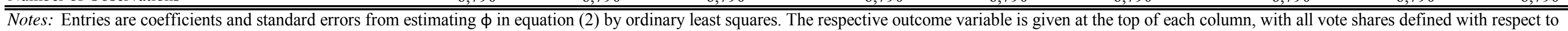

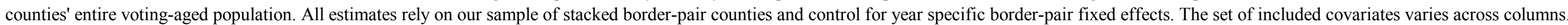

Heteroskedasticity robust standard errors are clustered by state and reported in parentheses. ***,**, and * denote statistical significance at the $1 \%$-, $5 \%$-, and $10 \%$-levels, respectively. 
Table 8: Summary Statistics for the Voter Registration Data, 2008 Presidential Election

\begin{tabular}{|c|c|c|c|c|c|c|}
\hline & \multicolumn{2}{|c|}{ All Voters } & \multicolumn{2}{|c|}{$\begin{array}{c}<25 \mathrm{~km} \text { to } \\
\text { DMA Border }\end{array}$} & \multicolumn{2}{|c|}{$\begin{array}{c}<5 \mathrm{~km} \text { to } \\
\text { DMA Border }\end{array}$} \\
\hline & Mean & $\mathrm{SD}$ & Mean & $\mathrm{SD}$ & Mean & $\mathrm{SD}$ \\
\hline \multicolumn{7}{|l|}{ Demographics: } \\
\hline Female & 0.54 & 0.50 & 0.54 & 0.50 & 0.53 & 0.50 \\
\hline Age & 47.74 & 17.07 & 48.83 & 17.11 & 49.38 & 16.82 \\
\hline Years Registered at Current Address & 11.70 & 11.30 & 12.63 & 11.92 & 12.60 & 11.79 \\
\hline \multicolumn{7}{|l|}{ Turnout \& Political Affiliation: } \\
\hline Voted in 2008 Presidential Election & 0.75 & 0.43 & 0.75 & 0.43 & 0.74 & 0.44 \\
\hline Registered Democrat & 0.36 & 0.48 & 0.36 & 0.48 & 0.34 & 0.47 \\
\hline Registered Republican & 0.30 & 0.46 & 0.31 & 0.46 & 0.33 & 0.47 \\
\hline "Other" or No Party Information & 0.34 & 0.47 & 0.33 & 0.47 & 0.33 & 0.47 \\
\hline \multicolumn{7}{|l|}{ GIS Measures: } \\
\hline Distance to Nearest DMA Border (in km) & 67.17 & 68.77 & 14.38 & 6.83 & 2.73 & 1.40 \\
\hline Street Address Level Match & 0.86 & 0.35 & 0.83 & 0.38 & 0.85 & 0.35 \\
\hline Zip Code Level Match & 0.14 & 0.35 & 0.17 & 0.38 & 0.15 & 0.35 \\
\hline City Level Match & 0.00 & 0.01 & 0.00 & 0.01 & 0.00 & 0.01 \\
\hline Number of Observations & \multicolumn{2}{|c|}{$106,463,198$} & \multicolumn{2}{|c|}{$20,272,672$} & \multicolumn{2}{|c|}{$2,464,111$} \\
\hline
\end{tabular}

Notes: Entries are descriptive statistics for the most important variables in our voter registration data set, by distance to the nearest media market border within a voter's state of registration. For precise definitions and the sources of all variables, see the Data Appendix. 
Table 9: RD Estimates of the Effect of Partisan Differences in Political Advertising on Partisan Differences in Turnout, 2008 Presidential Election

\begin{tabular}{ccccc}
\hline \hline \multirow{2}{*}{ A. Partisan Difference in Turnout across DMA Borders } & \multicolumn{5}{c}{ Bandwidth (in meters) } \\
\cline { 2 - 5 } Local Polynomial & 500 & 1,000 & 5,000 & 10 -fold C-V \\
\hline \multirow{2}{*}{ Linear } & 0.018 & 0.017 & 0.016 & 0.015 \\
& $(0.012)$ & $(0.012)$ & $(0.011)$ & $(0.010)$ \\
Quadratic & $0.027^{*}$ & 0.018 & $0.023^{* *}$ & $0.020^{*}$ \\
& $(0.015)$ & $(0.012)$ & $(0.010)$ & $(0.010)$ \\
Cubic & $0.036^{* *}$ & $0.025^{*}$ & $0.025^{* *}$ & $0.027^{* * *}$ \\
& $(0.017)$ & $(0.013)$ & $(0.011)$ & $(0.010)$ \\
Quartic & $0.036^{* *}$ & 0.022 & $0.020^{*}$ & $0.022^{* *}$ \\
& $(0.015)$ & $(0.015)$ & $(0.011)$ & $(0.010)$ \\
\cline { 2 - 5 } Number of Observations & 110,780 & 234,121 & $1,643,094$ & -- \\
\hline
\end{tabular}

\section{B. Wald Estimator}

\begin{tabular}{ccccc} 
& \multicolumn{4}{c}{ Bandwidth (in meters) } \\
\cline { 2 - 5 } Local Polynomial & 500 & 1,000 & 5,000 & 10 -fold C-V \\
\hline \multirow{2}{*}{ Linear } & 0.007 & 0.006 & 0.005 & 0.005 \\
& $(0.005)$ & $(0.004)$ & $(0.003)$ & $(0.003)$ \\
Quadratic & $0.011^{*}$ & 0.007 & $0.008^{* *}$ & $0.006^{*}$ \\
& $(0.006)$ & $(0.005)$ & $(0.004)$ & $(0.004)$ \\
Cubic & $0.015^{* *}$ & $0.010^{*}$ & $0.008^{* *}$ & $0.009^{* *}$ \\
& $(0.007)$ & $(0.006)$ & $(0.004)$ & $(0.004)$ \\
Quartic & $0.016^{* *}$ & 0.010 & $0.007^{*}$ & $0.008^{*}$ \\
& $(0.007)$ & $(0.006)$ & $(0.004)$ & $(0.004)$ \\
\hline \multirow{2}{*}{ Number of Observations } & 110,780 & 234,121 & $1,643,094$ & -- \\
\hline \hline
\end{tabular}

Notes: Entries in the upper panel are nonparametric estimates of the discontinuity in the partisan difference in turnout across media market borders, i.e., $\tau$ in equation (5). Larger values indicate an increase in turnout of registered Democrats relative to registered Republicans. The lower panel displays Wald estimates of the effect of partisan differences in political advertising on partisan differences in turnout (cf. equation (4)). All Wald estimates have been scaled so that the coefficients refer to the impact of 10 impressions per capita. As explained in the main text, the running variable is voters' distance to the nearest within-state media market border. All estimates are based on local polynomial regressions using a rectangular kernel. The order of the local polynomial is given on the left of each row, while the respective bandwidth is indicated at the top of each column. The rightmost column uses 10-fold cross-validation for bandwidth selection, with the holdout sample consisting of the 27,426 observations that lie within $100 \mathrm{~m}$ of a media market border. Following Imbens and Lemieux (2008), we use the optimally chosen bandwidth for the outcome equation for the Wald estimator. To account for unobserved spatial heterogeneity, every specification includes party-specific fixed effects for individual border segments of up to $10 \mathrm{~km}$ length. Heteroskedasticity robust standard errors are clustered by media market border and reported in parentheses. ${ }^{* *},{ }^{* *}$, and $*$ denote statistical significance at the $1 \%-, 5 \%$-, and $10 \%$-levels, respectively. 
Table 10: RD Estimates of the Effect of Total Political Advertising on Turnout, 2008 Presidential Election

\begin{tabular}{lcccc}
\hline \multirow{2}{*}{ A. Wald Estimates for Unaffiliated Voters } & \multicolumn{4}{c}{ Bandwidth (in meters) } \\
\cline { 2 - 5 } Local Polynomial & 500 & 1,000 & 5,000 & 10 -fold C-V \\
\hline \multirow{2}{*}{ Linear } & -0.001 & -0.002 & $-0.002^{*}$ & -0.002 \\
& $(0.002)$ & $(0.001)$ & $(0.001)$ & $(0.001)$ \\
Quadratic & 0.003 & -0.002 & -0.002 & -0.002 \\
& $(0.003)$ & $(0.002)$ & $(0.001)$ & $(0.001)$ \\
Cubic & 0.003 & 0.000 & -0.001 & -0.002 \\
& $(0.003)$ & $(0.002)$ & $(0.002)$ & $(0.002)$ \\
Quartic & 0.003 & 0.002 & -0.002 & 0.000 \\
& $(0.003)$ & $(0.002)$ & $(0.001)$ & $(0.001)$ \\
\cline { 2 - 5 } Number of Observations & 57,626 & 119,781 & 818,017 & -- \\
\hline
\end{tabular}

\section{B. Wald Estimates for All Voters}

\begin{tabular}{ccccc} 
& \multicolumn{4}{c}{ Bandwidth (in meters) } \\
\cline { 2 - 5 } Local Polynomial & 500 & 1,000 & 5,000 & 10 -fold C-V \\
\hline \multirow{2}{*}{ Linear } & -0.002 & -0.001 & -0.001 & $-0.002^{* *}$ \\
& $(0.001)$ & $(0.001)$ & $(0.001)$ & $(0.001)$ \\
Quadratic & 0.000 & -0.002 & -0.001 & -0.001 \\
& $(0.001)$ & $(0.001)$ & $(0.001)$ & $(0.001)$ \\
Cubic & 0.000 & -0.001 & 0.001 & -0.001 \\
& $(0.002)$ & $(0.001)$ & $(0.001)$ & $(0.001)$ \\
Quartic & 0.000 & 0.000 & -0.001 & 0.000 \\
& $(0.002)$ & $(0.001)$ & $(0.001)$ & $(0.001)$ \\
\cline { 2 - 5 } Number of Observations & 168,406 & 353,902 & $2,461,111$ & -- \\
\hline \hline
\end{tabular}

Notes: Entries in the upper panel are Wald estimates of the impact of total presidential advertising on turnout among voters who are not affiliated with any of the two major parties. The lower panel displays Wald estimates of the impact of total presidential advertising on all registered voters. All Wald estimates have been scaled so that the coefficients refer to the impact of 10 impressions per capita. As explained in the main text, the running variable is voters' distance to the nearest within-state media market border. All estimates are based on local polynomial regressions using a rectangular kernel. The order of the local polynomial is given on the left of each row, while the respective bandwidth is indicated at the top of each column. The rightmost column uses 10-fold cross-validation for bandwidth selection, with the holdout sample consisting of observations that lie within 100m of a media market border. Following Imbens and Lemieux (2008), we use the optimally chosen bandwidth for the outcome equation of the Wald estimator. To account for unobserved spatial heterogeneity, every specification includes fixed effects for individual border segments of up to $10 \mathrm{~km}$ length. Heteroskedasticity robust standard errors are clustered by media market border and reported in parentheses. ${ }^{* *}, * *$, and $*$ denote statistical significance at the $1 \%-, 5 \%$-, and $10 \%$-levels, respectively. 
Figure A.1: Total Presidential Advertising within Sixty Days of the 2008 Election, by Media Market

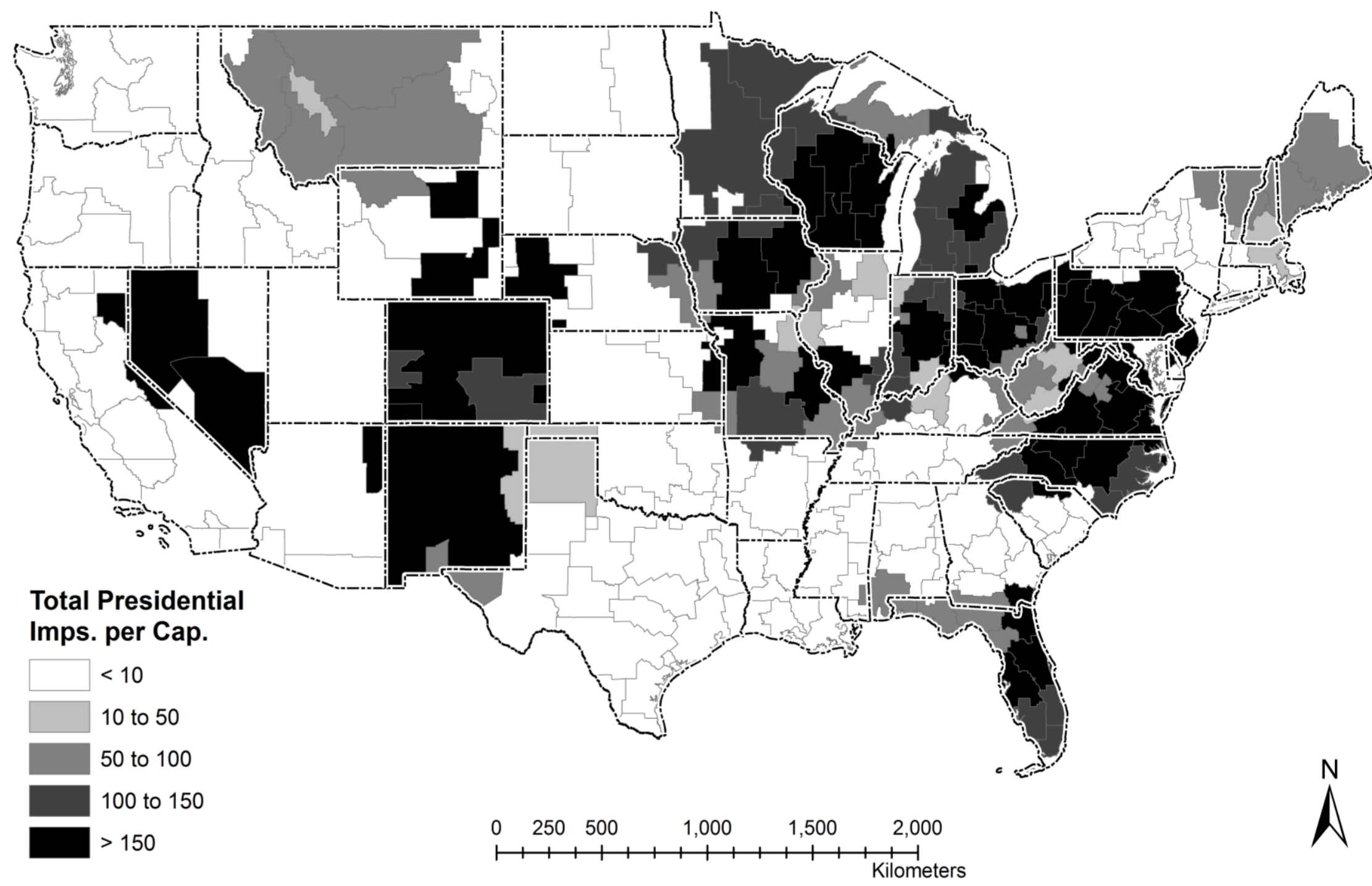

Notes: Figure displays the geographic distribution of all presidential advertising within 60 days of the 2008 presidential election. Advertising intensity is measured in impressions per capita among voting-aged adults. For additional details, see the Data Appendix. 
Figure A.2: Partisan Differences in Presidential Advertising within Sixty Days of the 2008 Election, by Media Market

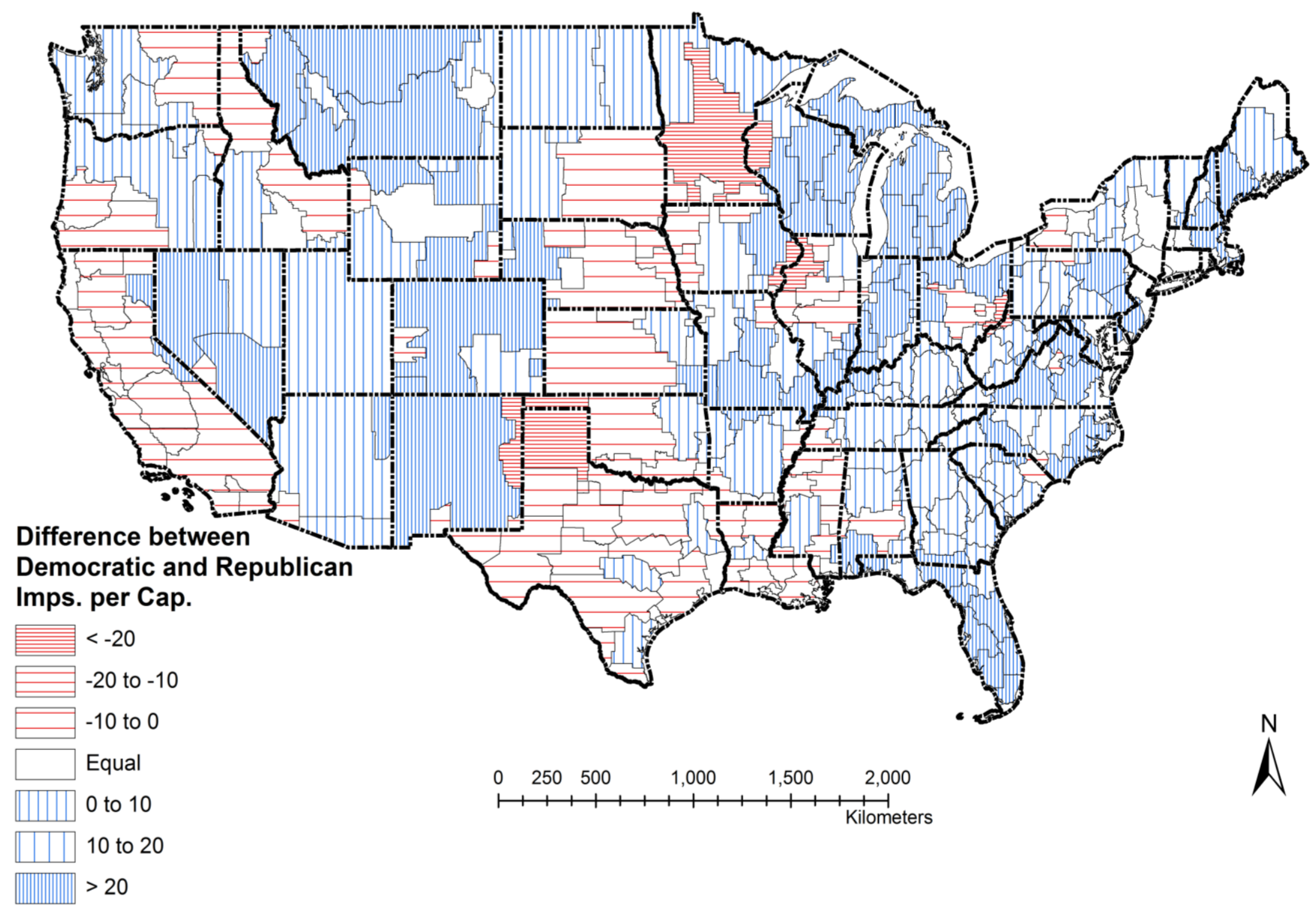

Notes: Figure displays the partisan difference in presidential advertising within 60 days of the 2008 presidential election, by DMA. Advertising intensity is measured in impressions per capita among voting-aged adults. For additional details, see the Data Appendix. 
Figure A.3: Relationship between Total Presidential Advertising and Turnout

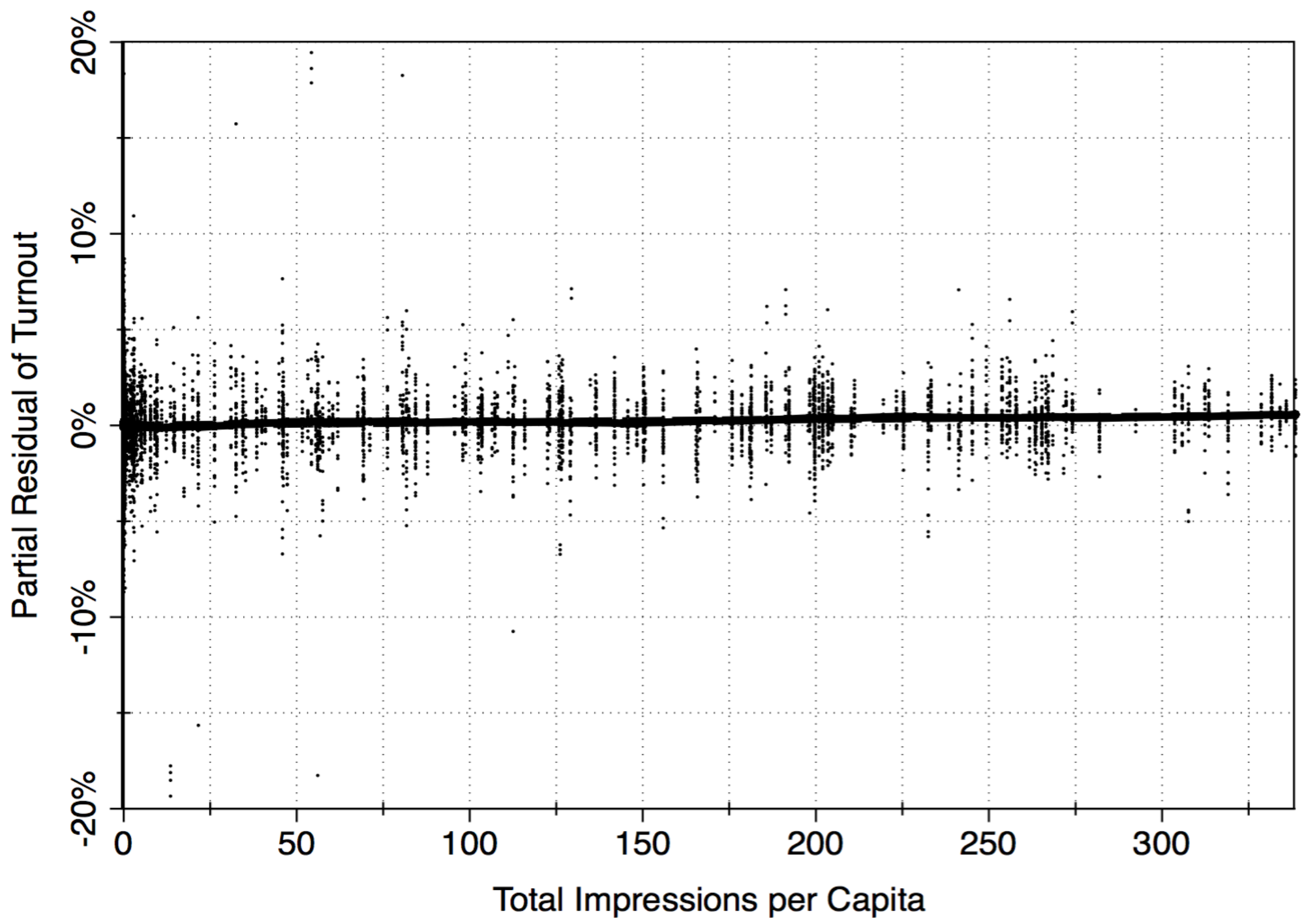

Notes: Figure plots residualized turnout against total presidential advertising. The partial residuals are based on the model in equation (2) using the full set of covariates, as explained in Appendix B. The dashed line shows the regression line implied by our workhorse linear model. The solid line represent the result of local regressions with a rectangular kernel and a bandwidth corresponding to $10 \%$ of the sample size. 


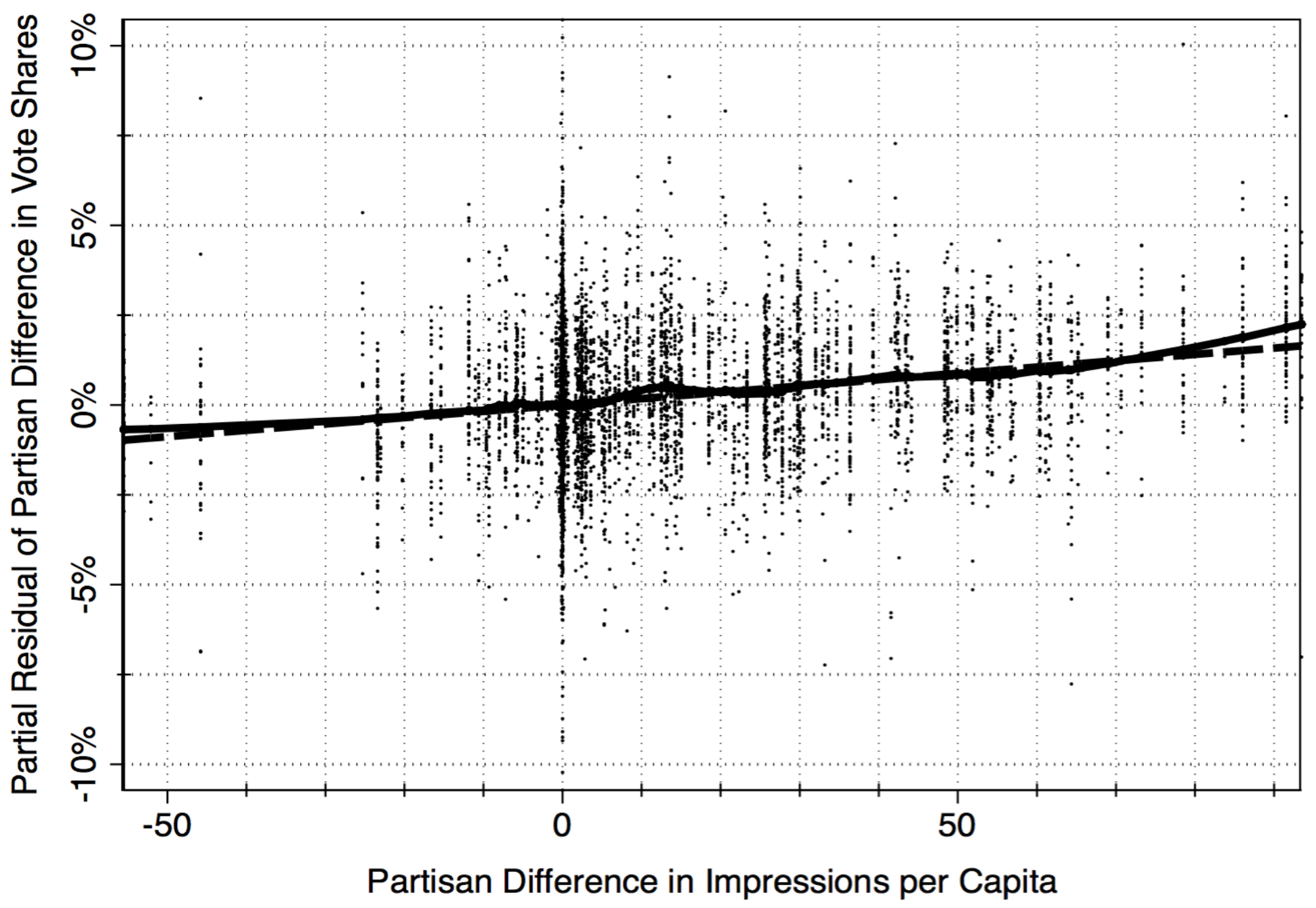

Notes: Figure plots the residualized partisan difference in vote shares againts the partisan difference in presidential advertising. The partial residuals are based on the model in equation (2) using the full set of covariates, as explained in Appendix B. The dashed line shows the regression line implied by our workhorse linear model. The solid line represent the result of local regressions with a rectangular kernel and a bandwidth corresponding to $10 \%$ of the sample size. 
Figure A.5: Relationship between a Candidate's Advertising and Vote Share

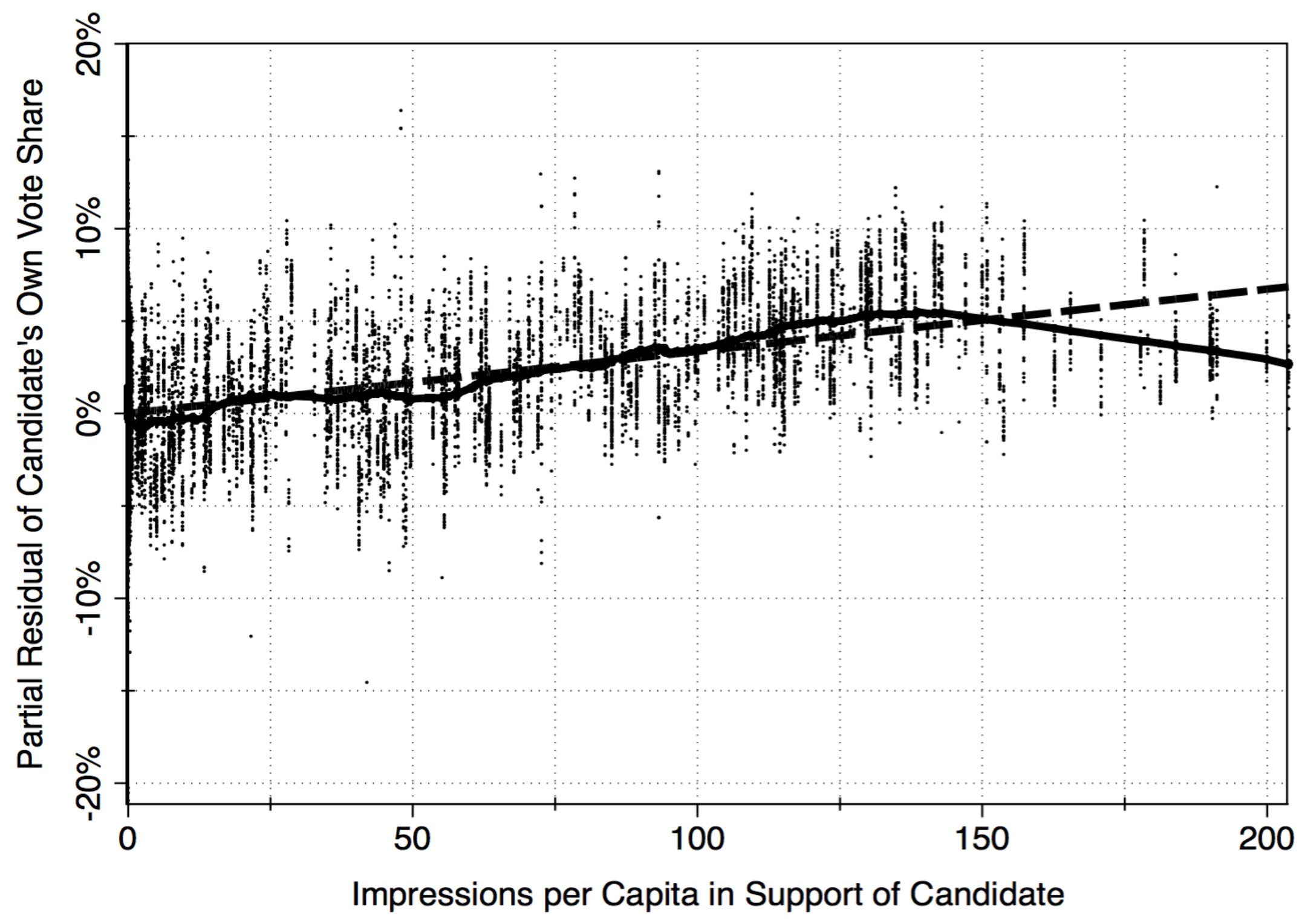

Notes: Figure plots residuals of a candidate's own vote share against the number of impressions that aired in his support. The partial residuals are based on the model in equation (2) using the full set of covariates, as explained in Appendix B. The dashed line shows the regression line implied by our workhorse linear model. The solid line represent the result of local regressions with a rectangular kernel and a bandwidth corresponding to $10 \%$ of the sample size. 
Figure A.6: Relationship between One Candidate's Advertising and Her Opponent's Vote Share

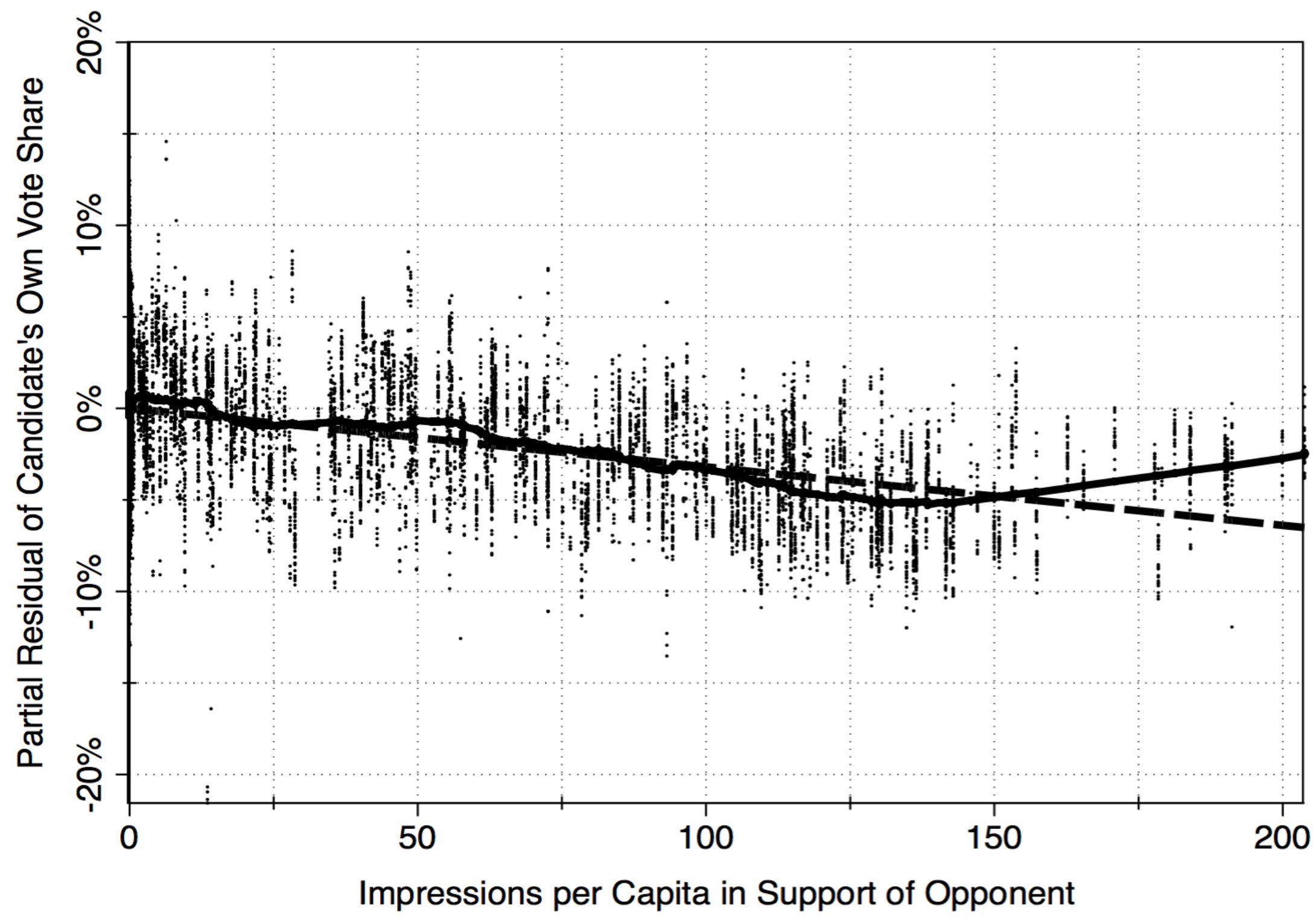

Notes: Figure plots residuals of a candidate's vote share against the number of impressions that aired in support of his opponent. The partial residuals are based on the model in equation (2) using the full set of covariates, as explained in Appendix B. The dashed line shows the regression line implied by our workhorse linear model. The solid line represent the result of local regressions with a rectangular kernel and a bandwidth corresponding to $10 \%$ of the sample size. 
Figure A.7: Number of Registered Voters within 170km of the Nearest Media Market Border

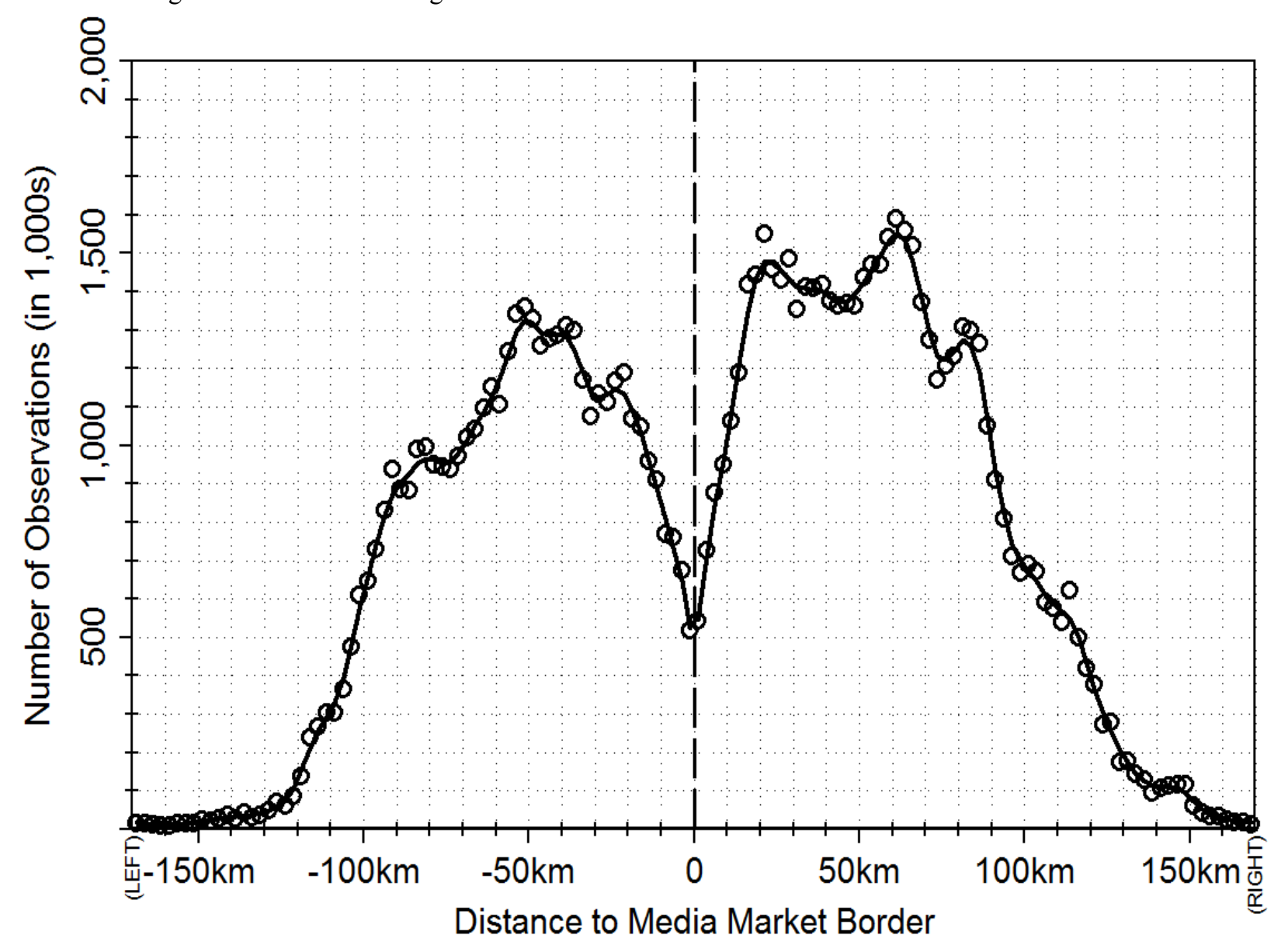

Notes: Figure shows the number of observations in our voter registration sample within $2.5 \mathrm{~km}$-wide bins around media market borders. As explained in the main text, the running variable is voters' distance to the nearest within-state media market border. Estimates of the associated density are based on the procedure of McCrary (2008). For precise definitions and the sources of all variables, see the Data Appendix.

Figure A.8: Number of Registered Voters within 25km of the Nearest Media Market Border

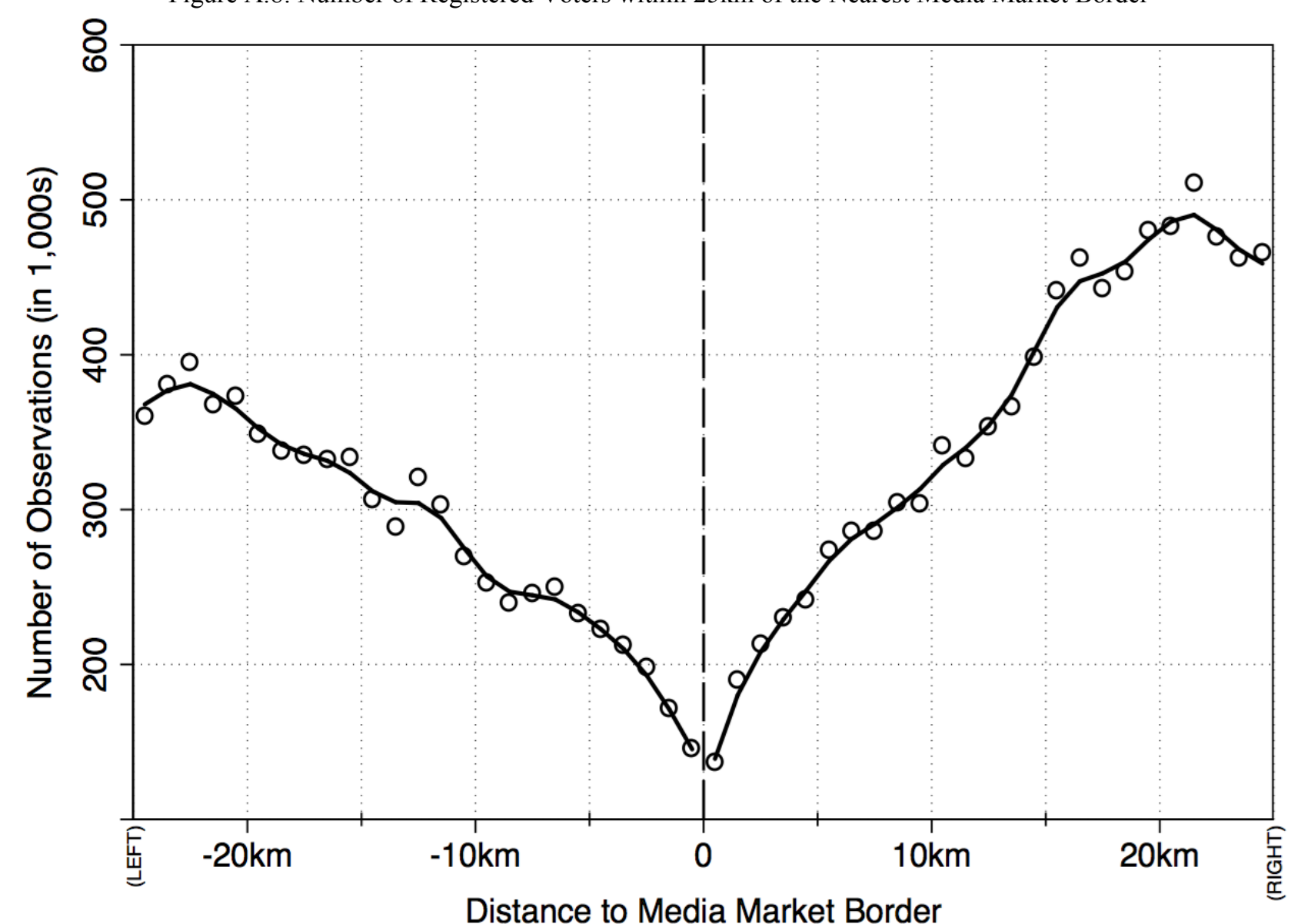

Notes: Figure shows the number of observations within a $25 \mathrm{~km}$ bandwidth around media market borders. Each bin is $1 \mathrm{~km}$ wide. As explained in the main text, the running variable is voters' distance to the nearest within-state media market border. Estimates of the associated density are based on the procedure of McCrary (2008). For precise definitions and the sources of all variables, see the Data Appendix. 
Figure A.9: Differences in Total Presidential Advertising across DMA Borders, 2008 Presidential Election

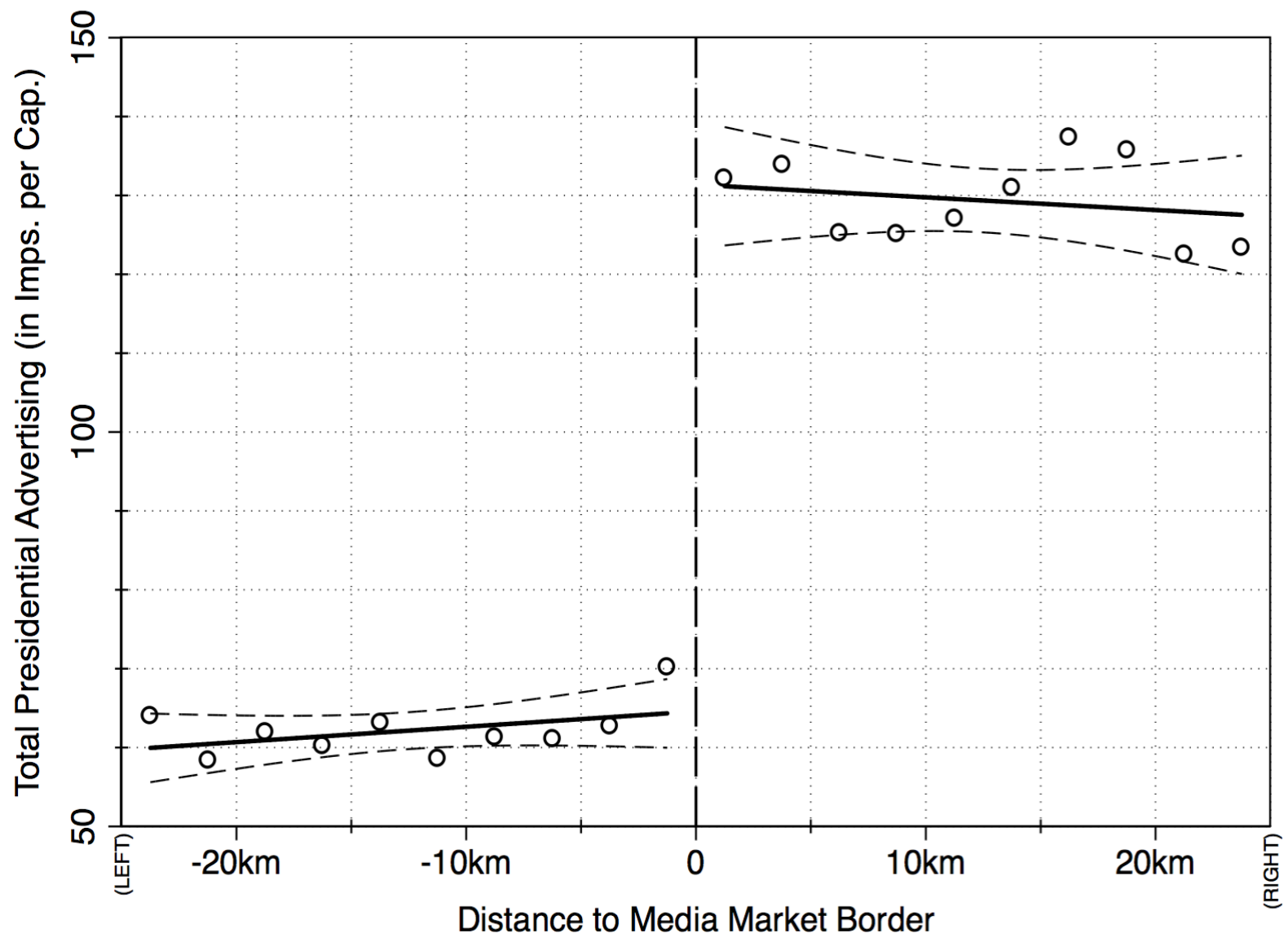

Notes: Figure plots average total presidential advertising during the 2008 presidential election within $2.5 \mathrm{~km}$-wide bins around media market borders. In a deviation from our RD design in the main text, we now use voters' residential addresses to calculate distance to the nearest within-state media market border, with negative values assigned to individuals who live in a media market in which total presidential advertising is lower than in the neighboring one. For precise definitions and the sources of all variables, see the Data Appendix.

Figure A.10: Differences in Overall Turnout across DMA Borders, 2008 Presidential Election

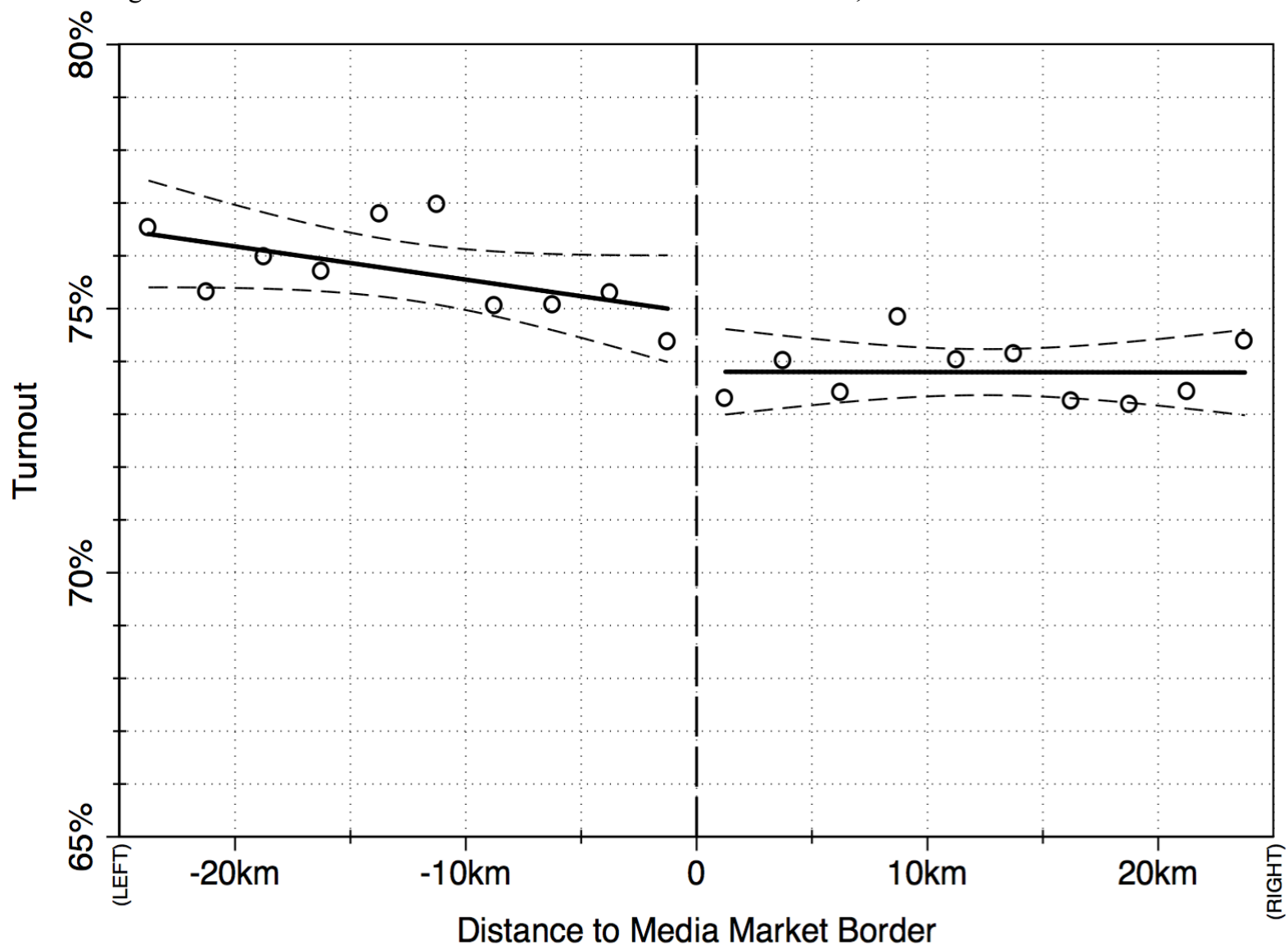

Notes: Figure plots average turnout among all voters during the 2008 presidential election within $2.5 \mathrm{~km}$-wide bins around media market borders. In a deviation from our RD design in the main text, we now use voters' residential addresses to calculate distance to the nearest within-state media market border, with negative values assigned to individuals who live in a media market in which total presidential advertising is lower than in the neighboring one. For precise definitions and the sources of all variables, see the Data Appendix. 
Table A.1: Descriptive Statistics, by Election Year

\begin{tabular}{|c|c|c|c|c|c|c|c|c|}
\hline & \multicolumn{4}{|c|}{ All Counties } & \multicolumn{4}{|c|}{ Border-Pair Counties } \\
\hline & Mean & $\mathrm{SD}$ & Min & Max & Mean & SD & Min & Max \\
\hline \multicolumn{9}{|l|}{ A. 2004 Presidential Election } \\
\hline \multicolumn{9}{|l|}{ Media Market Measures: } \\
\hline Presidential Impressions per Capita (in 10s) & 7.95 & 11.38 & 0.00 & 33.85 & 8.54 & 11.72 & 0.00 & 33.85 \\
\hline Partisan Difference in Imps. per Cap. (in 10s) & 1.05 & 1.94 & -2.53 & 6.90 & 1.09 & 1.95 & -2.53 & 6.90 \\
\hline Presidential GRPs (in 1,000 s) & 7.95 & 11.39 & 0.00 & 38.26 & 8.55 & 11.75 & 0.00 & 38.26 \\
\hline Number of Political Ads (in 1,000s) & 5.89 & 8.39 & 0.00 & 30.56 & 6.24 & 8.52 & 0.00 & 30.56 \\
\hline Non-Presidential Political Ads Imps. per Cap. (in 10s) & 15.59 & 13.96 & 0.00 & 56.57 & 15.71 & 14.22 & 0.00 & 56.57 \\
\hline Candidate Visits & 3.18 & 4.63 & 0.00 & 18.00 & 3.33 & 4.65 & 0.00 & 18.00 \\
\hline \multicolumn{9}{|l|}{ County-Level Variables: } \\
\hline Turnout (\%) & 58.17 & 9.12 & 29.46 & 100.00 & 57.59 & 9.05 & 31.00 & 100.00 \\
\hline Lagged Turnout (\%) & 52.93 & 8.85 & 23.70 & 97.10 & 52.47 & 8.77 & 27.24 & 97.10 \\
\hline Democratic Two-Party Vote Share (\%) & 40.31 & 12.40 & 9.09 & 90.52 & 39.79 & 11.08 & 9.09 & 83.06 \\
\hline Republican Two-Party Vote Share (\%) & 59.69 & 12.40 & 9.48 & 90.91 & 60.21 & 11.08 & 16.94 & 90.91 \\
\hline Percent White (\%) & 81.15 & 18.18 & 3.13 & 98.89 & 82.04 & 17.50 & 3.13 & 98.81 \\
\hline Percent Black $(\%)$ & 8.55 & 13.50 & 0.00 & 85.45 & 8.52 & 13.61 & 0.00 & 80.46 \\
\hline Percent Hispanic (\%) & 0.32 & 0.47 & 0.00 & 5.91 & 0.29 & 0.44 & 0.00 & 4.07 \\
\hline Percent Asian (\%) & 1.15 & 2.60 & 0.00 & 44.58 & 0.89 & 2.02 & 0.00 & 29.27 \\
\hline Percent Other Race (\%) & 8.84 & 12.36 & 0.80 & 95.72 & 8.26 & 11.62 & 0.80 & 95.72 \\
\hline Percent High School Dropouts (\%) & 22.56 & 8.70 & 3.24 & 58.01 & 23.88 & 8.83 & 3.24 & 58.01 \\
\hline Percent High School Educated (\%) & 54.65 & 6.69 & 23.78 & 68.92 & 55.16 & 6.45 & 29.23 & 68.79 \\
\hline Percent College Educated (\%) & 22.78 & 9.39 & 6.86 & 67.62 & 20.95 & 8.49 & 6.86 & 62.24 \\
\hline Median Household Income (in $\$ 1,000$ ) & 39.73 & 10.44 & 18.38 & 94.66 & 38.10 & 9.49 & 18.38 & 94.66 \\
\hline Percent in Poverty $(\%)$ & 12.65 & 4.98 & 2.25 & 38.59 & 13.13 & 4.99 & 3.05 & 38.59 \\
\hline Employment to Population (\%) & 44.70 & 18.30 & 10.43 & 310.35 & 42.21 & 15.73 & 12.55 & 310.35 \\
\hline Distance to State Capital (in $100 \mathrm{~km}$ ) & 1.78 & 1.21 & 0.00 & 8.26 & 1.75 & 1.11 & 0.03 & 7.50 \\
\hline Distance to Nearest City $>250,000$ Population (in $100 \mathrm{~km}$ ) & 5.34 & 3.33 & 0.00 & 43.30 & 5.15 & 3.01 & 0.09 & 15.36 \\
\hline Total Voting-Aged Population (in 1,000s) & 93.76 & 274.44 & 0.33 & 7175.92 & 64.44 & 185.47 & 0.33 & 2600.24 \\
\hline Number of Counties & \multicolumn{4}{|c|}{2,020} & \multicolumn{4}{|c|}{1,228} \\
\hline Number of Media Markets & \multicolumn{4}{|c|}{100} & \multicolumn{4}{|c|}{69} \\
\hline \multicolumn{9}{|l|}{ B. 2008 Presidential Election } \\
\hline \multicolumn{9}{|l|}{ Media Market Measures: } \\
\hline Presidential Impressions per Capita (in 10s) & 7.14 & 8.74 & 0.00 & 27.23 & 7.31 & 8.79 & 0.00 & 27.23 \\
\hline Partisan Difference in Imps. per Cap. (in 10s) & 1.23 & 2.42 & -5.55 & 9.35 & 1.28 & 2.44 & -5.55 & 9.35 \\
\hline Presidential GRPs (in 1,000s) & 7.52 & 9.21 & 0.00 & 29.20 & 7.70 & 9.26 & 0.00 & 29.20 \\
\hline Number of Political Ads (in 1,000s) & 6.32 & 8.39 & 0.00 & 34.67 & 6.36 & 8.26 & 0.00 & 34.67 \\
\hline Non-Presidential Political Ads Imps. per Cap. (in 10s) & 15.07 & 13.75 & 0.00 & 60.26 & 14.80 & 13.55 & 0.00 & 60.26 \\
\hline Candidate Visits & 1.58 & 2.05 & 0.00 & 11.67 & 1.53 & 1.96 & 0.00 & 11.67 \\
\hline \multicolumn{9}{|l|}{ County-Level Variables: } \\
\hline Turnout (\%) & 58.67 & 9.36 & 19.20 & 100.00 & 58.03 & 9.37 & 24.93 & 100.00 \\
\hline Lagged Turnout (\%) & 58.53 & 9.62 & 15.16 & 100.00 & 57.87 & 9.41 & 26.29 & 100.00 \\
\hline Democratic Two-Party Vote Share (\%) & 42.26 & 14.04 & 5.03 & 93.40 & 41.81 & 13.16 & 5.03 & 89.54 \\
\hline Republican Two-Party Vote Share (\%) & 57.74 & 14.04 & 6.60 & 94.97 & 58.19 & 13.16 & 10.46 & 94.97 \\
\hline Percent White (\%) & 79.03 & 19.52 & 2.78 & 99.12 & 79.35 & 19.37 & 2.92 & 99.12 \\
\hline Percent Black (\%) & 8.86 & 14.51 & 0.00 & 85.92 & 9.28 & 15.04 & 0.00 & 82.88 \\
\hline Percent Hispanic (\%) & 0.49 & 0.62 & 0.00 & 6.56 & 0.46 & 0.60 & 0.00 & 5.89 \\
\hline Percent Asian (\%) & 1.08 & 2.29 & 0.00 & 43.68 & 0.87 & 1.83 & 0.00 & 31.36 \\
\hline Percent Other Race (\%) & 10.54 & 14.19 & 0.58 & 96.14 & 10.04 & 13.88 & 0.66 & 96.14 \\
\hline Percent High School Dropouts (\%) & 22.89 & 8.75 & 3.44 & 65.46 & 23.97 & 8.88 & 3.44 & 65.46 \\
\hline Percent High School Educated (\%) & 54.82 & 6.62 & 23.55 & 74.30 & 55.17 & 6.48 & 25.82 & 74.30 \\
\hline Percent College Educated (\%) & 22.29 & 8.73 & 6.45 & 67.63 & 20.86 & 8.02 & 6.45 & 62.14 \\
\hline Median Household Income (in $\$ 1,000$ ) & 44.06 & 11.38 & 19.18 & 111.58 & 42.30 & 10.34 & 19.83 & 102.25 \\
\hline Percent in Poverty $(\%)$ & 14.42 & 5.72 & 2.79 & 49.38 & 15.10 & 5.73 & 3.05 & 49.38 \\
\hline Employment to Population (\%) & 44.62 & 18.16 & 9.06 & 383.44 & 42.49 & 17.09 & 12.64 & 383.44 \\
\hline Distance to State Capital (in $100 \mathrm{~km}$ ) & 1.97 & 1.31 & 0.00 & 8.27 & 1.94 & 1.21 & 0.02 & 8.27 \\
\hline Distance to Nearest City $>250,000$ Population (in 100km) & 5.90 & 3.49 & 0.00 & 43.30 & 5.69 & 3.29 & 0.09 & 16.60 \\
\hline Total Voting-Aged Population (in 1,000s) & 74 & 234 & 0 & 7,285 & 53 & 157 & 0 & 2,828 \\
\hline Number of Counties & \multicolumn{4}{|c|}{3,110} & \multicolumn{4}{|c|}{2012} \\
\hline Number of Media Markets & \multicolumn{4}{|c|}{207} & & 1 & & \\
\hline
\end{tabular}


Table A.2: Alternative Estimates of the Impact of Political Advertising on Voter Turnout

A. All Presidential Advertising

$\Delta$ Percent Voter Turnout

\begin{tabular}{|c|c|c|c|c|}
\hline & & & & \\
\hline & $(1)$ & $(2)$ & (3) & (4) \\
\hline \multirow[t]{2}{*}{$\Delta$ All Presidential Imps. per Cap. $(\div 10)$} & 0.016 & $0.034 *$ & 0.023 & $0.038 *$ \\
\hline & $(0.014)$ & $(0.019)$ & $(0.017)$ & $(0.021)$ \\
\hline \multicolumn{5}{|l|}{ Fixed Effects: } \\
\hline State & No & Yes & No & No \\
\hline Year & No & No & Yes & No \\
\hline State $\times$ Year & No & No & No & Yes \\
\hline \multicolumn{5}{|l|}{ Controls: } \\
\hline Demographic, Economic \& Geographic Variables & Yes & Yes & Yes & Yes \\
\hline Candidate Visits \& Non-Presidential Imps. per Cap. & Yes & Yes & Yes & Yes \\
\hline Lagged Turnout & Yes & Yes & Yes & Yes \\
\hline \multirow{2}{*}{ Sample } & Border-Pair & Border-Pair & Border-Pair & Border-Pair \\
\hline & Differences & Differences & Differences & Differences \\
\hline R-Squared & 0.844 & 0.851 & 0.844 & 0.854 \\
\hline Number of Observations & 3,395 & 3,395 & 3,395 & 3,395 \\
\hline
\end{tabular}

B. Positive vs. Negative Presidential Advertsing

\begin{tabular}{|c|c|c|c|c|}
\hline & \multicolumn{4}{|c|}{$\Delta$ Percent Voter Turnout } \\
\hline & $(5)$ & $(6)$ & $(7)$ & $(8)$ \\
\hline \multirow[t]{2}{*}{$\Delta$ Positive Presidential Imps. per Cap. $(\div 10)$} & 0.037 & 0.061 & $0.070^{*}$ & $0.082 * *$ \\
\hline & $(0.035)$ & $(0.037)$ & $(0.037)$ & $(0.039)$ \\
\hline \multirow[t]{2}{*}{$\Delta$ Negative Presidential Imps. per Cap. $(\div 10)$} & -0.002 & 0.012 & -0.014 & 0.002 \\
\hline & $(0.034)$ & $(0.036)$ & $(0.034)$ & $(0.035)$ \\
\hline \multicolumn{5}{|l|}{$\mathrm{H}_{0}:$ Both Coefficients $=0$} \\
\hline F-Statistic & 0.920 & 2.112 & 2.120 & 2.512 \\
\hline$p$-value & 0.406 & 0.133 & 0.132 & 0.092 \\
\hline \multicolumn{5}{|l|}{ Fixed Effects: } \\
\hline State & No & Yes & No & No \\
\hline Year & No & No & Yes & No \\
\hline State $\times$ Year & No & No & No & Yes \\
\hline \multicolumn{5}{|l|}{ Controls: } \\
\hline Demographic, Economic \& Geographic Variables & Yes & Yes & Yes & Yes \\
\hline Candidate Visits \& Non-Presidential Imps. per Cap. & Yes & Yes & Yes & Yes \\
\hline Lagged Turnout & Yes & Yes & Yes & Yes \\
\hline \multirow{2}{*}{ Sample } & Border-Pair & Border-Pair & Border-Pair & Border-Pair \\
\hline & Differences & Differences & Differences & Differences \\
\hline R-Squared & 0.844 & 0.851 & 0.844 & 0.854 \\
\hline Number of Observations & 3,395 & 3,395 & 3,395 & 3,395 \\
\hline
\end{tabular}

Notes: Entries are coefficients and standard errors from estimating $\phi$ in equation (1) by ordinary least squares. The outcome variable in all specifications is the difference in voter turnout (as percentage of the voting-aged population) between neighboring border counties. The upper panel estimates the impact of all presidential advertising, while the lower panel distinguishes between positve and negative ads. The set of included controls and fixed effects varies across columns. Heteroskedasticity robust standard errors are clustered by state and reported in parentheses. ***,**, and $*$ denote statistical significance at the 1\%-, 5\%-, and $10 \%$-levels, respectively. 
Table A.3: Alternative Estimates of the Effect of Partisan Differences in Advertising on Vote Shares

\section{A. All Presidential Advertising}

$\Delta$ Partisan Difference in Presidential Vote Shares

\begin{tabular}{|c|c|c|c|c|}
\hline & & & & \\
\hline & $(1)$ & $(2)$ & $(3)$ & $(4)$ \\
\hline$\Delta$ Partisan Difference in Presidential & $0.309 * * *$ & $0.299 * * *$ & $0.276^{* * *}$ & $0.329 * * *$ \\
\hline Impresssions per Capita $(\div 10)$ & $(0.063)$ & $(0.072)$ & $(0.061)$ & $(0.083)$ \\
\hline \multicolumn{5}{|l|}{ Fixed Effects: } \\
\hline State & No & Yes & No & No \\
\hline Year & No & No & Yes & No \\
\hline State $\times$ Year & No & No & No & Yes \\
\hline \multicolumn{5}{|l|}{ Controls: } \\
\hline Demographic, Economic \& Geographic Variables & Yes & Yes & Yes & Yes \\
\hline Candidate Visits \& Non-Presidential Imps. per Cap. & Yes & Yes & Yes & Yes \\
\hline Lagged Turnout & Yes & Yes & Yes & Yes \\
\hline \multirow{2}{*}{ Sample } & Border-Pair & Border-Pair & Border-Pair & Border-Pair \\
\hline & Differences & Differences & Differences & Differences \\
\hline R-Squared & 0.934 & 0.936 & 0.934 & 0.938 \\
\hline Number of Observations & 3,395 & 3,395 & 3,395 & 3,395 \\
\hline
\end{tabular}

\section{B. Democratic vs. Republican Advertsing}

$\Delta$ Partisan Difference in Presidential Vote Shares

(5)

(6)

6)

7)

$(8)$

$\Delta$ Democratic Presidential Imps. per Cap. $(\div 10)$

$\Delta$ Republican Presidential Imps. per Cap. $(\div 10)$

\begin{tabular}{llll}
$0.295^{* * *}$ & $0.324 * * *$ & $0.285^{* * *}$ & $0.350 * * *$ \\
$(0.063)$ & $(0.074)$ & $(0.063)$ & $(0.084)$ \\
-0.093 & -0.140 & -0.108 & -0.175 \\
$(0.098)$ & $(0.103)$ & $(0.096)$ & $(0.116)$ \\
\hline
\end{tabular}

$$
\begin{aligned}
& \mathrm{H}_{0}: \text { Both Coefficients }=0 \\
& \text { F-Statistic } \\
& p \text {-value }
\end{aligned}
$$

Fixed Effects:

State
Year
State $\times$ Year

Controls:

Demographic, Economic \& Geographic Variables

Candidate Visits \& Non-Presidential Imps. per Cap.

Lagged Turnout

Sample

\section{R-Squared}

Number of Observations

\begin{tabular}{cccc}
\hline & & & \\
27.516 & 16.957 & 19.714 & 12.920 \\
0.000 & 0.000 & 0.000 & 0.000 \\
\hline & & & \\
No & Yes & No & No \\
No & No & Yes & No \\
No & No & No & Yes \\
\hline & & & \\
Yes & Yes & Yes & Yes \\
Yes & Yes & Yes & Yes \\
Yes & Yes & Yes & Yes \\
\hline Border-Pair & Border-Pair & Border-Pair & Border-Pair \\
Differences & Differences & Differences & Differences \\
\hline 0.934 & 0.936 & 0.934 & 0.938 \\
3,395 & 3,395 & 3,395 & 3,395 \\
\hline
\end{tabular}

Notes: Entries are coefficients and standard errors from estimating $\phi$ in equation (1) by ordinary least squares. All variables have been differenced across border-pair counties. The outcome in all specifications is the partisan difference in presidential two-party vote shares (in percentage points), with larger values indicating more votes for the Democratic candidate. The regressor of interest in the upper panel is the partisan difference in presidential advertising (in impressions per capita), defined as the difference between advertising in support of the Democratic candidate and that for his Republican competitor. The lower panel distinguishes between Democratic and Republican ads. The set of included fixed effects varies across columns. Heteroskedasticity robust standard errors are clustered by state and reported in parentheses. $* * *, * *$, and $*$ denote statistical significance at the $1 \%-, 5 \%$, and $10 \%$-levels, respectively. 
Table A.4: Estimating the Impact of Political Advertising using Media Market Border Fixed Effects, 2004 \& 2008 Presidential Elections

A. Turnout

\begin{tabular}{|c|c|c|c|c|c|c|c|}
\hline & \multicolumn{7}{|c|}{ Percent Voter Turnout } \\
\hline & $(1)$ & (2) & (3) & $(4)$ & $(5)$ & $(6)$ & (7) \\
\hline Total Presidential Impressions per Capita $(\div 10)$ & $\begin{array}{l}0.198 * * * \\
(0.072)\end{array}$ & $\begin{array}{l}0.203^{* * *} \\
(0.070)\end{array}$ & $\begin{array}{l}0.077^{*} \\
(0.039)\end{array}$ & $\begin{array}{c}0.007 \\
(0.033)\end{array}$ & $\begin{array}{l}0.005 \\
(0.029)\end{array}$ & $\begin{array}{c}0.011 \\
(0.032)\end{array}$ & $\begin{array}{l}0.014 \\
(0.015)\end{array}$ \\
\hline \multicolumn{8}{|l|}{ Fixed Effects: } \\
\hline Year & No & Yes & Yes & No & No & No & No \\
\hline Media Market Border & No & No & Yes & No & No & No & No \\
\hline Media Market Border $\times$ Year & No & No & No & Yes & Yes & Yes & Yes \\
\hline \multicolumn{8}{|l|}{ Controls: } \\
\hline Demographic, Economic \& Geographic Variables & No & No & No & No & Yes & Yes & Yes \\
\hline Candidate Visits \& Non-Pres. Imps. per Cap. & No & No & No & No & No & Yes & Yes \\
\hline Lagged Dependent Variable & No & No & No & No & No & No & Yes \\
\hline Sample & $\begin{array}{c}\text { Unstacked } \\
\text { Border Counties }\end{array}$ & $\begin{array}{c}\text { Unstacked } \\
\text { Border Counties }\end{array}$ & $\begin{array}{c}\text { Unstacked } \\
\text { Border Counties }\end{array}$ & $\begin{array}{c}\text { Unstacked } \\
\text { Border Counties }\end{array}$ & $\begin{array}{c}\text { Unstacked } \\
\text { Border Counties }\end{array}$ & $\begin{array}{c}\text { Unstacked } \\
\text { Border Counties }\end{array}$ & $\begin{array}{c}\text { Unstacked } \\
\text { Border Counties }\end{array}$ \\
\hline R-Squared & 0.047 & 0.053 & 0.561 & 0.573 & 0.714 & 0.714 & 0.936 \\
\hline Number of Observations & 6,790 & 6,790 & 6,790 & 6,790 & 6,790 & 6,790 & 6,790 \\
\hline
\end{tabular}

B. Vote Shares

\begin{tabular}{|c|c|c|c|c|c|c|c|}
\hline & & & an Differenc & Presidential & Party Vote S & & \\
\hline & $(8)$ & (9) & $(10)$ & $(11)$ & $(12)$ & (13) & (14) \\
\hline $\begin{array}{l}\text { Difference Between Democratic and } \\
\text { Republican Imps. per Cap. }(\div 10)\end{array}$ & $\begin{array}{l}1.673 * * \\
(0.651)\end{array}$ & $\begin{array}{l}1.655^{* *} \\
(0.654)\end{array}$ & $\begin{array}{l}0.872 * * * \\
(0.277)\end{array}$ & $\begin{array}{l}0.744 * * \\
(0.301)\end{array}$ & $\begin{array}{l}0.608 * * * \\
(0.191)\end{array}$ & $\begin{array}{l}0.494 * * \\
(0.195)\end{array}$ & $\begin{array}{l}0.489 * * \\
(0.192)\end{array}$ \\
\hline
\end{tabular}

Fixed Effects:

Year

Media Market Borde

Media Market Border $\times$ Year

Controls:

Demographic, Economic \& Geographic Variables Candidate Visits \& Non-Pres. Imps. per Cap.

Lagged Dependent Variable

\begin{aligned} & No Y \\ & No No \\ & \hline\end{aligned}

\begin{tabular}{|c|c|c|c|c|c|c|}
\hline No & No & No & No & Yes & Yes & Yes \\
\hline No & No & No & No & No & Yes & Yes \\
\hline No & No & No & No & No & No & Yes \\
\hline Unstacked & Unstacked & Unstacked & Unstacked & Unstacked & Unstacked & Unstacked \\
\hline Border Counties & Border Counties & Border Counties & Border Counties & Border Counties & Border Counties & Border Counties \\
\hline 0.024 & 0.027 & 0.609 & 0.628 & 0.824 & 0.825 & 0.826 \\
\hline 6,790 & 6,790 & 6,790 & 6,790 & 6,790 & 6,790 & 6,790 \\
\hline
\end{tabular}

R-Squared

Number of Observations

Notes: Entries are coefficients and standard errors from estimating $\phi$ in equation (2) by ordinary least squares. In a deviation from our empirical approach in the main text, we

$6,790-6,790$

6,790 do not stack border counties and do not include border segment fixed effects. Instead, we explore the sensitivity of the estimates to using fixed effects for entire media market borders. The outcome in the upper panel is aggregate turnout (in percentage points). The outcome in the lower panel is the partisan difference in presidential two-party vote shares (in percentage points), with larger values indicating more votes for the Democratic candidate. The set of included controls varies across columns. Heteroskedasticity robust standard errors are clustered by state and reported in parentheses. ${ }^{* *}, * *$, and * denote statistical significance at the $1 \%$-, 5\%-, and $10 \%$-levels, respectively. 
Table A.5: Discontinuities in Turnout Among Partisans, by Party Affiliation

\begin{tabular}{|c|c|c|c|c|}
\hline \multicolumn{5}{|c|}{ A. Turnout among Registered Democrats } \\
\hline \multirow[b]{2}{*}{ Local Polynomial } & \multicolumn{4}{|c|}{ Bandwidth (in meters) } \\
\hline & 500 & 1,000 & 5,000 & 10-fold C-V \\
\hline \multirow[t]{2}{*}{ Linear } & $0.018 * *$ & 0.009 & 0.009 & 0.005 \\
\hline & $(0.008)$ & $(0.009)$ & $(0.011)$ & $(0.010)$ \\
\hline \multirow[t]{2}{*}{ Quadratic } & $0.025 * *$ & $0.016^{*}$ & $0.017 * *$ & 0.014 \\
\hline & $(0.011)$ & $(0.009)$ & $(0.008)$ & $(0.010)$ \\
\hline \multirow[t]{2}{*}{ Cubic } & $0.027 * *$ & $0.026 * * *$ & $0.017 *$ & $0.018 * *$ \\
\hline & $(0.013)$ & $(0.010)$ & $(0.009)$ & $(0.008)$ \\
\hline \multirow[t]{2}{*}{ Quartic } & $0.023 *$ & $0.022 *$ & 0.012 & $0.017 *$ \\
\hline & $(0.013)$ & $(0.012)$ & $(0.008)$ & $(0.009)$ \\
\hline Number of Observations & 55,350 & 118,183 & 843,329 & -- \\
\hline
\end{tabular}

\section{B. Turnout among Registered Republicans}

\begin{tabular}{|c|c|c|c|c|}
\hline \multirow[b]{2}{*}{ Local Polynomial } & \multicolumn{4}{|c|}{ Bandwidth (in meters) } \\
\hline & 500 & 1,000 & 5,000 & 10-fold C-V \\
\hline Linear & $\begin{array}{c}0.000 \\
(0.009)\end{array}$ & $\begin{array}{c}-0.007 \\
(0.007)\end{array}$ & $\begin{array}{l}-0.007 \\
(0.006)\end{array}$ & $\begin{array}{l}-0.007 \\
(0.006)\end{array}$ \\
\hline Quadratic & $\begin{array}{c}-0.002 \\
(0.011)\end{array}$ & $\begin{array}{c}-0.002 \\
(0.009)\end{array}$ & $\begin{array}{c}-0.006 \\
(0.006)\end{array}$ & $\begin{array}{l}-0.006 \\
(0.006)\end{array}$ \\
\hline Cubic & $\begin{array}{c}-0.008 \\
(0.012)\end{array}$ & $\begin{array}{c}0.001 \\
(0.011)\end{array}$ & $\begin{array}{c}-0.009 \\
(0.007)\end{array}$ & $\begin{array}{c}-0.009 \\
(0.007)\end{array}$ \\
\hline Quartic & $\begin{array}{c}-0.013 \\
(0.013)\end{array}$ & $\begin{array}{c}0.000 \\
(0.011)\end{array}$ & $\begin{array}{c}-0.008 \\
(0.008)\end{array}$ & $\begin{array}{c}-0.008 \\
(0.008)\end{array}$ \\
\hline Number of Observations & 55,430 & 115,938 & 799,765 & -- \\
\hline
\end{tabular}

Notes: Entries are nonparametric estimates of the discontinuity in turnout for a particular group of partisans only. As explained in the main text, the running variable is voters' distance to the nearest within-state media market border. All estimates are based on local polynomial regressions using a rectangular kernel. The order of the local polynomial is given on the left of each row, while the respective bandwidth is indicated at the top of each column. The rightmost column uses 10-fold cross-validation for bandwidth selection, with the holdout sample consisting of all supporters of the respective party who live within 100m of a media market border. To account for unobserved spatial heterogeneity, every specification includes fixed effects for individual border segments of up to $10 \mathrm{~km}$ length. Heteroskedasticity robust standard errors are clustered by media market border and reported in parentheses. ${ }^{* *}, * *$, and $*$ denote statistical significance at the $1 \%$-, $5 \%$ , and 10\%-levels, respectively. 
Table A.6: "First Stage" of the Wald Estimators

\begin{tabular}{lcccc}
\hline \hline \multirow{2}{*}{ A. Partisan Difference in Political Advertising across } & \multicolumn{3}{c}{ Media Market Borders } \\
Bandwidth (in meters) \\
\cline { 2 - 5 } Local Polynomial & 500 & 1,000 & 5,000 & 10 -fold C-V \\
\cline { 2 - 5 } \multicolumn{1}{c}{ Linear } & $26.603^{* * *}$ & $28.355^{* * *}$ & $33.231^{* * *}$ & $33.469^{* * *}$ \\
& $(4.256)$ & $(4.543)$ & $(5.927)$ & $(5.967)$ \\
Quadratic & $25.124^{* * *}$ & $25.976^{* * *}$ & $30.638^{* * *}$ & $31.158^{* * *}$ \\
& $(3.700)$ & $(4.039)$ & $(4.846)$ & $(5.080)$ \\
Cubic & $24.778^{* * *}$ & $25.200^{* * *}$ & $29.330^{* * *}$ & $29.510^{* * *}$ \\
& $(3.545)$ & $(3.673)$ & $(4.495)$ & $(4.509)$ \\
Quartic & $23.283^{* * *}$ & $24.339^{* * *}$ & $26.970^{* * *}$ & $28.194^{* * *}$ \\
& $(3.462)$ & $(3.468)$ & $(4.114)$ & $(4.343)$ \\
\cline { 2 - 5 } Number of Observations & 110,780 & 234,121 & $1,643,094$ & -- \\
\hline
\end{tabular}

\section{B. Difference in Total Political Advertising across Media Market Borders}

\begin{tabular}{ccccc} 
& \multicolumn{4}{c}{ Bandwidth (in meters) } \\
\cline { 2 - 5 } Local Polynomial & 500 & 1,000 & 5,000 & 10 -fold C-V \\
\hline \multirow{2}{*}{ Linear } & $52.980^{* * *}$ & $54.811^{* * *}$ & $61.318^{* * *}$ & $62.166^{* * *}$ \\
& $(9.313)$ & $(10.171)$ & $(12.198)$ & $(12.115)$ \\
Quadratic & $54.293^{* * *}$ & $53.844^{* * *}$ & $58.252^{* * *}$ & $62.262^{* * *}$ \\
& $(8.690)$ & $(8.860)$ & $(10.845)$ & $(12.599)$ \\
Cubic & $54.741^{* * *}$ & $53.495^{* * *}$ & $57.372^{* * *}$ & $58.756^{* * *}$ \\
& $(8.950)$ & $(8.531)$ & $(10.815)$ & $(11.192)$ \\
Quartic & $54.089^{* * *}$ & $53.705^{* * *}$ & $55.438^{* * *}$ & $58.121^{* * *}$ \\
& $(9.042)$ & $(8.209)$ & $(10.593)$ & $(10.679)$ \\
\cline { 2 - 5 } Number of Observations & 168,406 & 353,902 & $2,461,111$ & -- \\
\hline \hline
\end{tabular}

Notes: Entries in the upper panel are nonparametric estimates of the discontinuity in partisan differences in political advertising across media market borders. Larger values indicate more advertising in support of the Democratic candidate relative to his Republicans opponent. Entries in the lower panel are nonparametric estimates of the discontinuity in partisan differences in total political advertising across media market borders. The running variable is voters' distance to the nearest within-state media market border. In the upper panel, we assign negative values to individuals who live in a media market in which the partisan difference in presidential advertising is lower than in the neighboring one. In the lower panel, assignment to either side of the border is based on total presidential advertising. All estimates are based on local polynomial regressions using a rectangular kernel. The order of the local polynomial is given on the left of each row, while the respective bandwidth is indicated at the top of each column. The rightmost column uses 10-fold crossvalidation for bandwidth selection, with the holdout sample consisting of observations that lie within $100 \mathrm{~m}$ of a media market border. To account for unobserved spatial heterogeneity, every specification includes fixed effects for individual border segments of up to $10 \mathrm{~km}$ length. Heteroskedasticity robust standard errors are clustered by media market border and reported in parentheses. ${ }^{* *},{ }^{* *}$, and $*$ denote statistical significance at the $1 \%-, 5 \%$-, and $10 \%$-levels, respectively. 
Table A.7: Testing for Discontinuities in Voters' Observable Characteristics (I/III)

\begin{tabular}{lcccc}
\hline \hline \multirow{2}{*}{ Dependent Variable: Years Registered } & at Current Address \\
& \multicolumn{5}{c}{ Bandwidth (in meters) } \\
\cline { 2 - 5 } Local Polynomial & 500 & 1,000 & 5,000 & 10 -fold C-V \\
\hline \multirow{2}{*}{ Linear } & 0.119 & 0.162 & 0.190 & 0.099 \\
& $(0.242)$ & $(0.205)$ & $(0.155)$ & $(0.208)$ \\
Quadratic & 0.223 & 0.106 & 0.164 & 0.242 \\
& $(0.286)$ & $(0.213)$ & $(0.221)$ & $(0.280)$ \\
Cubic & 0.229 & 0.191 & 0.118 & 0.233 \\
& $(0.287)$ & $(0.279)$ & $(0.233)$ & $(0.307)$ \\
Quartic & 0.190 & 0.286 & 0.113 & 0.155 \\
& $(0.311)$ & $(0.297)$ & $(0.205)$ & $(0.305)$ \\
\cline { 2 - 5 } Number of Observations & 168,308 & 353,700 & $2,459,296$ & -- \\
\hline \hline
\end{tabular}

Notes: Entries are nonparametric estimates of the across-media market border discontinuity in how many years voters have been registered at their current address. The sample is limited to registered voters who are not missing information on the date of registration. As in the main text, the running variable is voters' distance to the nearest within-state media market border. All estimates are based on local polynomial regressions using a rectangular kernel. The order of the local polynomial is given on the left of each row, while the respective bandwidth is indicated at the top of each column. The rightmost column uses 10-fold cross-validation for bandwidth selection, with the holdout sample consisting of observations that lie within $100 \mathrm{~m}$ of a media market border. To account for unobserved spatial heterogeneity, every specification includes fixed effects for individual border segments of up to $10 \mathrm{~km}$ length. Heteroskedasticity robust standard errors are clustered by media market border and reported in parentheses. ${ }^{* *},{ }^{* *}$, and $*$ denote statistical significance at the $1 \%-, 5 \%-$, and $10 \%$-levels, respectively. 
Table A.8: Testing for Discontinuities in Voters' Observable Characteristics (II/III)

\begin{tabular}{lcccc}
\hline \hline Dependent Variable: Age & \multicolumn{5}{c}{ Bandwidth (in meters) } \\
\cline { 2 - 5 } Local Polynomial & 500 & 1,000 & 5,000 & 10 -fold C-V \\
\hline \multirow{2}{*}{ Linear } & -0.164 & -0.559 & -0.272 & 0.031 \\
& $(0.341)$ & $(0.535)$ & $(0.237)$ & $(0.403)$ \\
Quadratic & 0.059 & -0.221 & -0.470 & -0.082 \\
& $(0.502)$ & $(0.501)$ & $(0.405)$ & $(0.476)$ \\
Cubic & -0.263 & 0.257 & -1.155 & -0.037 \\
& $(0.553)$ & $(0.553)$ & $(0.720)$ & $(0.554)$ \\
Quartic & 0.017 & 0.216 & -0.919 & 0.304 \\
& $(0.574)$ & $(0.509)$ & $(0.607)$ & $(0.600)$ \\
\cline { 2 - 5 } Number of Observations & 161,030 & 337,508 & $2,356,642$ & -- \\
\hline \hline
\end{tabular}

Notes: Entries are nonparametric estimates of the across-media market border discontinuity in voters' age.

The sample is limited to registered voters who are not missing information on date of birth. As in the main text, the running variable is voters' distance to the nearest within-state media market border. All estimates are based on local polynomial regressions using a rectangular kernel. The order of the local polynomial is given on the left of each row, while the respective bandwidth is indicated at the top of each column. The rightmost column uses 10-fold cross-validation for bandwidth selection, with the holdout sample consisting of observations that lie within $100 \mathrm{~m}$ of a media market border. To account for unobserved spatial heterogeneity, every specification includes fixed effects for individual border segments of up to $10 \mathrm{~km}$ length.

Heteroskedasticity robust standard errors are clustered by media market border and reported in parentheses. $*^{* *},{ }^{* *}$, and $*$ denote statistical significance at the $1 \%-, 5 \%$, and $10 \%$-levels, respectively. 
Table A.9: Testing for Discontinuities in Voters' Observable Characteristics (III/III)

\begin{tabular}{ccccc}
\hline \hline \multirow{2}{*}{ Dependent Variable: Female } & \multicolumn{4}{c}{ Bandwidth (in meters) } \\
\cline { 2 - 5 } Local Polynomial & 500 & 1,000 & 5,000 & 10 -fold C-V \\
\hline \multirow{2}{*}{ Linear } & 0.004 & 0.000 & 0.002 & 0.002 \\
& $(0.005)$ & $(0.003)$ & $(0.002)$ & $(0.002)$ \\
Quadratic & 0.004 & 0.004 & 0.000 & 0.002 \\
& $(0.006)$ & $(0.004)$ & $(0.002)$ & $(0.002)$ \\
Cubic & 0.000 & 0.004 & -0.003 & 0.002 \\
& $(0.006)$ & $(0.006)$ & $(0.003)$ & $(0.002)$ \\
Quartic & 0.002 & 0.006 & -0.002 & 0.003 \\
& $(0.007)$ & $(0.006)$ & $(0.004)$ & $(0.003)$ \\
\cline { 2 - 5 } Number of Observations & 126,770 & 270,080 & $1,874,725$ & -- \\
\hline \hline
\end{tabular}

Notes: Entries are nonparametric estimates of the across-media market border discontinuity in voters' gender. The sample is limited to registered voters who are not missing information on gender. As in the main text, the running variable is voters' distance to the nearest within-state media market border. All estimates are based on local polynomial regressions using a rectangular kernel. The order of the local polynomial is given on the left of each row, while the respective bandwidth is indicated at the top of each column. The rightmost column uses 10-fold cross-validation for bandwidth selection, with the holdout sample consisting of observations that lie within $100 \mathrm{~m}$ of a media market border. To account for unobserved spatial heterogeneity, every specification includes fixed effects for individual border segments of up to $10 \mathrm{~km}$ length. Heteroskedasticity robust standard errors are clustered by media market border and reported in parentheses. ${ }^{* * *},{ }^{* *}$, and * denote statistical significance at the 1\%-, 5\%-, and 10\%-levels, respectively. 
Table A.10: Testing for Discontinuities in Non-Presidential Political Advertising

\begin{tabular}{|c|c|c|c|c|}
\hline \multicolumn{5}{|c|}{ Dependent Variable: Partisan Difference in Non-Presidential Political Advertising } \\
\hline \multirow[b]{2}{*}{ Local Polynomial } & \multicolumn{4}{|c|}{ Bandwidth (in meters) } \\
\hline & 500 & 1,000 & 5,000 & 10-fold C-V \\
\hline \multirow[t]{2}{*}{ Linear } & -1.032 & -2.278 & -2.304 & 1.876 \\
\hline & $(5.384)$ & $(5.833)$ & $(5.609)$ & $(4.880)$ \\
\hline \multirow[t]{2}{*}{ Quadratic } & 1.064 & -0.103 & -2.709 & 0.575 \\
\hline & $(4.577)$ & $(4.930)$ & $(5.833)$ & $(5.429)$ \\
\hline \multirow[t]{2}{*}{ Cubic } & 1.193 & 0.516 & -1.388 & -0.583 \\
\hline & $(4.613)$ & $(4.693)$ & $(5.789)$ & $(5.454)$ \\
\hline \multirow[t]{2}{*}{ Quartic } & 1.273 & 0.794 & -0.319 & -1.347 \\
\hline & $(4.722)$ & $(4.677)$ & $(5.595)$ & $(5.328)$ \\
\hline Number of Observations & 168,406 & 353,902 & $2,461,111$ & -- \\
\hline
\end{tabular}

Notes: Entries are nonparametric estimates of the across-media market discontinuity in the partisan gap in non presidential advertising. As in main text, the running variable is voters' distance to the nearest within-state media market border. All estimates are based on local polynomial regressions using a rectangular kernel. The order of the local polynomial is given on the left of each row, while the respective bandwidth is indicated at the top of each column. The rightmost column uses 10-fold cross-validation for bandwidth selection, with the holdout sample consisting of observations that lie within 100m of a media market border. To account for unobserved spatial heterogeneity, every specification includes fixed effects for individual border segments of up to $10 \mathrm{~km}$ length. Heteroskedasticity robust standard errors are clustered by media market border and reported in parentheses. ***, **, and * denote statistical significance at the 1\%-, 5\%-, and 10\%-levels, respectively. 
Table A.11: RD Estimates Controlling for Non-Presidential Political Advertising and Voters' Observable Characteristics

\begin{tabular}{ccccc}
\hline \hline \multirow{2}{*}{ A. Partisan Difference in Turnout across DMA Borders } & \multicolumn{4}{c}{ Bandwidth (in meters) } \\
\cline { 2 - 5 } Local Polynomial & 500 & 1,000 & 5,000 & 10 -fold C-V \\
\cline { 2 - 5 } Linear & 0.015 & 0.016 & 0.015 & 0.015 \\
& $(0.012)$ & $(0.011)$ & $(0.010)$ & $(0.009)$ \\
Quadratic & 0.018 & 0.013 & $0.023^{* *}$ & $0.020^{* *}$ \\
& $(0.014)$ & $(0.011)$ & $(0.009)$ & $(0.010)$ \\
Cubic & 0.026 & 0.018 & $0.026^{* *}$ & $0.028^{* * *}$ \\
& $(0.016)$ & $(0.013)$ & $(0.010)$ & $(0.009)$ \\
Quartic & $0.026^{*}$ & 0.013 & $0.019^{*}$ & $0.023^{* *}$ \\
& $(0.015)$ & $(0.014)$ & $(0.011)$ & $(0.010)$ \\
\hline
\end{tabular}

\begin{tabular}{ccccc} 
B. Wald Estimator & \multicolumn{4}{c}{ Bandwidth (in meters) } \\
\cline { 2 - 5 } Local Polynomial & 500 & 1,000 & 5,000 & 10 -fold C-V \\
\hline \multirow{2}{*}{ Linear } & 0.006 & 0.006 & 0.005 & 0.005 \\
& $(0.005)$ & $(0.004)$ & $(0.003)$ & $(0.003)$ \\
Quadratic & 0.008 & 0.005 & $0.007 * *$ & $0.006^{*}$ \\
& $(0.006)$ & $(0.004)$ & $(0.003)$ & $(0.003)$ \\
Cubic & 0.011 & 0.008 & $0.009^{* *}$ & $0.009^{* * *}$ \\
& $(0.007)$ & $(0.005)$ & $(0.004)$ & $(0.004)$ \\
Quartic & $0.011^{*}$ & 0.006 & $0.007^{*}$ & $0.008^{* *}$ \\
& $(0.007)$ & $(0.006)$ & $(0.004)$ & $(0.004)$ \\
\cline { 2 - 5 } Number of Observations & 110,780 & 234,121 & $1,643,094$ & -- \\
\hline \hline
\end{tabular}

Notes: Entries in the upper panel are estimates of the discontinuity in the partisan difference in turnout across media market borders, i.e., $\tau$ in equation (5). Larger values indicate an increase in turnout of registered Democrats relative to registered Republicans. The lower panel displays Wald estimates of the impact of partisan differences in political advertising on partisan differences in turnout (cf. equation (4)). All Wald estimates have been scaled so that the coefficients refer to the impact of 10 impressions per capita. As explained in the main text, the running variable is voters' distance to the nearest within-state media market border. All estimates are based on local polynomial regressions using a rectangular kernel. The order of the local polynomial is given on the left of each row, while the respective bandwidth is indicated at the top of each column. The rightmost column uses 10-fold cross-validation for bandwidth selection, with the holdout sample consisting of observations that lie within $100 \mathrm{~m}$ of a media market border. Following Imbens and Lemieux (2008), we use the optimally chosen bandwidth for the outcome equation in both panels. To account for unobserved spatial heterogeneity, every specification includes party-specific fixed effects for individual border segments of up to $10 \mathrm{~km}$ length. Further, all specifications control for non-presidential political advertising, voters' age, gender, the number of years an individual has been registered at her address, as well as indicator variables for missing values on each covariate. Heteroskedasticity robust standard errors are clustered by media market border and reported in parentheses. ${ }^{* *},{ }^{* *}$, and ${ }^{*}$ denote statistical significance at the $1 \%-, 5 \%$-, and $10 \%$-levels, respectively. 
Table A.12: RD Estimates for Street Address Level-Matched Observations Only

\begin{tabular}{ccccc}
\hline \hline \multirow{2}{*}{ A. Partisan Difference in Turnout across DMA Borders } & \multicolumn{4}{c}{ Bandwidth (in meters) } \\
\cline { 2 - 5 } Local Polynomial & 500 & 1,000 & 5,000 & 10 -fold C-V \\
\cline { 2 - 5 } Linear & 0.018 & 0.016 & 0.015 & 0.014 \\
& $(0.012)$ & $(0.012)$ & $(0.011)$ & $(0.011)$ \\
Quadratic & $0.027^{*}$ & 0.018 & $0.023^{* *}$ & $0.020^{*}$ \\
& $(0.015)$ & $(0.012)$ & $(0.010)$ & $(0.011)$ \\
Cubic & $0.035^{* *}$ & $0.024^{*}$ & $0.022^{*}$ & $0.026^{* *}$ \\
& $(0.016)$ & $(0.013)$ & $(0.011)$ & $(0.011)$ \\
Quartic & $0.038^{* *}$ & 0.022 & $0.018^{*}$ & $0.019^{*}$ \\
& $(0.015)$ & $(0.015)$ & $(0.011)$ & $(0.011)$ \\
\hline \multirow{2}{*}{ Number of Observations } & 101,287 & 212,750 & $1,401,712$ & -- \\
\hline
\end{tabular}

\section{B. Wald Estimator}

\begin{tabular}{|c|c|c|c|c|}
\hline \multirow[b]{2}{*}{ Local Polynomial } & \multicolumn{4}{|c|}{ Bandwidth (in meters) } \\
\hline & 500 & 1,000 & 5,000 & 10-fold C-V \\
\hline Linear & $\begin{array}{c}0.007 \\
(0.005)\end{array}$ & $\begin{array}{c}0.005 \\
(0.004)\end{array}$ & $\begin{array}{c}0.004 \\
(0.004)\end{array}$ & $\begin{array}{c}0.004 \\
(0.003)\end{array}$ \\
\hline Quadratic & $\begin{array}{c}0.011 * \\
(0.006)\end{array}$ & $\begin{array}{c}0.007 \\
(0.005)\end{array}$ & $\begin{array}{c}0.007 * * \\
(0.004)\end{array}$ & $\begin{array}{c}0.006 * \\
(0.004)\end{array}$ \\
\hline Cubic & $\begin{array}{c}0.015 * * \\
(0.007)\end{array}$ & $\begin{array}{c}0.010 * \\
(0.006)\end{array}$ & $\begin{array}{c}0.007 * \\
(0.004)\end{array}$ & $\begin{array}{c}0.009 * * \\
(0.004)\end{array}$ \\
\hline Quartic & $\begin{array}{c}0.017 * * \\
(0.007)\end{array}$ & $\begin{array}{c}0.009 \\
(0.006)\end{array}$ & $\begin{array}{c}0.007 \\
(0.004)\end{array}$ & $\begin{array}{c}0.007 \\
(0.004)\end{array}$ \\
\hline Number of Observations & 101,287 & 212,750 & $1,401,712$ & -- \\
\hline
\end{tabular}

Notes: Entries in the upper panel are estimates of the discontinuity in the partisan difference in turnout across media market borders, i.e., $\tau$ in equation (5). The sample is limited to registered Democrats and Republicans for whom our geocoding procedure is able to locate the exact street address. The lower panel displays Wald estimates of the impact of partisan differences in political advertising on partisan differences in turnout (cf. equation (4)). All Wald estimates have been scaled so that the coefficients refer to the impact of 10 impressions per capita. As explained in the main text, the running variable is voters' distance to the nearest within-state media market border. All estimates are based on local polynomial regressions using a rectangular kernel. The order of the local polynomial is given on the left of each row, while the respective bandwidth is indicated at the top of each column. The rightmost column uses 10 -fold cross-validation for bandwidth selection, with the holdout sample consisting of observations that lie within $100 \mathrm{~m}$ of a media market border. Following Imbens and Lemieux (2008), we use the optimally chosen bandwidth for the outcome equation in both panels. To account for unobserved spatial heterogeneity, every specification includes party-specific fixed effects for individual border segments of up to $10 \mathrm{~km}$ length. Heteroskedasticity robust standard errors are clustered by media market border and reported in parentheses. ${ }^{* *}, * *$, and * denote statistical significance at the $1 \%-, 5 \%-$, and $10 \%$-levels, respectively. 
Table A.13: RD Estimates Restricting Attention to Registered Voters in Counties with No Out-of-Market TV Stations on the FCC's Significantly Viewed List

\begin{tabular}{ccccc}
\hline \hline \multirow{2}{*}{ A. Partisan Difference in Turnout across DMA Borders } & \multicolumn{4}{c}{ Bandwidth (in meters) } \\
\cline { 2 - 5 } Local Polynomial & 500 & 1,000 & 5,000 & 10 -fold C-V \\
\cline { 2 - 5 } Linear & 0.019 & 0.023 & 0.042 & 0.021 \\
& $(0.028)$ & $(0.023)$ & $(0.027)$ & $(0.022)$ \\
Quadratic & 0.024 & 0.017 & $0.051^{* *}$ & 0.026 \\
& $(0.034)$ & $(0.027)$ & $(0.024)$ & $(0.026)$ \\
Cubic & 0.059 & 0.017 & $0.044^{*}$ & 0.025 \\
& $(0.040)$ & $(0.033)$ & $(0.026)$ & $(0.031)$ \\
Quartic & $0.074^{* *}$ & 0.055 & $0.043 *$ & 0.026 \\
& $(0.035)$ & $(0.034)$ & $(0.024)$ & $(0.034)$ \\
\cline { 2 - 5 } Number of Observations & 26,644 & 58,490 & 372,438 & -- \\
\hline
\end{tabular}

\section{B. Wald Estimator}

Bandwidth (in meters)

\begin{tabular}{|c|c|c|c|c|}
\hline \multirow[b]{2}{*}{ Local Polynomial } & \\
\hline & 500 & 1,000 & 5,000 & 10-fold C-V \\
\hline Linear & $\begin{array}{c}0.009 \\
(0.020)\end{array}$ & $\begin{array}{c}0.017 \\
(0.023)\end{array}$ & $\begin{array}{c}0.071 \\
(0.056)\end{array}$ & $\begin{array}{c}0.018 \\
(0.024)\end{array}$ \\
\hline Quadratic & $\begin{array}{c}0.010 \\
(0.022)\end{array}$ & $\begin{array}{c}0.011 \\
(0.022)\end{array}$ & $\begin{array}{c}0.077 \\
(0.051)\end{array}$ & $\begin{array}{c}0.020 \\
(0.026)\end{array}$ \\
\hline Cubic & $\begin{array}{c}0.027 \\
(0.028)\end{array}$ & $\begin{array}{c}0.007 \\
(0.022)\end{array}$ & $\begin{array}{c}0.056 \\
(0.046)\end{array}$ & $\begin{array}{c}0.015 \\
(0.025)\end{array}$ \\
\hline Quartic & $\begin{array}{c}0.032 \\
(0.026)\end{array}$ & $\begin{array}{c}0.028 \\
(0.028)\end{array}$ & $\begin{array}{c}0.048 \\
(0.039)\end{array}$ & $\begin{array}{c}0.013 \\
(0.024)\end{array}$ \\
\hline Number of Observations & 26,644 & 58,490 & 372,438 & -- \\
\hline
\end{tabular}

Notes: Entries in the upper panel are estimates of the discontinuity in the partisan difference in turnout across media market borders, i.e., $\tau$ in equation (5). The sample is limited to registered Democrats and Republicans who live in a county where no out-of-market TV stations appear on the FCC's Significantly Viewed List. The lower panel displays Wald estimates of the impact of partisan differences in political advertising on partisan differences in turnout (cf. equation (4)). All Wald estimates have been scaled so that the coefficients refer to the impact of 10 impressions per capita. As in the main text, the running variable is voters' distance to the nearest within-state media market border. All estimates are based on local polynomial regressions using a rectangular kernel. The order of the local polynomial is given on the left of each row, while the respective bandwidth is indicated at the top of each column. The rightmost column uses 10 -fold cross-validation for bandwidth selection, with the holdout sample consisting of observations that lie within $100 \mathrm{~m}$ of a media market border. Following Imbens and Lemieux (2008), we use the optimally chosen bandwidth for the outcome equation in both panels. To account for unobserved spatial heterogeneity, every specification includes party-specific fixed effects for individual border segments of up to $10 \mathrm{~km}$ length. Heteroskedasticity robust standard errors are clustered by media market border and reported in parentheses. ${ }^{* * *}, * *$, and $*$ denote statistical significance at the 1\%-, 5\%-, and 10\%-levels, respectively. 
Table A.14: Testing for Discontinuities in Newspapers' Readership

\begin{tabular}{lcccc}
\hline \hline \multirow{2}{*}{ Dependent Variable: Newspaper Circulation per Household } & \multicolumn{4}{c}{ Bandwidth (in meters) } \\
\cline { 2 - 5 } Local Polynomial & 5,000 & 10,000 & 15,000 & 10 -fold C-V \\
\hline \multirow{2}{*}{ Linear } & -0.004 & -0.011 & -0.009 & -0.001 \\
& $(0.019)$ & $(0.009)$ & $(0.007)$ & $(0.005)$ \\
Quadratic & 0.007 & -0.003 & -0.009 & -0.008 \\
& $(0.025)$ & $(0.016)$ & $(0.012)$ & $(0.007)$ \\
Cubic & 0.067 & 0.003 & -0.012 & -0.010 \\
& $(0.042)$ & $(0.021)$ & $(0.016)$ & $(0.012)$ \\
Quartic & 0.051 & 0.013 & -0.004 & -0.017 \\
& $(0.061)$ & $(0.026)$ & $(0.021)$ & $(0.016)$ \\
\cline { 2 - 5 } Number of Observations & 5,297 & 8,650 & 11,518 & -- \\
\hline \hline
\end{tabular}

Notes: Entries are estimates of the across-media market discontinuity in newspapers' circulation. Information on newspapers' circulation by ZIP code comes from the Alliance for Audited Media. The running variable is the distance from a ZIP code's centroid to the nearest within-state media market border. All estimates are based on local polynomial regressions using a rectangular kernel. The order of the local polynomial is given on the left of each row, while the respective bandwidth is indicated at the top of each column. The rightmost column uses 10-fold cross-validation for bandwidth selection, with the holdout sample consisting of newspaper-ZIP code observations for which the ZIP code centroid lies within less than $5 \mathrm{~km}$ of a media market border. To account for unobserved spatial heterogeneity, every specification includes a newspaper-media market border fixed effect. Heteroskedasticity robust standard errors are clustered by media market border and reported in parentheses. ***, **, and * denote statistical significance at the $1 \%$, $5 \%-$, and $10 \%$-levels, respectively. 
Table A.15: Testing for Discontinuities in School Districts' Expenditures

\begin{tabular}{ccccc} 
Dependent Variable: Log Expenditures per Student & \multicolumn{2}{c}{ Bandwidth (in meters) } \\
\cline { 2 - 5 } Local Polynomial & 5,000 & 10,000 & 15,000 & 10 -fold C-V \\
\hline \multirow{2}{*}{ Linear } & -0.011 & 0.014 & 0.007 & -0.001 \\
& $(0.054)$ & $(0.031)$ & $(0.021)$ & $(0.013)$ \\
Quadratic & -0.109 & -0.054 & -0.011 & -0.001 \\
Cubic & $(0.086)$ & $(0.046)$ & $(0.035)$ & $(0.023)$ \\
Quartic & $0.155^{*}$ & -0.032 & -0.017 & -0.002 \\
& $(0.091)$ & $(0.061)$ & $(0.051)$ & $(0.032)$ \\
Number of Observations & 0.226 & -0.071 & -0.027 & -0.012 \\
\cline { 2 - 5 } & $(0.141)$ & $(0.086)$ & $(0.064)$ & $(0.042)$ \\
\hline
\end{tabular}

Notes: Entries are estimates of the across-media market discontinuity in local school districts' total expenditures per student. Information on school expenditures comes from the National Center for Education Statistics Common Core of Data School Finance Survey for the 2009-10 school year. The running variable is the distance from a school district's centroid to the nearest within-state media market border. All estimates are based on local polynomial regressions using a rectangular kernel. The order of the local polynomial is given on the left of each row, while the respective bandwidth is indicated at the top of each column. The rightmost column uses 10-fold cross-validation for bandwidth selection, with the holdout sample consisting of school districts whose centroid lies within less than $5 \mathrm{~km}$ of a media market border. To account for unobserved heterogeneity across space and district type, every specification includes a media market border fixed effect as well as a fixed effect for district type, i.e., "elementary," "secondary," or "combined." Heteroskedasticity robust standard errors are clustered by media market border and reported in parentheses. ***, **, and $*$ denote statistical significance at the 1\%-, 5\%-, and $10 \%$-levels, respectively. 
Table A.16: RD Estimates of the Effect of Partisan Differences in Political Advertising, by Gender

\begin{tabular}{ccccc}
\hline \hline \multirow{2}{*}{ A. Wald Estimates for Males } & \multicolumn{4}{c}{ Bandwidth (in meters) } \\
\cline { 2 - 5 } Local Polynomial & 500 & 1,000 & 5,000 & 10 -fold C-V \\
\cline { 2 - 5 } Linear & 0.013 & 0.004 & 0.005 & 0.005 \\
& $(0.011)$ & $(0.008)$ & $(0.006)$ & $(0.005)$ \\
Quadratic & 0.012 & 0.009 & 0.007 & 0.005 \\
& $(0.013)$ & $(0.010)$ & $(0.006)$ & $(0.006)$ \\
Cubic & 0.012 & 0.018 & 0.007 & 0.007 \\
& $(0.017)$ & $(0.013)$ & $(0.008)$ & $(0.008)$ \\
Quartic & 0.015 & 0.007 & 0.011 & 0.009 \\
& $(0.020)$ & $(0.015)$ & $(0.008)$ & $(0.007)$ \\
\cline { 2 - 5 } Number of Observations & 40,278 & 86,078 & 593,398 & -- \\
\hline
\end{tabular}

B. Wald Estimates for Females

\begin{tabular}{ccccc} 
& \multicolumn{4}{c}{ Bandwidth (in meters) } \\
\cline { 2 - 5 } Local Polynomial & 500 & 1,000 & 5,000 & 10 -fold C-V \\
\hline \multirow{2}{*}{ Linear } & -0.002 & 0.004 & 0.002 & 0.002 \\
& $(0.005)$ & $(0.005)$ & $(0.003)$ & $(0.003)$ \\
Quadratic & 0.001 & -0.001 & 0.006 & 0.005 \\
& $(0.008)$ & $(0.005)$ & $(0.004)$ & $(0.004)$ \\
Cubic & 0.009 & 0.002 & $0.008^{*}$ & $0.008^{* *}$ \\
& $(0.010)$ & $(0.007)$ & $(0.004)$ & $(0.004)$ \\
Quartic & 0.008 & 0.008 & 0.003 & $0.008^{*}$ \\
& $(0.011)$ & $(0.008)$ & $(0.005)$ & $(0.004)$ \\
\cline { 2 - 5 } Number of Observations & 45,619 & 98,449 & 689,828 & -- \\
\hline \hline
\end{tabular}

Notes: Entries are Wald estimates of the impact of partisan differences in political advertising on partisan differences in turnout among male (upper panel) and female voters (lower panel). All estimates have been scaled so that the coefficients refer to the impact of 10 impressions per capita. As in the main text, the running variable is voters' distance to the nearest within-state media market border. All estimates are based on local polynomial regressions using a rectangular kernel. The order of the local polynomial is given on the left of each row, while the respective bandwidth is indicated at the top of each column. The rightmost column uses 10-fold cross-validation for bandwidth selection, with the holdout sample consisting of observations that lie within 100m of a media market border. Following Imbens and Lemieux (2008), we use the optimally chosen bandwidth for the outcome equation of the Wald estimator. To account for unobserved spatial heterogeneity, every specification includes party-specific fixed effects for individual border segments of up to $10 \mathrm{~km}$ length. Heteroskedasticity robust standard errors are clustered by media market border and reported in parentheses. ${ }^{* *}, * *$, and $*$ denote statistical significance at the $1 \%-, 5 \%$-, and $10 \%$-levels, respectively. 
Table A.17: RD Estimates of the Effect of Partisan Differences in Political Advertising, by Age Group

\begin{tabular}{lcccc}
\hline \hline \multirow{2}{*}{$\begin{array}{l}\text { A. Wald Estimates for 18- to 34-Year-Olds } \\
\text { Local Polynomial }\end{array}$} & \multicolumn{4}{c}{ Bandwidth (in meters) } \\
\cline { 2 - 5 } Linear & 0.004 & 1,000 & 5,000 & 10 -fold C-V \\
& $(0.027)$ & $(0.019)$ & 0.004 & 0.004 \\
Quadratic & -0.016 & -0.006 & 0.006 & $(0.008)$ \\
& $(0.038)$ & $(0.024)$ & $(0.013)$ & 0.006 \\
Cubic & -0.028 & 0.020 & 0.012 & $0.011)$ \\
& $(0.049)$ & $(0.031)$ & $(0.015)$ & $(0.013)$ \\
Quartic & -0.001 & 0.006 & 0.026 & 0.021 \\
& $(0.063)$ & $(0.040)$ & $(0.020)$ & $(0.016)$ \\
\hline \multirow{2}{*}{ Number of Observations } & 17,103 & 36,342 & 270,449 & -- \\
\hline
\end{tabular}

B. Wald Estimates for 35- to 64-Year-Olds

\begin{tabular}{ccccc} 
& \multicolumn{4}{c}{ Bandwidth (in meters) } \\
\cline { 2 - 5 } Local Polynomial & 500 & 1,000 & 5,000 & 10 -fold C-V \\
\hline \multirow{2}{*}{ Linear } & 0.002 & 0.002 & 0.002 & 0.002 \\
& $(0.005)$ & $(0.004)$ & $(0.003)$ & $(0.003)$ \\
Quadratic & 0.007 & 0.003 & $0.007 * *$ & 0.005 \\
& $(0.006)$ & $(0.005)$ & $(0.003)$ & $(0.003)$ \\
Cubic & 0.012 & 0.003 & $0.010^{* *}$ & $0.009^{* *}$ \\
& $(0.008)$ & $(0.006)$ & $(0.004)$ & $(0.004)$ \\
Quartic & 0.008 & 0.006 & 0.005 & $0.009^{* *}$ \\
& $(0.009)$ & $(0.007)$ & $(0.004)$ & $(0.004)$ \\
\cline { 2 - 5 } Number of Observations & 66,565 & 139,565 & 979,126 & -- \\
\hline
\end{tabular}

C. Wald Estimates for $\geq 65$-Year-Olds

\begin{tabular}{ccccc} 
& \multicolumn{4}{c}{ Bandwidth (in meters) } \\
\cline { 2 - 5 } Local Polynomial & 500 & 1,000 & 5,000 & 10 -fold C-V \\
\hline \multirow{2}{*}{ Linear } & 0.001 & 0.001 & 0.001 & 0.001 \\
& $(0.005)$ & $(0.004)$ & $(0.002)$ & $(0.001)$ \\
Quadratic & -0.003 & 0.001 & 0.002 & 0.002 \\
& $(0.007)$ & $(0.005)$ & $(0.002)$ & $(0.002)$ \\
Cubic & -0.005 & 0.001 & 0.004 & 0.002 \\
& $(0.008)$ & $(0.006)$ & $(0.003)$ & $(0.002)$ \\
Quartic & -0.007 & -0.003 & $0.005 *$ & 0.003 \\
& $(0.011)$ & $(0.008)$ & $(0.003)$ & $(0.002)$ \\
\cline { 2 - 4 } Number of Observations & 25,854 & 54,717 & 369,751 & -- \\
\hline \hline
\end{tabular}

Notes: Entries are Wald estimates of the impact of partisan differences in political advertising on partisan differences in turnout, by age group. All estimates have been scaled so that the coefficients refer to the impact of 10 impressions per capita. As in the main text, the running variable is voters' distance to the nearest withinstate media market border. All estimates are based on local polynomial regressions using a rectangular kernel. The order of the local polynomial is given on the left of each row, while the respective bandwidth is indicated at the top of each column. The rightmost column uses 10 -fold cross-validation for bandwidth selection, with the holdout sample consisting of observations that lie within $100 \mathrm{~m}$ of a media market border. Following Imbens and Lemieux (2008), we use the optimally chosen bandwidth for the outcome equation of the Wald estimator. To account for unobserved spatial heterogeneity, every specification includes party-specific fixed effects for individual border segments of up to $10 \mathrm{~km}$ length. Heteroskedasticity robust standard errors are clustered by media market border and reported in parentheses. ${ }^{* *}, * *$, and $*$ denote statistical significance at the $1 \%$-, $5 \%$, and $10 \%$-levels, respectively. 
Table A.18: RD Estimates of the Effect of Total Political Advertising on Aggregate Turnout Restricting Attention to Registered Voters in Counties with No Out-of-Market TV Stations on the FCC's Significantly Viewed List

\begin{tabular}{|c|c|c|c|c|}
\hline \multicolumn{5}{|c|}{ A. Partisan Difference in Aggregate Turnout across DMA Borders } \\
\hline \multirow[b]{2}{*}{ Local Polynomial } & \multicolumn{4}{|c|}{ Bandwidth (in meters) } \\
\hline & 500 & 1,000 & 5,000 & 10-fold C-V \\
\hline \multirow[t]{2}{*}{ Linear } & -0.007 & $-0.015 *$ & -0.014 & -0.010 \\
\hline & $(0.009)$ & $(0.009)$ & $(0.012)$ & $(0.013)$ \\
\hline \multirow[t]{2}{*}{ Quadratic } & 0.007 & $-0.024 * *$ & -0.014 & -0.003 \\
\hline & $(0.013)$ & $(0.010)$ & $(0.011)$ & $(0.011)$ \\
\hline \multirow[t]{2}{*}{ Cubic } & 0.020 & 0.000 & -0.001 & -0.001 \\
\hline & $(0.020)$ & $(0.013)$ & $(0.013)$ & $(0.012)$ \\
\hline \multirow[t]{2}{*}{ Quartic } & 0.024 & 0.015 & -0.015 & 0.000 \\
\hline & $(0.023)$ & $(0.018)$ & $(0.011)$ & $(0.012)$ \\
\hline Number of Observations & 39,224 & 85,040 & 529,406 & -- \\
\hline
\end{tabular}

\section{B. Wald Estimator}

\begin{tabular}{|c|c|c|c|c|}
\hline \multirow[b]{2}{*}{ Local Polynomial } & \multicolumn{4}{|c|}{ Bandwidth (in meters) } \\
\hline & 500 & 1,000 & 5,000 & 10-fold C-V \\
\hline Linear & $\begin{array}{l}-0.001 \\
(0.002)\end{array}$ & $\begin{array}{c}-0.003 \\
(0.003)\end{array}$ & $\begin{array}{l}-0.005 \\
(0.005)\end{array}$ & $\begin{array}{c}-0.004 \\
(0.006)\end{array}$ \\
\hline Quadratic & $\begin{array}{c}0.001 \\
(0.002)\end{array}$ & $\begin{array}{c}-0.005 \\
(0.003)\end{array}$ & $\begin{array}{c}-0.005 \\
(0.004)\end{array}$ & $\begin{array}{c}-0.001 \\
(0.004)\end{array}$ \\
\hline Cubic & $\begin{array}{c}0.003 \\
(0.003)\end{array}$ & $\begin{array}{c}0.000 \\
(0.002)\end{array}$ & $\begin{array}{c}0.000 \\
(0.004)\end{array}$ & $\begin{array}{c}0.000 \\
(0.004)\end{array}$ \\
\hline Quartic & $\begin{array}{c}0.004 \\
(0.003)\end{array}$ & $\begin{array}{c}0.003 \\
(0.003)\end{array}$ & $\begin{array}{l}-0.004 \\
(0.004)\end{array}$ & $\begin{array}{c}0.000 \\
(0.004)\end{array}$ \\
\hline Number of Observations & 39,224 & 85,040 & 529,406 & -- \\
\hline
\end{tabular}

Notes: Entries in the upper panel are nonparametric estimates of the across-media market border discontinuity in turnout among all voters. The sample is limited to voters who live in a county where no outof-market TV stations appear in the FCC's Significantly Viewed List. Estimates in the middle panel refer to the discontinuity in total presidential advertising. The lower panel displays Wald estimates of the impact of total presidential advertising on overall turnout. In a deviation from our RD design in the main text, we now use voters' residential addresses to calculate distance to the nearest within-state media market border, with negative values assigned to individuals who live in a media market in which total presidential advertising is lower than in the neighboring one. All estimates are based on local polynomial regressions using a rectangular kernel. The order of the local polynomial is given on the left of each row, while the respective bandwidth is indicated at the top of each column. The rightmost column uses 10-fold cross-validation for bandwidth selection, with the holdout sample consisting of observations that lie within $100 \mathrm{~m}$ of a media market border. Following Imbens and Lemieux (2008), we use the optimally chosen bandwidth for the outcome equation in both panels. To account for unobserved spatial heterogeneity, every specification includes party-specific fixed effects for individual border segments of up to $10 \mathrm{~km}$ length. Heteroskedasticity robust standard errors are clustered by media market border and reported in parentheses. ***, **, and * denote statistical significance at the 1\%-, 5\%-, and 10\%-levels, respectively. 